Дмитриева Л. Н., Чумачкова Е.А., Краснов Я. М., Осина Н. А., Сафронов В.А.,

Иванова А.В., Карнаухов И. Г., Караваева Т.Б., Щербакова С. А., Кутырев В. В.

\title{
Распространение вариантов вируса SARS-COV-2, вызывающих озабоченность (VOC) и интерес (VOI) на основе количества их геномов, депонированных в базу данных GISAID за неделю с 27.11. по 03.12.2021 г.
}

ФКУЗ Российский научно-исследовательский противочумныий институт «Микроб» Роспотребнадзора, Саратов, Российская Федерачия

В обзоре представлен анализ геновариантов вируса SARS-CoV-2, вызывающих озабоченность (VOC) и интерес (VOI) на основе их геномов в базе GISAID за неделю с 27.11.2021 г. по 03.12.2021 г.

На сегодняшний день в базе данных GISAID всего представлено 5656154 генома вируса SARS-COV-2, за прошедшую неделю в базу данных депонировано еще 187730 геномов (за предыдущую неделю 182336 геномов).

Всего депонировано 4344876 геномов четырех вариантов, по классификации ВО3 - вызывающие озабоченность (VOC) - 76,8 \% от общего числа депонированных геномов вируса SARS-COV-2 (на предыдущей неделе - 76,1\%). Геновариантов, представляющих интерес (VOI), депонировано 22989 (0,4% от общего числа депонированных геномов виpyca SARS-COV-2).

\section{Варианты, вызывающие озабоченность (VOC)}

По данным ВО3 геновариант Alpha циркулирует в 197 странах мира, геновариант Beta - в 147 странах, геновариант Gamma - в 105 странах, геновариант Delta - в 201 стране, Omicron - в 19 странах.

В начале ноября 2021 года обнаружен вариант вируса SARS-COV-2, принадлежащий Pango Lineage B.1.1.529, с большим количеством мутаций S-гена.

В международную базу данных GISAID первый образец геномной последовательности нового варианта был размещен 23 ноября. Полногеномная последовательность нового вируса SARS-CoV-2 в базу данных GISAID была депонирована 27 ноября.

26 ноября 2021 г. ВОЗ по рекомендации Технической консультативной группы по эволюции вируса SARS-CoV-2 (ТКГЭВ) объявила вариант В.1.1.529 вызывающим озабоченность и присвоила ему наименование Omicron GR/484A (B.1.1.529).

Информация по обновленным данным о депонированных геномах вируса SARSCOV-2 вариантов VOC: 202012/01, B.1.1.7 (Alpha), 501Y.V2, B.1.351 (Beta), P.1 (Gamma), B.1.617.2 (Delta) и Omicron GR/484A (B.1.1.529) в базе GISAID дана в таблице 1.

Вариант VOC 202012/01 (линия B.1.1.7), Alpha 
Относительно 26 ноября в базе данных GISAID представлено еще 835 новых геномов вируса SARS-COV-2, относящихся к варианту VOC 202012/01 (Alpha) (за предыдущую неделю 3746 геномов). Итого - 1146473 генома вируса варианта B.1.1.7 (Alpha).

В базе данных GISAID зафиксировано 180 стран и территорий, в которых циркулируют геномы варианта Alpha: Албания, Алжир, Андорра, Ангола, Ангилья, Антигуа и Барбуда, Аргентина, Армения, Аруба, Австралия, Австрия, Азербайджан, Афганистан, Багамские Острова, Бахрейн, Бангладеш, Барбадос, Беларусь, Бельгия, Белиз, Бенин, Бермудские острова, Бонайре, Босния и Герцеговина, Бразилия, Британские Виргинские острова, Болгария, Буркина-Фасо, Бурунди, Великобритания, Венесуэла, Вьетнам, Венгрия, Виргинские острова (США), Габон, Гамбия, Грузия, Германия, Гана, Гибралтар, Греция, Гренада, Гваделупа, Гуам, Гватемала, Гвинея, Гвинея-Бисау, Гаити, Гондурас, Дания, Джибути, Доминика, Доминиканская Республика, Демократическая Республика Конго, Египет, Замбия, Исландия, Индия, Индонезия, Иордания, Иран, Ирак, Ирландия, Израиль, Испания, Италия, Кабо-Верде, Камбоджа, Камерун, Канада, Канарские острова, Катар, Каймановы острова, Китай, Колумбия, Коста-Рика, Кот-д’Ивуар, Кюрасао, Кипр, Казахстан, Кения, Косово, Кувейт, Латвия, Ливан, Ливия, Либерия Лихтенштейн, Литва, Люксембург, Мадагаскар, Малави, Малайзия, Мальдивы, Мальта, Мартиника, Маврикий, Майотта, Мексика, Молдова, Монако, Монтсеррат, Марокко, Мозамбик, Мьянма, Намибия, Непал, Нидерланды, Новая Зеландия, Нигер, Нигерия, Норвегия, ОАЭ, Оман, Пакистан, Палестина, Парагвай, Панама, Перу, Польша, Португалия, Пуэрто-Рико, Реюньон, Румыния, Россия, Руанда, Республика Конго, Республика Фиджи, Республика Вануату, Республика Сейшельские Острова, Северная Македония, Содружество Северных Марианских Островов, Сент-Люсия, Сальвадор, Саудовская Аравия, Сенегал, Сербия, Сингапур, Синт-Мартен, Словакия, Словения, Сомали, Суринам, Судан, США, Тайвань, Таиланд, Того, Тринидад и Тобаго, Тунис, Турция, Теркс и Кайкос, Уганда Украина, Узбекистан, Уоллис и Футуна, Филиппины, Фарерские острова, Финляндия, Франция, Французская Гвиана, Хорватия, Чехия, Черногория, Чад, Чили, Швеция, Швейцария, Шри-Ланка, ЦАР, Экваториальная Гвинея, Эстония, Эфиопия, Эквадор, Южная Африка, Южная Корея, Южный Судан, Ямайка, Япония.

Доля геноварианта Alpha в структуре VOC на анализируемой неделе в сравнении с предыдущей уменьшилась с 2,1 до 0,5\%.

На 3 декабря 2021 года динамика доли депонированных в базу GISAID геномов вируса вариантов 202012/01 (Alpha) дает следующую картину по странам (рис. 1 - 6). 


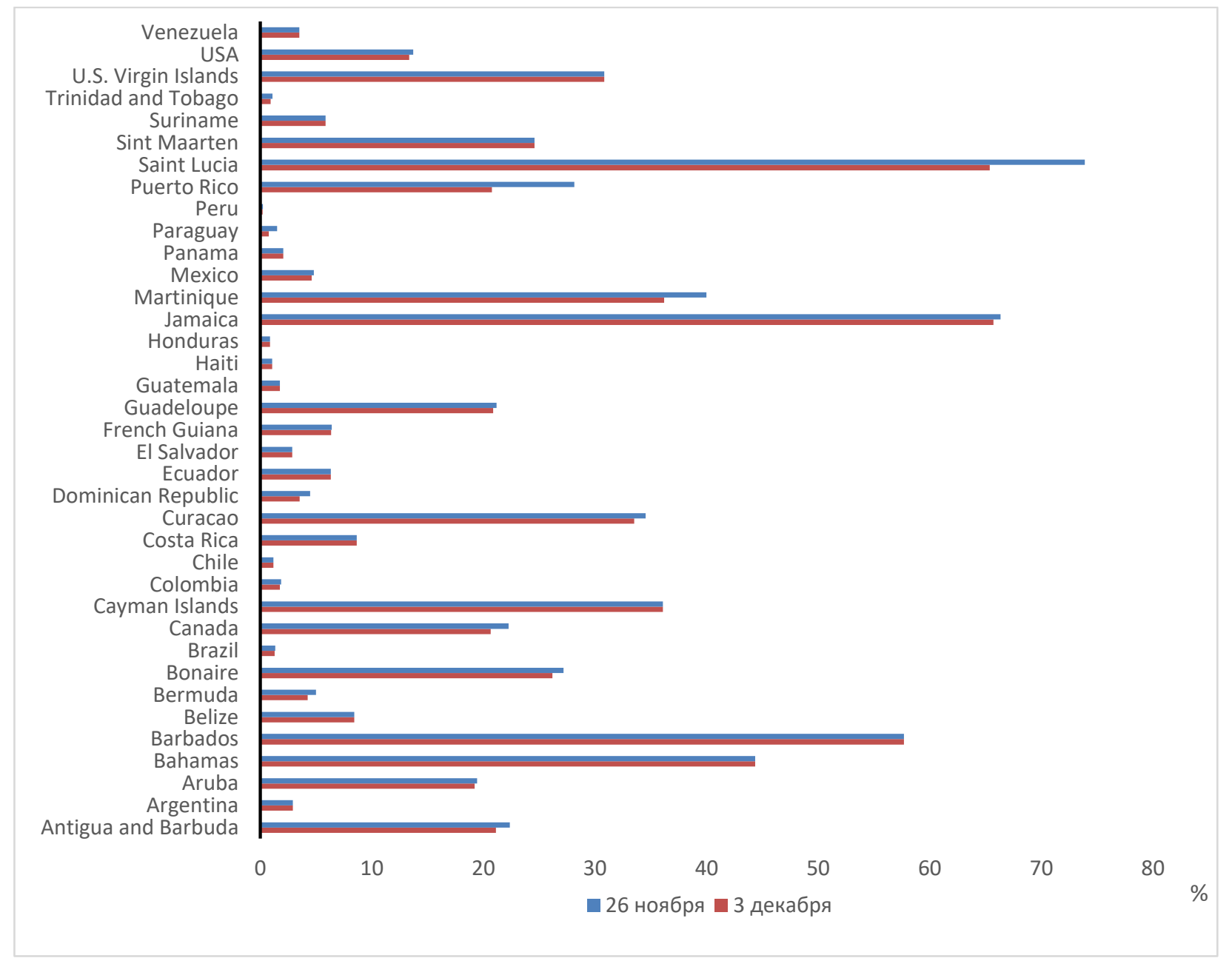

Рисунок 1 Доля геноварианта Alpha от общего числа депонированных геномов (на 26.11.2021 г. и 03.12.2021 г.) в странах Американского региона. 


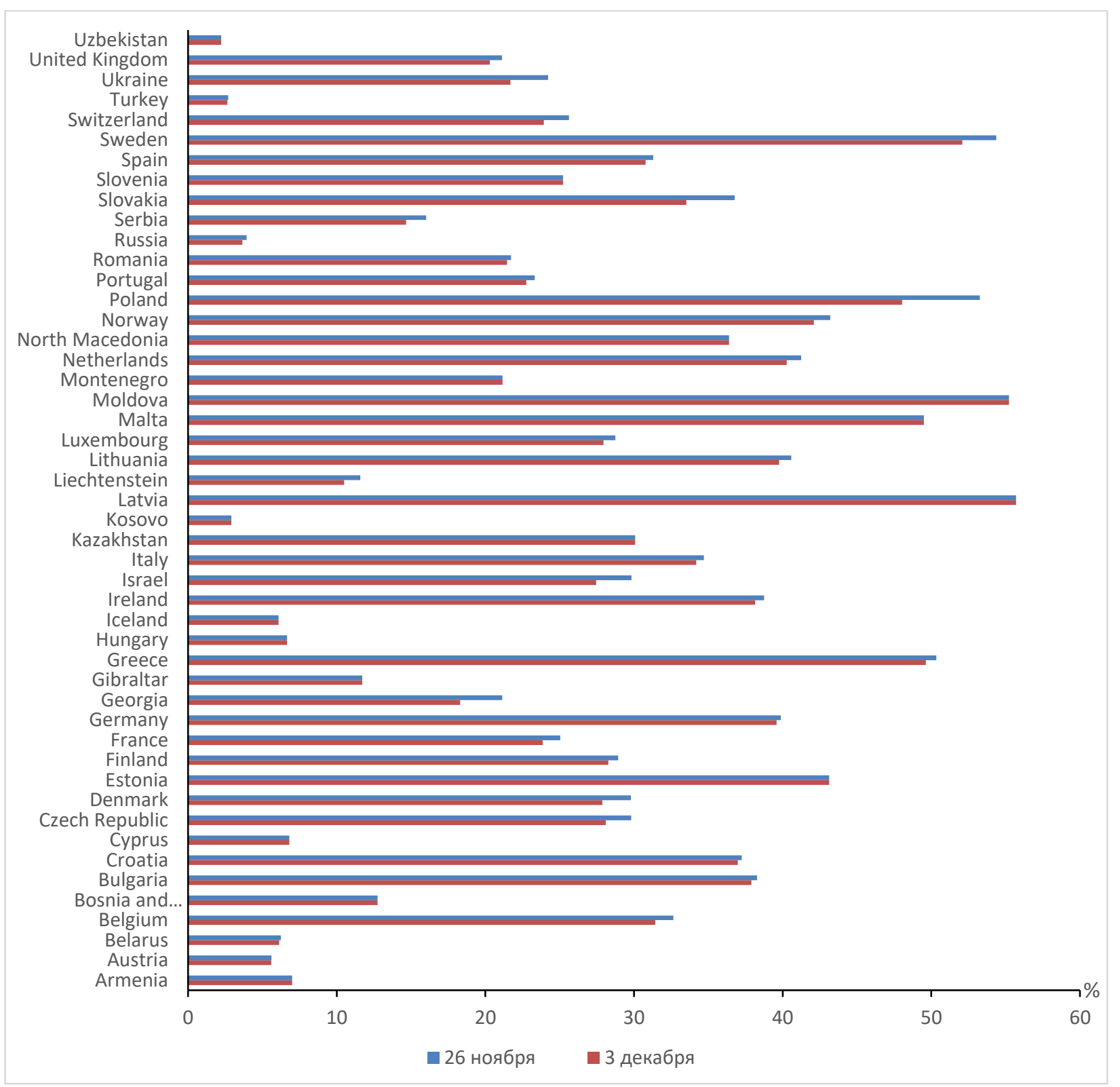

Рисунок 2 Доля геноварианта Alpha от общего числа депонированных геномов (на 26.11.2021 г. и 03.12.2021 г.) в странах Европейского региона 


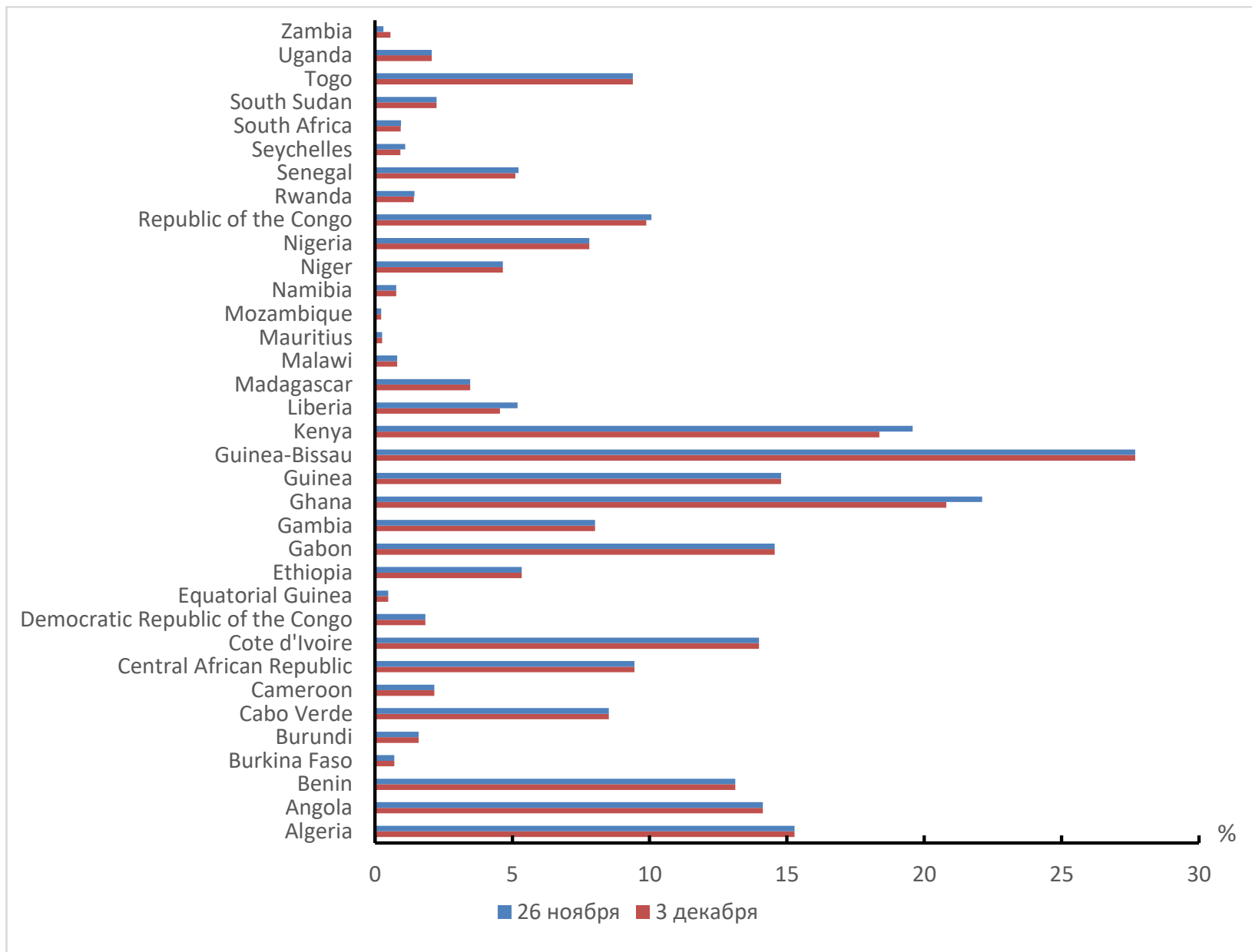

Рисунок 3 Доля геноварианта Alpha от общего числа депонированных геномов (на 26.11.2021 г. и 03.12.2021 г.) в странах Африканского региона

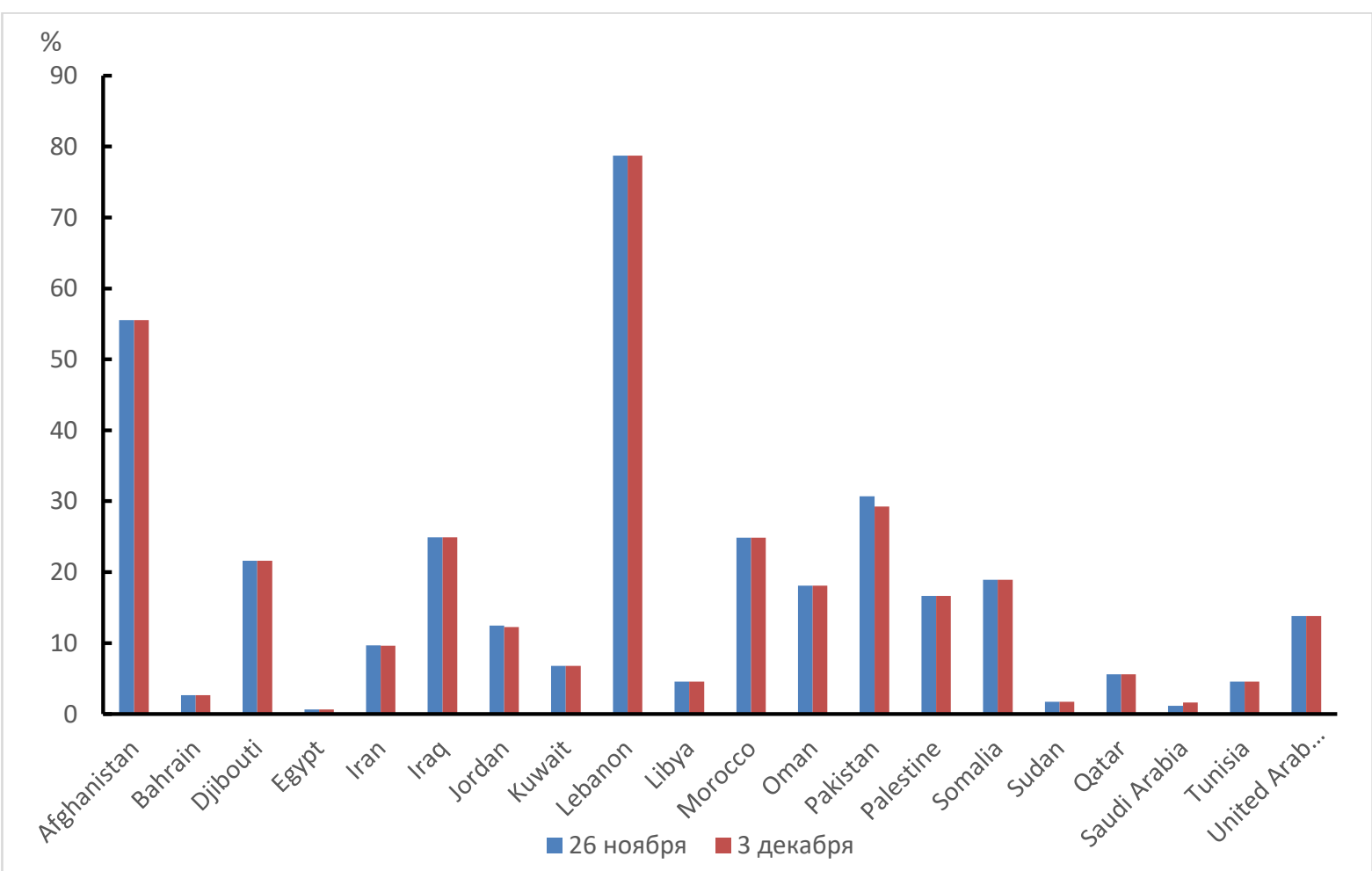

Рисунок 4 Доля геноварианта Alpha от общего числа депонированных геномов (на 26.11.2021 г. и 03.12.2021 г.) в странах Восточного Средиземноморья 


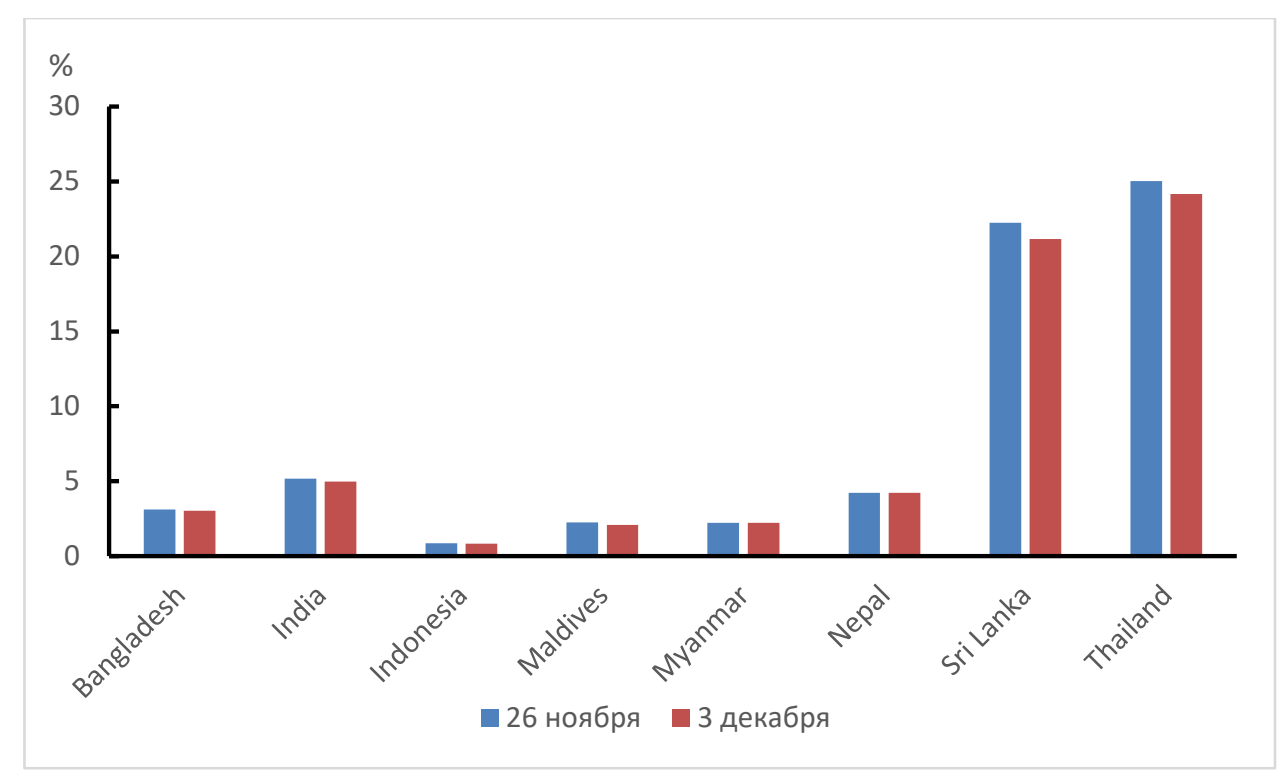

Рисунок 5 Доля геноварианта Alpha от общего числа депонированных геномов (на 26.11.2021 г. и 03.12.2021 г.) в странах Юго-Восточной Азии

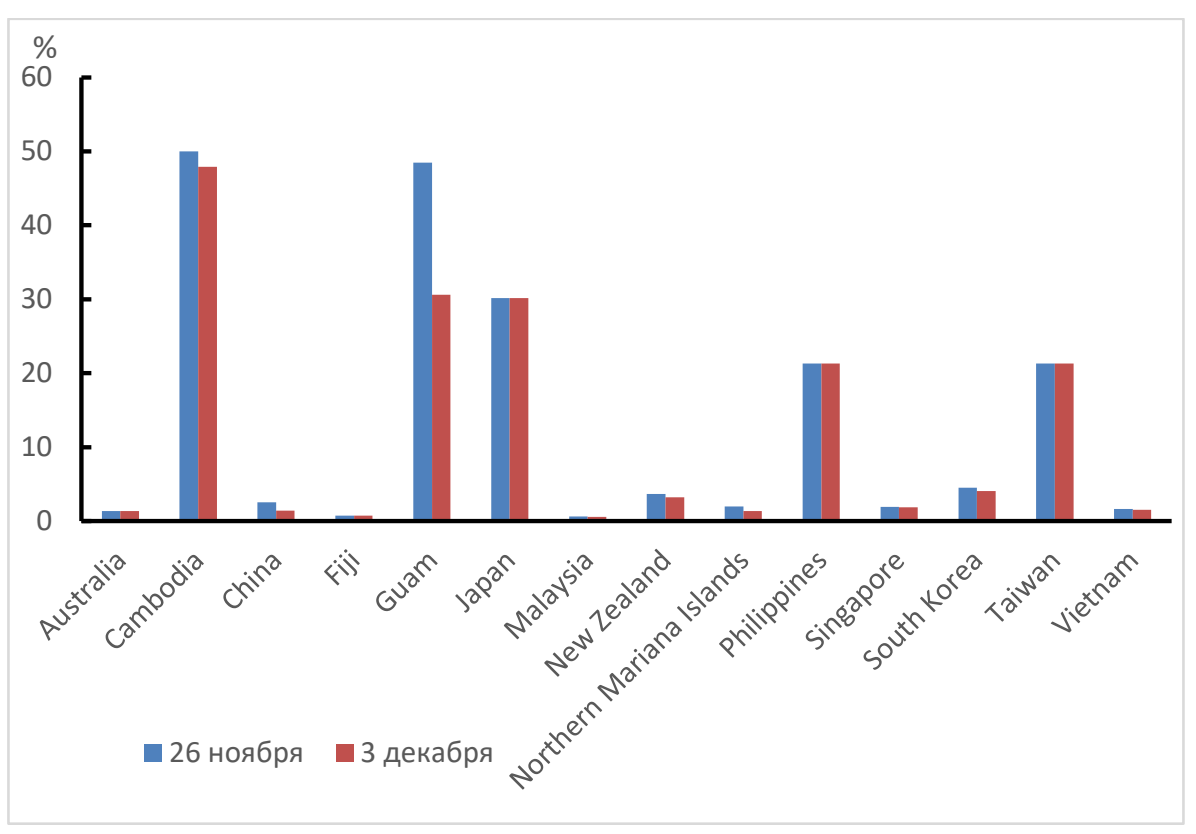

Рисунок 6 Доля геноварианта Alpha от общего числа депонированных геномов (на 26.11.2021 г. и 03.12.2021 г.) в странах Западно-Тихоокеанского региона

\section{Вариант 501Y.V2, ген S (линия B.1.351+B.1.351.2+B.1.351.3), Beta.}

На 3 декабря в базе данных размещено 39315 геномов, относящихся к линии B.1.351. В международной базе данных GISAID за анализируемую неделю депонировано 1023 геноварианта Beta (за предыдущую неделю 208 геномов). Доля геноварианта Beta в структуре VOC на анализируемой неделе увеличилась с 0,1 до 0,5 \%. 
Всего по базе данных GISAID депонированы геномы варианта Beta из 117 стран и территорий: Австралия, Австрия, Аруба, Ангола, Андорра, Аргентина, Бангладеш, Бахрейн, Бенин, Ботсвана, Болгария, Бельгия, Бразилия, Бруней, Бурунди, Великобритания, Гана, Гваделупа, Гватемала, Гвинея-Бисау, Германия, Габон, Греция, Грузия, Гуам, Дания, ДРК, Джибутти, Замбия, Зимбабве, Израиль, Иордания, Италия, Испания, Ирландия, Иран, Ирак, Индия, Индонезия, Исландия, Канада, Камерун, Каймановы острова, Котд’Ивуар, Кения, Коморы, Коста-Рика, Колумбия, Китай, Кувейт, Катар, Латвия, Лесото, Литва, Либерия, Люксембург, Мадагаскар, Малави, Малайзия, Мальта, Мартини́ка, Мозамбик, Майотта, Маврикий, Мексика, Монако, Марокко, Намибия, Нидерланды, Нигерия, Норвегия, Новая Зеландия, ОАЭ, Оман, Пакистан, Панама, Португалия, Польша, Пуэрто-Рико, Россия, Руанда, Румыния, Реюньон, Республика Сейшельские Острова, Саудовская Аравия, Северная Македония, Сингапур, Синт-Мартен, Сомали, Суринам, Словакия, Словения, США, Тайвань, Тайланд, Тунис, Турция, Того, Уганда, Филиппины, Финляндия, Франция, Французская Гвиана, Хорватия, ЦАР, Чили, Чехия, Швеция, Швейцария, Шри-Ланка, Экваториальная Гвинея, Эсватини, Эстония, Южная Корея, ЮАР, Южный Судан, Япония.

C начала пандемии наибольшее число геновариантов Beta в базе данных GISAID представили ЮАР (6838 или 17,7 \% от всех депонированных вариантов Beta), Франция (3399 или 8,8 \%), Филиппины (3182 или 8,2 \%), США (3037 или 7,8 \%), Реюньон (2663 или 6,8 \%), Швеция (2575 или 6,6 \%), Германия (2252 или 5,8 \%).

\section{Вариант Р.1 (линия В.1.1.28), Gamma.}

C 1 ноября 2020 года в базе GISAID представлено 116784 генома SARS-CoV-2 варианта P.1 Gamma. За анализируемую неделю в базу данных депонировано 981 данного варианта вируса. (за предыдущую неделю 1348 геномов). Доля геноварианта Gamma в структуре VOC на анализируемой неделе уменьшилась с 0,8 до 0,5\%.

В базе данных GISAID на 3 декабря циркуляция геноварианта Gamma зафиксирована в 93 странах и территориях: Ангола, Аргентина, Аруба, Австралия, Австрия, Антигуа и Барбуда, Багамы, Бангладеш, Бахрейн, Барбадос, Белиз, Бонайре, Бразилия, Бельгия, Боливия, Босния и Герцеговина, Великобритания, Венесуэла, Виргинские острова (США), Гаити, Гана, Гайана, Германия, Гуам, Гондурас, Греция, Гватемала, Дания, Доминиканская Республика, Израиль, Индия, Италия, Ирландия, Испания, Иордания, Исландия, Канада, Каймановы острова, Камбоджа, Камерун, Колумбия, Коста-Рика, Китай, Кюрасао, Литва, Литва, Люксембург, Лихтенштейн, Мальта, Мартиника, Мексика, Монтсеррат, Намибия, Нидерланды, Норвегия, Новая Зеландия, ОАЭ, Пакистан, Парагвай, Перу, Португалия, Польша, Пуэрто-Рико, Республика Конго, Румыния, Россия, Сальвадор, Словения, Сингапур, Синт-Ма́ртен, Суринам, США, Тайвань, Таиланд, Тринидад и Тобаго, Турция, Уругвай, Фарерские острова, Филиппины, Финляндия, Франция, Французская Гвиана, Чили, Чехия, Черногория, Хорватия, Швейцария, Швеция, Эквадор, ЮАР, Южная Корея, Япония.

C начала пандемии наибольшее число геновариантов Gamma в базе данных GISAID размещены из стран Американского региона (около 90,0 \%), в том числе: Брази- 
лия (38,9 \% от всех представленных геновариантов Gamma), США (25,1 \%), Канада (13,8 $\%)$.

\section{Вариант Delta (B.1.617.2)}

С декабря 2020 года в международную базу данных GISAID загружено 3041916 геномных последовательностей вируса SARS-CoV-2 варианта Delta. За последнюю неделю в базу данных было депонировано ещё 182007 геномов данного варианта вируса (за предыдущую неделю 170 147).

На сегодняшний день в базе данных GISAID зафиксировано депонирование варианта Delta из 177 стран и территорий: Австралия, Австрия, Ангилья, Ангола, Американские Виргинские острова, Андорра, Антигуа и Барбуда, Аргентина, Армения, Аруба, Албания, Алжир, Азербайджан, Афганистан, Бангладеш, Багамы, Барбадос, Бахрейн, Беларусь, Бельгия, Белиз, Бенин, Болгария, Бонайре, Босния и Герцеговина, Ботсвана, Бразилия, Бруней, Буркина-Фасо, Бурунди, Великобритания, Венесуэла, Виргинские Острова, Вьетнам, Восточный Тимор, Габон, Гаити, Гайана, Гана, Гамбия, Гваделупа, Гватемала, Гвинея, Гвинея-Бисау, Германия, Гибралтар, Греция, Гренада, Грузия, Гондурас, Гуам, Дания, ДРК, Джибути Доминиканская Республика, Египет, Замбия, Зимбабве, Израиль, Индия, Индонезия, Иордания, Иран, Ирак, Ирландия, Исландия, Испания, Италия, Казахстан, Камбоджа, Камерун, Канада, Катар, Каймановы Острова, Китай, Кипр, Кения, Колумбия, Косово, Коста-Рика, Кувейт, Кюрасао, Латвия, Либерия, Литва, Ливан, Лихтенштейн, Люксембург, Маврикий, Майотта, Малайзия, Мальдивы, Малави, Мальта, Марокко, Мартиника, Мексика, Молдова, Мозамбик, Монтсеррат, Мьянма, Монако, Монголия, Намибия, Непал, Нигерия, Нидерланды, Новая Зеландия, Норвегия, Оман, ОАЭ, Пакистан, Панама, Папуа - Новая Гвинея, Перу, Польша, Португалия, Парагвай, Пуэрто-Рико, Реюньон, Республика Фиджи, Россия, Румыния, Руанда, Республика Конго, Республика Мали, Республика Сейшельские Острова, Сальвадор, Саудовская Аравия, Сенегал, Сингапур, Синт-Мартен, Северная Македония, Северные Марианские острова, Сент-Люсия, Сент-Винсент и Гренадины, Сен-Бартелеми, Сербия, Словакия, Словения, США, Суринам, Сьерра-Леоне, Союз Коморских Островов, Таиланд, Тайвань, Теркс и Кайкос, Того, Тринидад и Тобаго, Тунис, Турция, Украина, Уганда, Узбекистан, Филиппины, Финляндия, Франция, Французская Гвиана, Французская Полинезия, Хорватия, ЦАР, Чешская Республика, Черногория, Чили, Швейцария, Швеция, Шри-Ланка, Эквадор, Экваториальная Гвинея, Эстония, Эсватини, Эфиопия,Южная Корея, ЮАР, Южный Судан, Ямайка, Япония.

Доля геноварианта Delta в структуре VOC на анализируемой неделе в сравнении с предыдущей увеличилась с 96,9\% до 98,3\%.

За последние 4 недели наибольшее число геновариантов Delta в базе данных GISAID размещены из Великобритании (122 013 полных генома или 48,4 \% от всех геновариантов Delta депонированных за данный период), США (50 631 геном или 20,1%), Дании (26 734 генома или 10,6\%).

На 3 декабря 2021 года динамика доли депонированных в базу GISAID геномов вируса вариантов Delta (B.1.617.2) дает следующую картину по странам (рис. 7 - 12). 


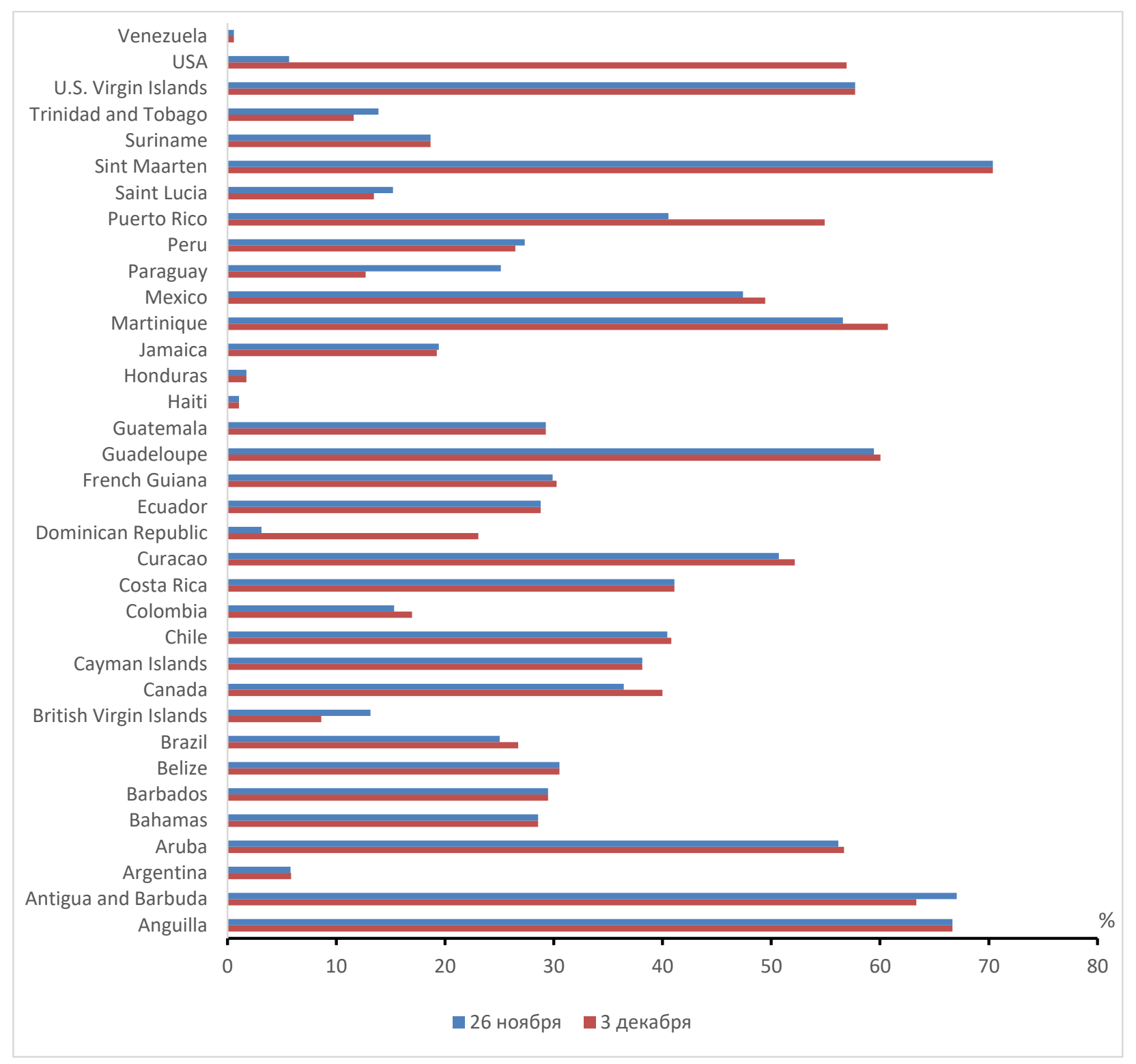

Рисунок 7 Доля геноварианта Delta от общего числа депонированных геномов (на 26.11.2021 г. и 03.12.2021 г.) в странах Американского региона. 


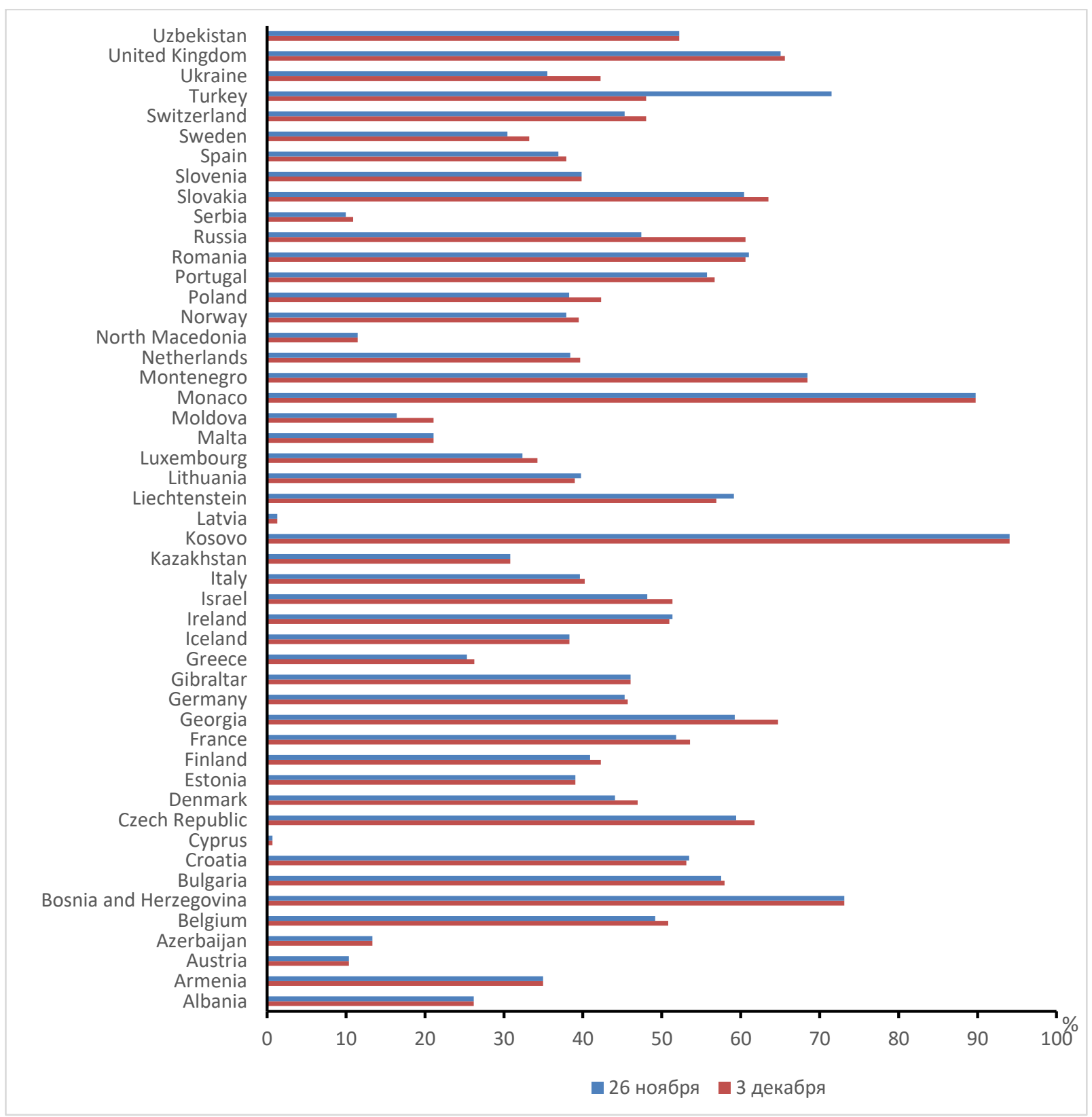

Рисунок 8 Доля геноварианта Delta от общего числа депонированных геномов (на 26.11.2021 г. и 03.12.2021 г.) в странах Европейского региона. 


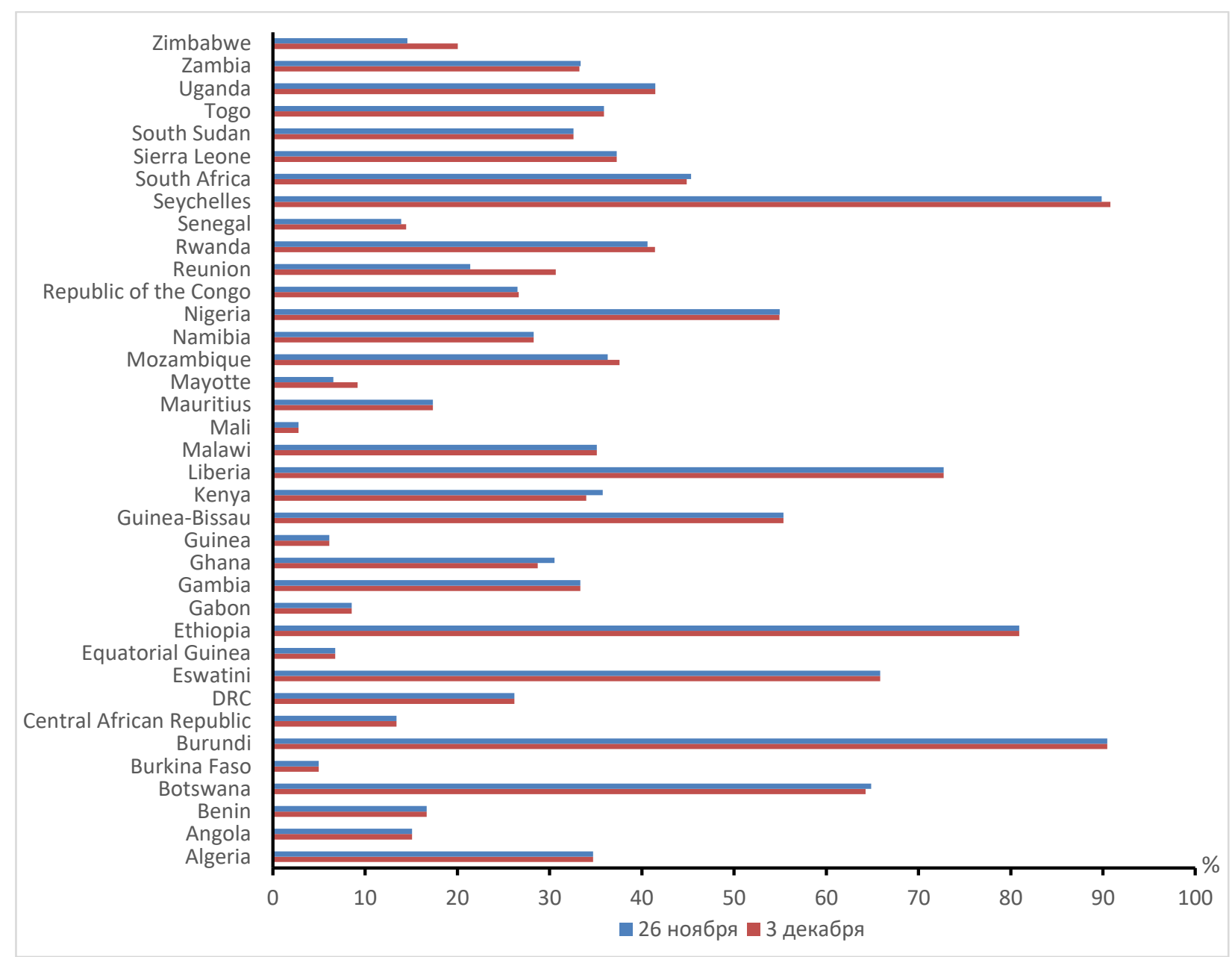

Рисунок 9 Доля геноварианта Delta от общего числа депонированных геномов (на 26.11.2021 г. и 03.12.2021 г.) в странах Африканского региона. 


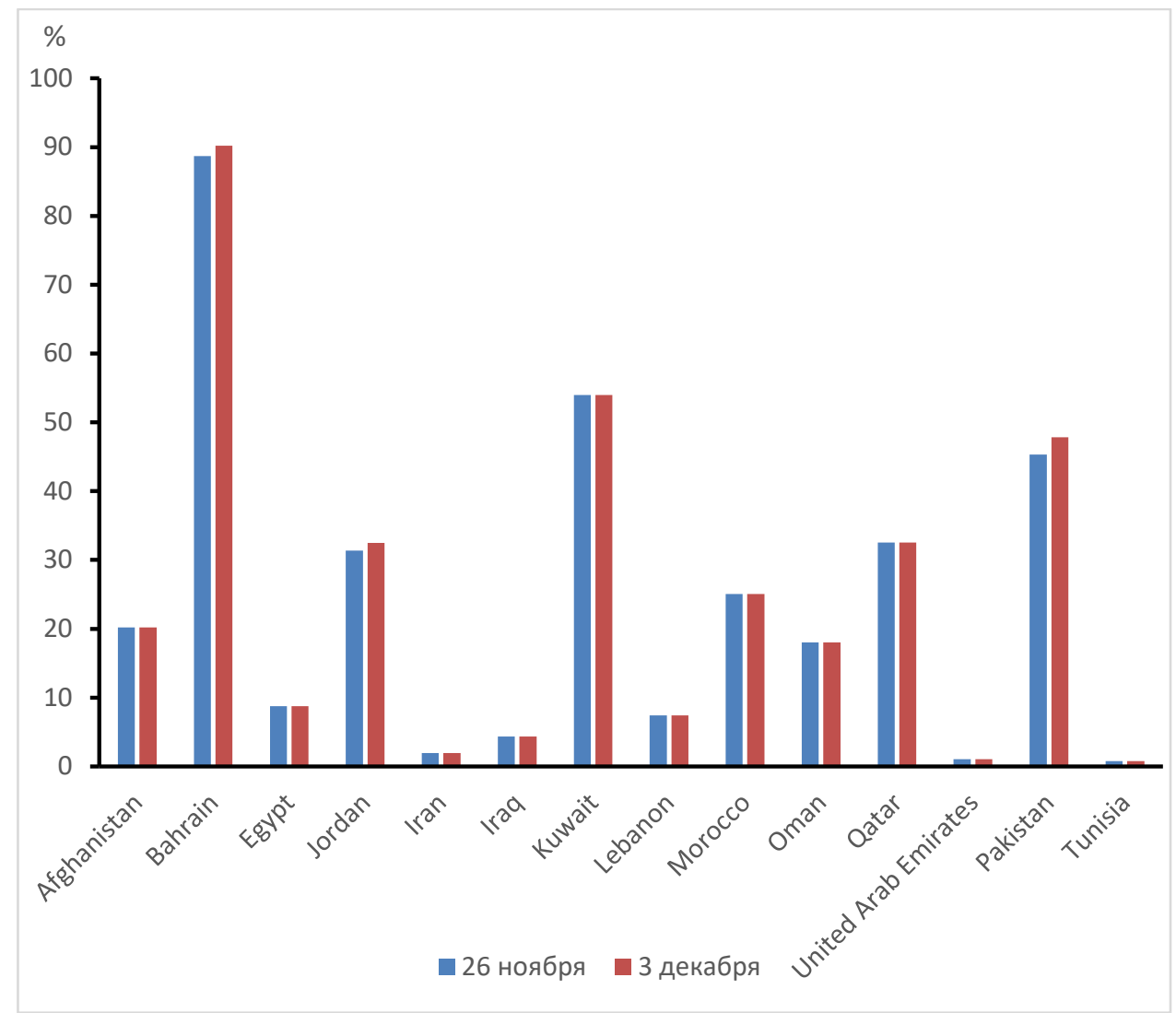

Рисунок 10 Доля геноварианта Delta от общего числа депонированных геномов (на 26.11.2021 г. и 03.12.2021 г.) в странах Восточного Средиземноморья

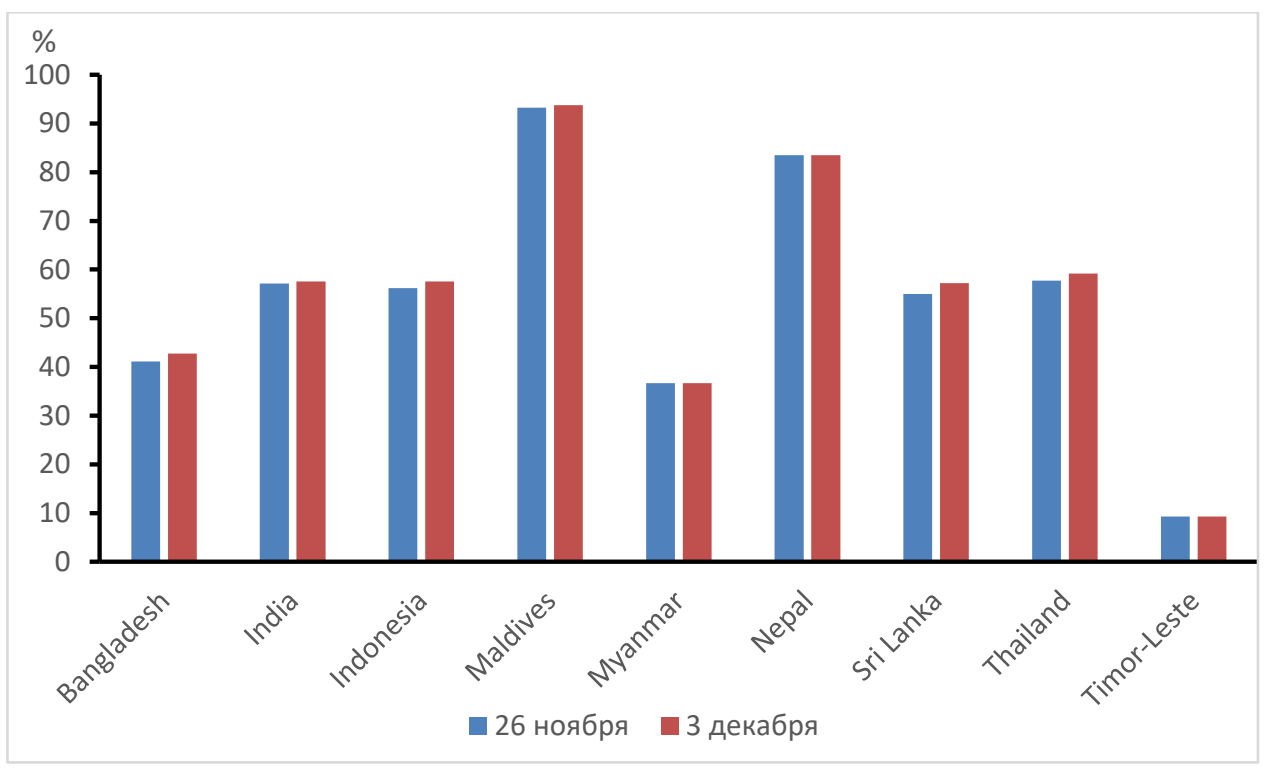

Рисунок 11 Доля геноварианта Delta от общего числа депонированных геномов (на 26.11.2021 г. и 03.12.2021 г.) в странах Юго-Восточной Азии 


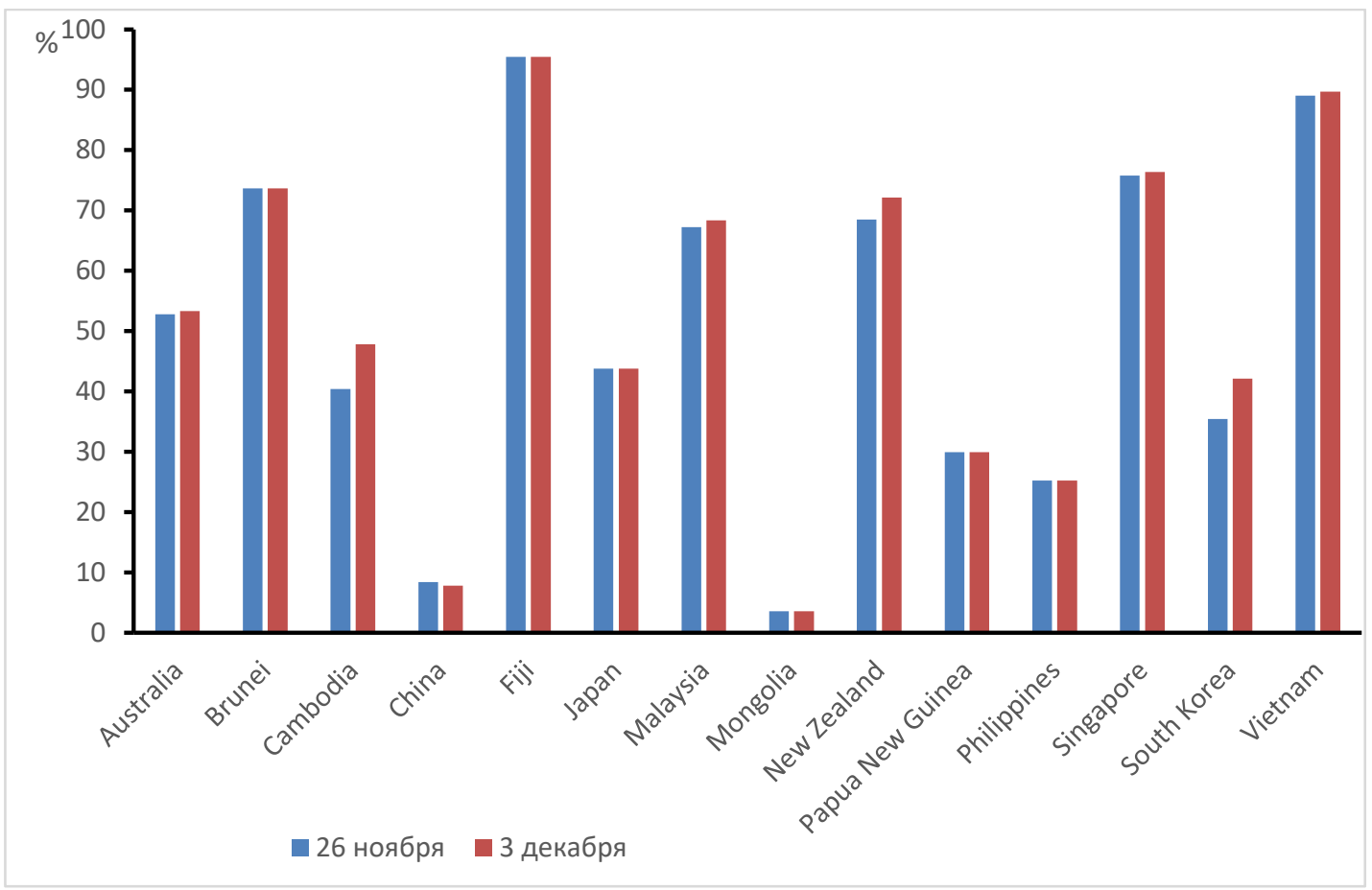

Рисунок 12 Доля геноварианта Delta от общего числа депонированных геномов (на 26.11.2021 г. и 03.12.2021 г.) в странах Западно-Тихоокеанского региона

\section{Вариант}

\section{Omicron GR/484A (B.1.1.529)}

На 3 декабря 2021 года в международной базе данных GISAID депонировано 389 геномов варианта Omicron из 27 стран и территорий: Австралия, Австрия, Бельгия, Ботсвана, Бразилия, Великобритания, Гана, Германия, Гонконг, Италия, Испания, Индия, Израиль, Ирландия, Канада, Нидерланды, Норвегия, Португалия, Реюньон, США, Франция, Чехия, Швеция, Швейцария, ЮАР, Южная Корея, Япония.

Доля геноварианта в структуре VOC на анализируемой неделе составила 0,2 \% (на предыдущей - 0,04\%).

Более половины $(55,9 \%)$ геномных последовательностей данного варианта вируса SARS-COV-2 депонировано из ЮАР. 


\section{Варианты вируса SARS-CoV-2 вызывающие интерес (VOI)}

Варианты вируса SARS-COV-2, классифицированные как вызывающие интерес (VOI) в базе GISAID представлены линиями Lambda GR/452Q.V1 (C.37) и Mu GH (B.1.621+B.1.621.1).

Информация по данным о депонированных геномах вируса Lambda (C.37) и $\mathrm{Mu}$ (В.1.621+В.1.621.1) приведена в таблице 2.

\section{Вариант VOI Lambda GR/452Q.V1 (C.37)}

На 3 декабря 2021 года в международной базе данных GISAID представлено 9282 генома варианта Lambda (C.37). За анализируемую неделю в базу данных геномы данного варианта вируса не депонированы.

Всего в базе данных GISAID зафиксировано депонирование варианта Lambda (C.37) из 47 стран и территорий: Ангола, Аруба, Аргентина, Австралия, Бельгия, Боливия, Бразилия, Великобритания, Венесуэла, Гватемала, Гвинейская Республика, Германия, Дания, Доминиканская Республика, Ирландия, Италия, Израиль, Испания, Индия, Канада, Колумбия, Коста-Рика, Кюрасао, Люксембург, Мексика, Майотта, Нидерланды, Норвегия, Панама, Перу, Польша, Португалия, Пуэрто-Рико, Сальвадор, Сент-Китс и Невис, СинтМартен, США, Турция, Уругвай, Франция, Швейцария, Швеция, Чили, Чехия, Эквадор, ЮАР, Япония.

Доля геноварианта Lambda в структуре VOI, размещенных за анализируемую неделю в сравнении с предыдущей неделей уменьшилась с 44,1 до 0 \%.

В абсолютных значениях наибольшее число геномных последовательностей данного варианта за все время пандемии депонировано из стран Американского региона - более 90\%, в том числе: Перу (42,1\% от всех геновариантов Lambda), Чили (19,5\%), США (13,5 $\%)$ и Аргентины $(10,2 \%)$.

Удельный вес варианта Lambda в общем числе отсеквенированных штаммов в странах в среднем составил 3,5 \%. Доля генома, относящегося к варианту Lambda выше средней отмечена в странах: Сент-Китс и Невис - 86,2 \%, Перу - 35,0 \%, Чили - 11,3 \%, Эквадор - 8,6 \%, Аргентине - 8,5 \%, Сальвадоре - 5,3\%.

\section{Вариант VOI Mu GH (B.1.621+B.1.621.1)}

Всего в базе данных GISAID депонировано 13707 геномных последовательностей варианта Мu. За анализируемую неделю в базу данных было депонировано 139 геномов данного варианта вируса (за предыдущую неделю -422 генома).

По состоянию на 3 декабря 2021 года в базе данных GISAID зафиксировано депонирование геноварианта Мu из 60 стран: Аруба, Австрия, Американские Виргинские острова, Аргентина, Барбадос, Бельгия, Бонайр, Боливия, Бразилия, Британские Виргинские острова, Великобритания, Венесуэла, Германия, Гватемала, Гибралтар, Дания, Доминиканская Республика, Израиль, Индия, Ирак, Ирландия, Испания, Италия, Канада, Катар, Каймановы острова, Китай, Колумбия, Коста-Рика, Кюрасао, Лихтенштейн, Люксембург, Марокко, Мальта, Мексика, Нидерланды, Панама, Перу, Польша, Португалия, ПуэртоРико, Россия, Республика Гаити, Румыния, Словения, Словакия, Синт Мартен, США, 
Турция, Теркс и Кайкос, Финляндия, Франция, Швеция, Швейцария, Чехия, Чили, Эквадор, Южная Корея, Ямайка, Япония.

Доля геномов варианта Мu в структуре VOI, размещенных за анализируемую неделю в сравнении с предыдущей неделей увеличилась с 55,9 до 100,0 \%.

В абсолютных значениях наибольшее число геномов данного варианта за все время пандемии депонировали США (42,7 \% от всех геновариантов Мu) и Колумбия $(28,9 \%)$.

Удельный вес варианта Мu в общем числе отсеквенированных штаммов в странах в среднем составил 3,9 \%, выше этот показатель в странах - Британские Виргинские острова, где доля данного геноварианта составляет 70,7 \%, Колумбия - 48,4 \%, Доминиканская Республика - 20,2 \%, Эквадор - 12,5\%. 
Таблица 1 - Количество депонированных геномов вариантов Alpha (B.1.1.7), Beta (B.1.351), Gamma (P.1) и Delta (B.1.617.2) варианта вируса SARS-CoV-2 в базе GISAID.

\begin{tabular}{|c|c|c|c|c|c|c|c|}
\hline \multirow[b]{2}{*}{ Страна } & \multirow[b]{2}{*}{$\begin{array}{c}\text { Учреждение, проводившее } \\
\text { секвенирование }\end{array}$} & \multicolumn{3}{|c|}{$\begin{array}{l}\text { Количество депонированных геномов } \\
\text { SARS-CoV-2 }\end{array}$} & \multicolumn{3}{|c|}{$\begin{array}{c}\text { В том числе количество геномов, } \\
\text { депонированных } \\
\text { за последние } 4 \text { недели } \\
\text { (06.11.21 -03.12.21) } \\
\end{array}$} \\
\hline & & $\begin{array}{c}\text { Варианты: } \\
\text { Alpha (B.1.1.7) } \\
\text { Beta (B.1.351) } \\
\text { Gamma (P.1) } \\
\text { Delta } \\
\text { (B.1.617.2) } \\
\text { Omicron } \\
\text { (B.1.1.529) }\end{array}$ & Всего & $\begin{array}{c}\text { Процент ге- } \\
\text { номов, отно- } \\
\text { сящихся к } \\
\text { варианту: } \\
\text { Alpha } \\
\text { (B.1.1.7) } \\
\text { Beta (B.1.351) } \\
\text { Gamma (P.1) } \\
\text { Delta } \\
\text { (B.1.617.2) } \\
\text { Omicron } \\
\text { (B.1.1.529) }\end{array}$ & $\begin{array}{c}\text { Варианты: } \\
\text { Alpha } \\
\text { (B.1.1.7) } \\
\text { Beta } \\
\text { (B.1.351) } \\
\text { Gamma } \\
\text { (P.1) } \\
\text { Delta } \\
\text { (B.1.617.2) } \\
\text { Omicron } \\
\text { (B.1.1.529) }\end{array}$ & Всего & $\begin{array}{c}\text { Процент ге- } \\
\text { номов, отно- } \\
\text { сящихся к } \\
\text { варианту: } \\
\text { Alpha } \\
\text { (B.1.1.7) } \\
\text { Beta } \\
\text { (B.1.351) } \\
\text { Gamma (P.1) } \\
\text { Delta } \\
\text { (B.1.617.2) } \\
\text { Omicron } \\
\text { (B.1.1.529) }\end{array}$ \\
\hline $\begin{array}{c}\text { Австралия } \\
\text { (стабилизация забо- } \\
\text { леваемости) }\end{array}$ & $\begin{array}{l}\text { NSW Health Pathology - Insti- } \\
\text { tute of Clinical Pathology and } \\
\text { Medical Research; Westmead } \\
\text { Hospital; University of Sydney }\end{array}$ & $\begin{array}{l}\text { Alpha }-585 \\
\text { Beta }-93 \\
\text { Gamma }-8 \\
\text { Delta }-23245 \\
\text { Omicron }-9\end{array}$ & 43568 & $\begin{array}{l}\text { Alpha }-1,3 \\
\text { Beta }-0,2 \\
\text { Gamma }-0 \\
\text { Delta }-53,4 \\
\text { Omicron }-0\end{array}$ & $\begin{array}{l}\text { Alpha }-0 \\
\text { Beta }-0 \\
\text { Gamma }-0 \\
\text { Delta }-1463 \\
\text { Omicron }-9\end{array}$ & 1586 & $\begin{array}{l}\text { Alpha }-0 \\
\text { Beta }-0 \\
\text { Gamma }-0 \\
\text { Delta }-92,2 \\
\text { Omicron }-0,6\end{array}$ \\
\hline $\begin{array}{c}\text { Австрия } \\
\text { (снижение заболевае- } \\
\text { мости) }\end{array}$ & $\begin{array}{l}\text { Bergthaler laboratory, CeMM } \\
\text { Research Center for Molecular } \\
\text { Medicine of the Austrian Acad- } \\
\text { emy of Sciences }\end{array}$ & $\begin{array}{l}\text { Alpha }-3864 \\
\text { Beta }-268 \\
\text { Gamma }-39 \\
\text { Delta }-7164 \\
\text { Omicron }-4\end{array}$ & 69152 & $\begin{array}{l}\text { Alpha }-5,6 \\
\text { Beta }-0,4 \\
\text { Gamma }-0,1 \\
\text { Delta }-10,4 \\
\text { Omicron }-0\end{array}$ & $\begin{array}{l}\text { Alpha }-0 \\
\text { Beta }-0 \\
\text { Gamma }-0 \\
\text { Delta }-90 \\
\text { Omicron }-4\end{array}$ & 236 & $\begin{array}{l}\text { Alpha }-0 \\
\text { Beta }-0 \\
\text { Gamma }-0 \\
\text { Delta }-38,1 \\
\text { Omicron }-1,7\end{array}$ \\
\hline
\end{tabular}




\begin{tabular}{|c|c|c|c|c|c|c|c|}
\hline $\begin{array}{c}\text { Азербайджан } \\
\text { (снижение заболевае- } \\
\text { мости) }\end{array}$ & $\begin{array}{l}\text { National Hematology and Trans- } \\
\text { fusiology Center }\end{array}$ & $\begin{array}{l}\text { Alpha }-3 \\
\text { Beta }-0 \\
\text { Gamma }-0 \\
\text { Delta }-2\end{array}$ & 15 & $\begin{array}{l}\text { Alpha }-20,0 \\
\text { Beta }-0 \\
\text { Gamma }-0 \\
\text { Delta }-13,3\end{array}$ & $\begin{array}{l}\text { Alpha }-0 \\
\text { Beta }-0 \\
\text { Gamma }-0 \\
\text { Delta }-0\end{array}$ & 0 & $\begin{array}{l}\text { Alpha }-0 \\
\text { Beta }-0 \\
\text { Gamma }-0 \\
\text { Delta }-0\end{array}$ \\
\hline $\begin{array}{c}\text { Албания } \\
\text { (снижение заболевае- } \\
\text { мости) }\end{array}$ & $\begin{array}{l}\text { Respiratory Virus Unit, National } \\
\text { Infection Service, Public Health } \\
\text { England }\end{array}$ & $\begin{array}{l}\text { Alpha }-28 \\
\text { Beta }-0 \\
\text { Gamma }-0 \\
\text { Delta }-11 \\
\end{array}$ & 42 & $\begin{array}{l}\text { Alpha }-66,7 \\
\text { Beta }-0 \\
\text { Gamma }-0 \\
\text { Delta }-26,2 \\
\end{array}$ & $\begin{array}{l}\text { Alpha }-0 \\
\text { Beta }-0 \\
\text { Gamma }-0 \\
\text { Delta }-0\end{array}$ & 0 & $\begin{array}{l}\text { Alpha }-0 \\
\text { Beta }-0 \\
\text { Gamma }-0 \\
\text { Delta }-0\end{array}$ \\
\hline $\begin{array}{c}\text { Алжир } \\
\text { (рост заболеваемости) }\end{array}$ & $\begin{array}{l}\text { National Reference Center for } \\
\text { Viruses of Respiratory Infec- } \\
\text { tions, Institut Pasteur, Paris }\end{array}$ & $\begin{array}{l}\text { Alpha }-11 \\
\text { Beta }-0 \\
\text { Gamma }-0 \\
\text { Delta }-25\end{array}$ & 72 & $\begin{array}{l}\text { Alpha }-15,3 \\
\text { Beta }-0 \\
\text { Gamma }-0 \\
\text { Delta }-34,7\end{array}$ & $\begin{array}{l}\text { Alpha }-0 \\
\text { Beta }-0 \\
\text { Gamma }-0 \\
\text { Delta }-0\end{array}$ & 0 & $\begin{array}{l}\text { Alpha }-0 \\
\text { Beta }-0 \\
\text { Gamma }-0 \\
\text { Delta }-0\end{array}$ \\
\hline $\begin{array}{c}\text { Американские } \\
\text { Виргинские острова }\end{array}$ & UW Virology Lab & $\begin{array}{l}\text { Alpha }-132 \\
\text { Beta }-0 \\
\text { Gamma }-2 \\
\text { Delta }-247\end{array}$ & 428 & $\begin{array}{l}\text { Alpha }-30,8 \\
\text { Beta }-0 \\
\text { Gamma }-0,5 \\
\text { Delta }-57,7\end{array}$ & $\begin{array}{l}\text { Alpha }-0 \\
\text { Beta }-0 \\
\text { Gamma }-0 \\
\text { Delta }-0\end{array}$ & 0 & $\begin{array}{l}\text { Alpha }-0 \\
\text { Beta }-0 \\
\text { Gamma }-0 \\
\text { Delta }-0\end{array}$ \\
\hline Ангилья & $\begin{array}{l}\text { Carrington Lab, Department of } \\
\text { PreClinical Sciences, Faculty of } \\
\text { Medical Sciences, The Universi- } \\
\text { ty of the West Indies }\end{array}$ & $\begin{array}{l}\text { Alpha }-2 \\
\text { Beta }-0 \\
\text { Gamma }-0 \\
\text { Delta }-8 \\
\end{array}$ & 12 & $\begin{array}{l}\text { Alpha }-16,7 \\
\text { Beta }-0 \\
\text { Gamma }-0 \\
\text { Delta }-66,7\end{array}$ & $\begin{array}{l}\text { Alpha }-0 \\
\text { Beta }-0 \\
\text { Gamma }-0 \\
\text { Delta }-0\end{array}$ & 0 & $\begin{array}{l}\text { Alpha }-0 \\
\text { Beta }-0 \\
\text { Gamma }-0 \\
\text { Delta }-0\end{array}$ \\
\hline $\begin{array}{c}\text { Ангола } \\
\text { (снижение заболевае- } \\
\text { мости) }\end{array}$ & $\begin{array}{l}\text { KRISP, KZN Research Innova- } \\
\text { tion and Sequencing Platform }\end{array}$ & $\begin{array}{l}\text { Alpha }-149 \\
\text { Beta }-271 \\
\text { Gamma }-1 \\
\text { Delta }-159 \\
\end{array}$ & 1055 & $\begin{array}{l}\text { Alpha }-14,1 \\
\text { Beta }-25,7 \\
\text { Gamma }-0,1 \\
\text { Delta }-15,1\end{array}$ & $\begin{array}{l}\text { Alpha }-0 \\
\text { Beta }-0 \\
\text { Gamma }-0 \\
\text { Delta }-0\end{array}$ & 0 & $\begin{array}{l}\text { Alpha }-0 \\
\text { Beta }-0 \\
\text { Gamma }-0 \\
\text { Delta }-0\end{array}$ \\
\hline $\begin{array}{c}\text { Андорра } \\
\text { (рост заболеваемости) }\end{array}$ & Instituto de Salud Carlos III & $\begin{array}{l}\text { Alpha }-7 \\
\text { Beta }-2 \\
\text { Gamma }-0 \\
\text { Delta }-25\end{array}$ & 35 & $\begin{array}{l}\text { Alpha }-20,0 \\
\text { Beta }-8,0 \\
\text { Gamma }-0 \\
\text { Delta }-71,4\end{array}$ & $\begin{array}{l}\text { Alpha }-0 \\
\text { Beta }-0 \\
\text { Gamma }-0 \\
\text { Delta }-0\end{array}$ & 0 & $\begin{array}{l}\text { Alpha }-0 \\
\text { Beta }-0 \\
\text { Gamma }-0 \\
\text { Delta }-0\end{array}$ \\
\hline $\begin{array}{c}\text { Антигуа и Барбуда } \\
\text { (снижение заболевае- } \\
\text { мости) }\end{array}$ & $\begin{array}{l}\text { Carrington Lab, Department of } \\
\text { Preclinical Sciences, Faculty of } \\
\text { Medical Sciences, The Universi- } \\
\text { ty of the West Indies, St Augus- } \\
\text { tine Campus }\end{array}$ & $\begin{array}{l}\text { Alpha }-19 \\
\text { Beta }-0 \\
\text { Gamma }-3 \\
\text { Delta }-57\end{array}$ & 90 & $\begin{array}{l}\text { Alpha }-21,1 \\
\text { Beta }-0 \\
\text { Gamma }-3,3 \\
\text { Delta }-63,3\end{array}$ & $\begin{array}{l}\text { Alpha }-0 \\
\text { Beta }-0 \\
\text { Gamma }-0 \\
\text { Delta }-0\end{array}$ & 0 & $\begin{array}{l}\text { Alpha }-0 \\
\text { Beta }-0 \\
\text { Gamma }-0 \\
\text { Delta }-0\end{array}$ \\
\hline
\end{tabular}




\begin{tabular}{|c|c|c|c|c|c|c|c|}
\hline $\begin{array}{c}\text { Аргентина } \\
\text { (рост заболеваемости) }\end{array}$ & $\begin{array}{l}\text { Instituto Nacional Enfermedad- } \\
\text { esInfecciosasC.G.Malbran }\end{array}$ & $\begin{array}{l}\text { Alpha }-325 \\
\text { Beta }-1 \\
\text { Gamma }-2511 \\
\text { Delta }-652\end{array}$ & 11141 & $\begin{array}{l}\text { Alpha }-2,9 \\
\text { Beta }-0 \\
\text { Gamma }-22,5 \\
\text { Delta }-5,9\end{array}$ & $\begin{array}{l}\text { Alpha }-0 \\
\text { Beta }-0 \\
\text { Gamma }-1 \\
\text { Delta }-13\end{array}$ & 17 & $\begin{array}{l}\text { Alpha }-0 \\
\text { Beta }-0 \\
\text { Gamma }-5,9 \\
\text { Delta }-76,5\end{array}$ \\
\hline $\begin{array}{c}\text { Армения } \\
\text { (снижение заболевае- } \\
\text { мости) }\end{array}$ & $\begin{array}{l}\text { Institute of Molecular Biology } \\
\text { NAS RA, Republic of Armenia, } \\
\text { Department of Bioengineering, } \\
\text { BioinformaticsInstitute and Mo- } \\
\text { lecular Biology IBMPh RAU, } \\
\text { Republic of Armenia }\end{array}$ & $\begin{array}{l}\text { Alpha }-10 \\
\text { Beta }-0 \\
\text { Gamma }-0 \\
\text { Delta }-50\end{array}$ & 143 & $\begin{array}{l}\text { Alpha }-7,0 \\
\text { Beta }-0 \\
\text { Gamma }-0 \\
\text { Delta }-35,0\end{array}$ & $\begin{array}{l}\text { Alpha }-0 \\
\text { Beta }-0 \\
\text { Gamma }-0 \\
\text { Delta }-0\end{array}$ & 0 & $\begin{array}{l}\text { Alpha }-0 \\
\text { Beta }-0 \\
\text { Gamma }-0 \\
\text { Delta }-0\end{array}$ \\
\hline Аруба & $\begin{array}{l}\text { National Institute for Public } \\
\text { Health and the Environ- } \\
\text { ment(RIVM) }\end{array}$ & $\begin{array}{l}\text { Alpha }-551 \\
\text { Beta }-4 \\
\text { Gamma }-123 \\
\text { Delta }-1625 \\
\end{array}$ & 2867 & $\begin{array}{l}\text { Alpha }-19,2 \\
\text { Beta }-0,1 \\
\text { Gamma }-4,3 \\
\text { Delta }-56,7 \\
\end{array}$ & $\begin{array}{l}\text { Alpha }-0 \\
\text { Beta }-0 \\
\text { Gamma }-0 \\
\text { Delta }-33\end{array}$ & 33 & $\begin{array}{l}\text { Alpha }-0 \\
\text { Beta }-0 \\
\text { Gamma }-0 \\
\text { Delta }-100,0\end{array}$ \\
\hline $\begin{array}{c}\text { Афганистан } \\
\text { (снижение заболевае- } \\
\text { мости) }\end{array}$ & WRAIR & $\begin{array}{l}\text { Alpha }-55 \\
\text { Beta }-0 \\
\text { Gamma }-0 \\
\text { Delta }-20\end{array}$ & 99 & $\begin{array}{l}\text { Alpha }-55,6 \\
\text { Beta }-0 \\
\text { Gamma }-0 \\
\text { Delta }-20,2\end{array}$ & $\begin{array}{l}\text { Alpha }-0 \\
\text { Beta }-0 \\
\text { Gamma }-0 \\
\text { Delta }-0\end{array}$ & 0 & $\begin{array}{l}\text { Alpha }-0 \\
\text { Beta }-0 \\
\text { Gamma }-0 \\
\text { Delta }-0\end{array}$ \\
\hline $\begin{array}{l}\text { Багамские острова } \\
\text { (рост заболеваемости) }\end{array}$ & $\begin{array}{l}\text { Laboratory of Respiratory Vi- } \\
\text { ruses and Measles, Oswaldo } \\
\text { Cruz Institute, FIOCRUZ }\end{array}$ & $\begin{array}{l}\text { Alpha }-59 \\
\text { Beta }-0 \\
\text { Gamma }-1 \\
\text { Delta }-38 \\
\end{array}$ & 133 & $\begin{array}{l}\text { Alpha }-44,4 \\
\text { Beta }-0 \\
\text { Gamma }-0,8 \\
\text { Delta }-28,6 \\
\end{array}$ & $\begin{array}{l}\text { Alpha }-0 \\
\text { Beta }-0 \\
\text { Gamma }-0 \\
\text { Delta }-0\end{array}$ & 0 & $\begin{array}{l}\text { Alpha }-0 \\
\text { Beta }-0 \\
\text { Gamma }-0 \\
\text { Delta }-0\end{array}$ \\
\hline $\begin{array}{c}\text { Бангладеш } \\
\text { (рост заболеваемости) }\end{array}$ & $\begin{array}{l}\text { Child Health Research Founda- } \\
\text { tion }\end{array}$ & $\begin{array}{l}\text { Alpha }-96 \\
\text { Beta }-414 \\
\text { Gamma }-1 \\
\text { Delta }-1362\end{array}$ & 3184 & $\begin{array}{l}\text { Alpha }-3,0 \\
\text { Beta }-13,0 \\
\text { Gamma }-0 \\
\text { Delta }-42,8\end{array}$ & $\begin{array}{l}\text { Alpha }-0 \\
\text { Beta }-0 \\
\text { Gamma }-0 \\
\text { Delta }-0\end{array}$ & 0 & $\begin{array}{l}\text { Alpha }-0 \\
\text { Beta }-0 \\
\text { Gamma }-0 \\
\text { Delta }-0\end{array}$ \\
\hline $\begin{array}{c}\text { Барбадос } \\
\text { (снижение заболевае- } \\
\text { мости) }\end{array}$ & $\begin{array}{l}\text { Carrington Lab, Department of } \\
\text { PreClinical Sciences, Building } \\
\text { 36, First Floor Biochemistry } \\
\text { Unit, Faculty of Medical Scienc- } \\
\text { es, The University of the West } \\
\text { Indies }\end{array}$ & $\begin{array}{l}\text { Alpha }-45 \\
\text { Beta }-0 \\
\text { Gamma }-5 \\
\text { Delta }-23\end{array}$ & 78 & $\begin{array}{l}\text { Alpha }-57,7 \\
\text { Beta }-0 \\
\text { Gamma }-6,4 \\
\text { Delta }-29,5\end{array}$ & $\begin{array}{l}\text { Alpha }-0 \\
\text { Beta }-0 \\
\text { Gamma }-0 \\
\text { Delta }-0\end{array}$ & 0 & $\begin{array}{l}\text { Alpha }-0 \\
\text { Beta }-0 \\
\text { Gamma }-0 \\
\text { Delta }-0\end{array}$ \\
\hline
\end{tabular}




\begin{tabular}{|c|c|c|c|c|c|c|c|}
\hline $\begin{array}{c}\text { Бахрейн } \\
\text { (снижение заболевае- } \\
\text { мости) }\end{array}$ & $\begin{array}{l}\text { Communicable Disease Labora- } \\
\text { tory, Public Health Directorate }\end{array}$ & $\begin{array}{l}\text { Alpha }-60 \\
\text { Beta }-12 \\
\text { Gamma }-1 \\
\text { Delta }-2046\end{array}$ & 2269 & $\begin{array}{l}\text { Alpha }-2,6 \\
\text { Beta }-0,5 \\
\text { Gamma }-0 \\
\text { Delta }-90,2\end{array}$ & $\begin{array}{l}\text { Alpha }-0 \\
\text { Beta }-0 \\
\text { Gamma }-0 \\
\text { Delta }-277\end{array}$ & 278 & $\begin{array}{l}\text { Alpha }-0 \\
\text { Beta }-0 \\
\text { Gamma }-0 \\
\text { Delta }-99,6\end{array}$ \\
\hline $\begin{array}{c}\text { Беларусь } \\
\text { (рост заболеваемости) }\end{array}$ & $\begin{array}{l}\text { Laboratory for HIV and oppor- } \\
\text { tunistic infections diagnosis The } \\
\text { Republican Research and Practi- } \\
\text { cal Center for Epidemiology and } \\
\text { Microbiology(RRPCEM) }\end{array}$ & $\begin{array}{l}\text { Alpha }-3 \\
\text { Beta }-0 \\
\text { Gamma }-0 \\
\text { Delta }-1\end{array}$ & 49 & $\begin{array}{l}\text { Alpha }-6,1 \\
\text { Beta }-0 \\
\text { Gamma }-0 \\
\text { Delta }-2,0\end{array}$ & $\begin{array}{l}\text { Alpha }-0 \\
\text { Beta }-0 \\
\text { Gamma }-0 \\
\text { Delta }-0\end{array}$ & 0 & $\begin{array}{l}\text { Alpha }-0 \\
\text { Beta }-0 \\
\text { Gamma }-0 \\
\text { Delta }-0\end{array}$ \\
\hline $\begin{array}{c}\text { Белиз } \\
\text { (стабилизация забо- } \\
\text { леваемости) }\end{array}$ & $\begin{array}{l}\text { Texas Children's Microbiome } \\
\text { Center }\end{array}$ & $\begin{array}{l}\text { Alpha }-27 \\
\text { Beta }-0 \\
\text { Gamma }-22 \\
\text { Delta }-98 \\
\end{array}$ & 321 & $\begin{array}{l}\text { Alpha }-8,4 \\
\text { Beta }-0 \\
\text { Gamma }-6,9 \\
\text { Delta }-30,5\end{array}$ & $\begin{array}{l}\text { Alpha }-0 \\
\text { Beta }-0 \\
\text { Gamma }-0 \\
\text { Delta }-0\end{array}$ & 0 & $\begin{array}{l}\text { Alpha }-0 \\
\text { Beta }-0 \\
\text { Gamma }-0 \\
\text { Delta }-0\end{array}$ \\
\hline $\begin{array}{c}\text { Бельгия } \\
\text { (снижение заболевае- } \\
\text { мости) }\end{array}$ & $\begin{array}{l}\text { KU Leuven, Rega Institute, } \\
\text { Clinical and Epidemiological } \\
\text { Virology }\end{array}$ & $\begin{array}{l}\text { Alpha }-21221 \\
\text { Beta }-1124 \\
\text { Gamma }-2044 \\
\text { Delta }-34318 \\
\text { Omicron }-2 \\
\end{array}$ & 67542 & $\begin{array}{l}\text { Alpha }-31,4 \\
\text { Beta }-1,7 \\
\text { Gamma }-3,0 \\
\text { Delta }-50,8 \\
\text { Omicron }-0\end{array}$ & $\begin{array}{l}\text { Alpha }-1 \\
\text { Beta }-0 \\
\text { Gamma }-0 \\
\text { Delta }-2036 \\
\text { Omicron }-2 \\
\end{array}$ & 2459 & $\begin{array}{l}\text { Alpha }-0 \\
\text { Beta }-0 \\
\text { Gamma }-0 \\
\text { Delta }-82,8 \\
\text { Omicron }-0,1\end{array}$ \\
\hline $\begin{array}{c}\text { Бенин } \\
\text { (рост заболеваемости) }\end{array}$ & $\begin{array}{l}\text { Institut für Virologie - Institute } \\
\text { of Virology - Charite }\end{array}$ & $\begin{array}{l}\text { Alpha }-37 \\
\text { Beta }-1 \\
\text { Gamma }-0 \\
\text { Delta }-47\end{array}$ & 282 & $\begin{array}{l}\text { Alpha }-13,1 \\
\text { Beta }-0,4 \\
\text { Gamma }-0 \\
\text { Delta }-16,7\end{array}$ & $\begin{array}{l}\text { Alpha }-0 \\
\text { Beta }-0 \\
\text { Gamma }-0 \\
\text { Delta }-0\end{array}$ & 0 & $\begin{array}{l}\text { Alpha }-0 \\
\text { Beta }-0 \\
\text { Gamma }-0 \\
\text { Delta }-0 \\
\end{array}$ \\
\hline Бермудские острова & $\begin{array}{l}\text { Respiratory Virus Unit, National } \\
\text { Infection Service, Public Health } \\
\text { England }\end{array}$ & $\begin{array}{l}\text { Alpha }-2 \\
\text { Beta }-0 \\
\text { Gamma }-0 \\
\text { Delta }-0\end{array}$ & 47 & $\begin{array}{l}\text { Alpha }-4,3 \\
\text { Beta }-0 \\
\text { Gamma }-0 \\
\text { Delta }-0\end{array}$ & $\begin{array}{l}\text { Alpha }-0 \\
\text { Beta }-0 \\
\text { Gamma }-0 \\
\text { Delta }-0\end{array}$ & 0 & $\begin{array}{l}\text { Alpha }-0 \\
\text { Beta }-0 \\
\text { Gamma }-0 \\
\text { Delta }-0\end{array}$ \\
\hline $\begin{array}{c}\text { Болгария } \\
\text { (снижение заболевае- } \\
\text { мости) }\end{array}$ & $\begin{array}{l}\text { National Center of Infectious } \\
\text { and Parasitic Diseases }\end{array}$ & $\begin{array}{l}\text { Alpha }-3070 \\
\text { Beta }-3 \\
\text { Gamma }-0 \\
\text { Delta }-4695\end{array}$ & 8101 & $\begin{array}{l}\text { Alpha }-37,9 \\
\text { Beta }-0 \\
\text { Gamma }-0 \\
\text { Delta }-58,0\end{array}$ & $\begin{array}{l}\text { Alpha }-0 \\
\text { Beta }-0 \\
\text { Gamma }-0 \\
\text { Delta }-0\end{array}$ & 0 & $\begin{array}{l}\text { Alpha }-0 \\
\text { Beta }-0 \\
\text { Gamma }-0 \\
\text { Delta }-0\end{array}$ \\
\hline
\end{tabular}




\begin{tabular}{|c|c|c|c|c|c|c|c|}
\hline $\begin{array}{c}\text { Боливия } \\
\text { (снижение заболевае- } \\
\text { мости) }\end{array}$ & $\begin{array}{l}\text { Laboratory of Respiratory Vi- } \\
\text { ruses and Measles, Oswaldo } \\
\text { Cruz Institute, FIOCRUZ }\end{array}$ & $\begin{array}{l}\text { Alpha }-0 \\
\text { Beta }-0 \\
\text { Gamma }-22 \\
\text { Delta }-0\end{array}$ & 155 & $\begin{array}{l}\text { Alpha }-0 \\
\text { Beta }-0 \\
\text { Gamma }-14,2 \\
\text { Delta }-0\end{array}$ & $\begin{array}{l}\text { Alpha }-0 \\
\text { Beta }-0 \\
\text { Gamma }-0 \\
\text { Delta }-0\end{array}$ & 0 & $\begin{array}{l}\text { Alpha }-0 \\
\text { Beta }-0 \\
\text { Gamma }-0 \\
\text { Delta }-0\end{array}$ \\
\hline Бонэйр & $\begin{array}{l}\text { National Institute for Public } \\
\text { Health and the Environ- } \\
\text { ment(RIVM) }\end{array}$ & $\begin{array}{l}\text { Alpha }-183 \\
\text { Beta }-0 \\
\text { Gamma }-1 \\
\text { Delta }-484\end{array}$ & 699 & $\begin{array}{l}\text { Alpha }-26,2 \\
\text { Beta }-0 \\
\text { Gamma }-0,1 \\
\text { Delta }-69,2\end{array}$ & $\begin{array}{l}\text { Alpha }-0 \\
\text { Beta }-0 \\
\text { Gamma }-0 \\
\text { Delta }-27\end{array}$ & 34 & $\begin{array}{l}\text { Alpha }-0 \\
\text { Beta }-0 \\
\text { Gamma }-0 \\
\text { Delta }-79,4\end{array}$ \\
\hline $\begin{array}{c}\text { Босния } \\
\text { и Герцеговина } \\
\text { (рост заболеваемости) }\end{array}$ & $\begin{array}{l}\text { University of Sarajevo, Veteri- } \\
\text { nary Faculty, Laboratory for } \\
\text { Molecular Diagnostic and Re- } \\
\text { search Laboratory }\end{array}$ & $\begin{array}{l}\text { Alpha }-75 \\
\text { Beta }-0 \\
\text { Gamma }-3 \\
\text { Delta }-430\end{array}$ & 588 & $\begin{array}{l}\text { Alpha }-12,8 \\
\text { Beta }-0 \\
\text { Gamma }-0,5 \\
\text { Delta }-73,1\end{array}$ & $\begin{array}{l}\text { Alpha }-0 \\
\text { Beta }-0 \\
\text { Gamma }-0 \\
\text { Delta }-0\end{array}$ & 0 & $\begin{array}{l}\text { Alpha }-0 \\
\text { Beta }-0 \\
\text { Gamma }-0 \\
\text { Delta }-0\end{array}$ \\
\hline $\begin{array}{c}\text { Ботсвана } \\
\text { (стабилизация забо- } \\
\text { леваемости) }\end{array}$ & $\begin{array}{l}\text { Botswana Institute for Technol- } \\
\text { ogy Research and Innovation }\end{array}$ & $\begin{array}{l}\text { Alpha }-0 \\
\text { Beta }-337 \\
\text { Gamma }-0 \\
\text { Delta }-1050 \\
\text { Omicron }-19\end{array}$ & 1634 & $\begin{array}{l}\text { Alpha }-0 \\
\text { Beta }-20,6 \\
\text { Gamma }-0 \\
\text { Delta }-64,3 \\
\text { Omicron - } 1,2\end{array}$ & $\begin{array}{l}\text { Alpha }-0 \\
\text { Beta }-0 \\
\text { Gamma }-0 \\
\text { Delta }-66 \\
\text { Omicron }-19\end{array}$ & 89 & $\begin{array}{l}\text { Alpha }-0 \\
\text { Beta }-0 \\
\text { Gamma }-0 \\
\text { Delta }-74,2 \\
\text { Omicron - } \\
21,3\end{array}$ \\
\hline $\begin{array}{c}\text { Бразилия } \\
\text { (снижение заболевае- } \\
\text { мости) }\end{array}$ & $\begin{array}{l}\text { Instituto Adolfo Lutz, Interdici- } \\
\text { plinary Procedures Center, Stra- } \\
\text { tegic Laboratory }\end{array}$ & $\begin{array}{l}\text { Alpha }-1005 \\
\text { Beta }-10 \\
\text { Gamma }-45281 \\
\text { Delta }-20724 \\
\text { Omicron }-3 \\
\end{array}$ & 77541 & $\begin{array}{l}\text { Alpha - 1,3 } \\
\text { Beta - 0 } \\
\text { Gamma - 58,4 } \\
\text { Delta - 26,7 } \\
\text { Omicron - } 0 \\
\end{array}$ & $\begin{array}{l}\text { Alpha }-0 \\
\text { Beta }-0 \\
\text { Gamma }-3 \\
\text { Delta }-751 \\
\text { Omicron }-3 \\
\end{array}$ & 902 & $\begin{array}{l}\text { Alpha }-0 \\
\text { Beta }-0 \\
\text { Gamma }-0,3 \\
\text { Delta }-83,3 \\
\text { Omicron }-0,3\end{array}$ \\
\hline $\begin{array}{c}\text { Британские } \\
\text { Виргинские Острова }\end{array}$ & Caribbean Public Health Agency & $\begin{array}{l}\text { Alpha }-1 \\
\text { Beta }-5 \\
\text { Gamma }-0 \\
\text { Delta }-5\end{array}$ & 58 & $\begin{array}{l}\text { Alpha }-1,7 \\
\text { Beta }-13,2 \\
\text { Gamma }-0 \\
\text { Delta }-8,6\end{array}$ & $\begin{array}{l}\text { Alpha }-0 \\
\text { Beta }-0 \\
\text { Gamma }-0 \\
\text { Delta }-0\end{array}$ & 0 & $\begin{array}{l}\text { Alpha }-0 \\
\text { Beta }-0 \\
\text { Gamma }-0 \\
\text { Delta }-0\end{array}$ \\
\hline $\begin{array}{c}\text { Бруней } \\
\text { (снижение заболевае- } \\
\text { мости) }\end{array}$ & $\begin{array}{l}\text { National Public Health Labora- } \\
\text { tory, National Centre for Infec- } \\
\text { tious Diseases(National Virolo- } \\
\text { gy Reference Laboratory) }\end{array}$ & $\begin{array}{l}\text { Alpha }-0 \\
\text { Beta }-1 \\
\text { Gamma }-0 \\
\text { Delta }-28\end{array}$ & 38 & $\begin{array}{l}\text { Alpha }-0 \\
\text { Beta }-2,6 \\
\text { Gamma }-0 \\
\text { Delta }-73,7\end{array}$ & $\begin{array}{l}\text { Alpha }-0 \\
\text { Beta }-0 \\
\text { Gamma }-0 \\
\text { Delta }-0\end{array}$ & 0 & $\begin{array}{l}\text { Alpha }-0 \\
\text { Beta }-0 \\
\text { Gamma }-0 \\
\text { Delta }-0\end{array}$ \\
\hline
\end{tabular}




\begin{tabular}{|c|c|c|c|c|c|c|c|}
\hline $\begin{array}{c}\text { Буркина Фасо } \\
\text { (стабилизация забо- } \\
\text { леваемости) }\end{array}$ & $\begin{array}{l}\text { Laboratoire bacteriologie virolo- } \\
\text { gie CHUSS }\end{array}$ & $\begin{array}{l}\text { Alpha }-3 \\
\text { Beta }-0 \\
\text { Gamma }-0 \\
\text { Delta }-21\end{array}$ & 424 & $\begin{array}{l}\text { Alpha }-0,7 \\
\text { Beta }-0 \\
\text { Gamma }-0 \\
\text { Delta }-5,0\end{array}$ & $\begin{array}{l}\text { Alpha }-0 \\
\text { Beta }-0 \\
\text { Gamma }-0 \\
\text { Delta }-0\end{array}$ & 0 & $\begin{array}{l}\text { Alpha }-0 \\
\text { Beta }-0 \\
\text { Gamma }-0 \\
\text { Delta }-0\end{array}$ \\
\hline $\begin{array}{c}\text { Бурунди } \\
\text { (рост заболеваемости) }\end{array}$ & $\begin{array}{l}\text { MRC/UVRI \& LSHTM Uganda } \\
\text { Research Unit, National Institute } \\
\text { of Public Health }\end{array}$ & $\begin{array}{l}\text { Alpha }-1 \\
\text { Beta }-5 \\
\text { Gamma }-0 \\
\text { Delta }-57\end{array}$ & 63 & $\begin{array}{l}\text { Alpha }-1,6 \\
\text { Beta }-7,9 \\
\text { Gamma }-0 \\
\text { Delta }-90,5 \\
\end{array}$ & $\begin{array}{l}\text { Alpha }-0 \\
\text { Beta }-0 \\
\text { Gamma }-0 \\
\text { Delta }-0\end{array}$ & 0 & $\begin{array}{l}\text { Alpha }-0 \\
\text { Beta }-0 \\
\text { Gamma }-0 \\
\text { Delta }-0\end{array}$ \\
\hline $\begin{array}{c}\text { Вануату } \\
\text { (стабилизация забо- } \\
\text { леваемости) }\end{array}$ & $\begin{array}{l}\text { Microbiological Diagnostic Unit } \\
\text { - Public Health Laboratory } \\
\text { (MDU-PHL) }\end{array}$ & $\begin{array}{l}\text { Alpha }-1 \\
\text { Beta }-0 \\
\text { Gamma }-0 \\
\text { Delta }-0\end{array}$ & 2 & $\begin{array}{l}\text { Alpha }-50,0 \\
\text { Beta }-0 \\
\text { Gamma }-0 \\
\text { Delta }-0 \\
\end{array}$ & $\begin{array}{l}\text { Alpha }-0 \\
\text { Beta }-0 \\
\text { Gamma }-0 \\
\text { Delta }-0\end{array}$ & 0 & $\begin{array}{l}\text { Alpha }-0 \\
\text { Beta }-0 \\
\text { Gamma }-0 \\
\text { Delta }-0\end{array}$ \\
\hline $\begin{array}{c}\text { Великобритания } \\
\text { (рост заболеваемости) }\end{array}$ & $\begin{array}{l}\text { COVID-19 Genomics UK } \\
\text { (COG-UK) Consortium. Well- } \\
\text { come Sanger Institute for the } \\
\text { COVID-19 Genomics } \\
\text { UK(COG-UK) consortium. }\end{array}$ & $\begin{array}{l}\text { Alpha }-272321 \\
\text { Beta }-1077 \\
\text { Gamma }-253 \\
\text { Delta }-879818 \\
\text { Omicron }-18\end{array}$ & 1341165 & $\begin{array}{l}\text { Alpha }-20,3 \\
\text { Beta }-0,1 \\
\text { Gamma }-0 \\
\text { Delta }-65,6 \\
\text { Omicron }-0\end{array}$ & $\begin{array}{l}\text { Alpha }-0 \\
\text { Beta }-0 \\
\text { Gamma }-0 \\
\text { Delta }- \\
122013 \\
\text { Omicron }-18\end{array}$ & 138220 & $\begin{array}{l}\text { Alpha }-0 \\
\text { Beta }-0 \\
\text { Gamma- } 0 \\
\text { Delta }-88,3 \\
\text { Omicron }-0\end{array}$ \\
\hline $\begin{array}{c}\text { Венгрия } \\
\text { (снижение заболевае- } \\
\text { мости) }\end{array}$ & $\begin{array}{l}\text { National Laboratory of Virolo- } \\
\text { gy, Szentágothai Research Cen- } \\
\text { tre }\end{array}$ & $\begin{array}{l}\text { Alpha }-29 \\
\text { Beta }-0 \\
\text { Gamma }-0 \\
\text { Delta }-0 \\
\end{array}$ & 435 & $\begin{array}{l}\text { Alpha }-6,7 \\
\text { Beta }-0 \\
\text { Gamma }-0 \\
\text { Delta }-0 \\
\end{array}$ & $\begin{array}{l}\text { Alpha }-0 \\
\text { Beta }-0 \\
\text { Gamma }-0 \\
\text { Delta }-0\end{array}$ & 0 & $\begin{array}{l}\text { Alpha }-0 \\
\text { Beta }-0 \\
\text { Gamma }-0 \\
\text { Delta }-0 \\
\end{array}$ \\
\hline $\begin{array}{c}\text { Венесуэла } \\
\text { (снижение заболевае- } \\
\text { мости) }\end{array}$ & $\begin{array}{l}\text { Laboratorio de Virología Mo- } \\
\text { lecular }\end{array}$ & $\begin{array}{l}\text { Alpha }-6 \\
\text { Beta }-0 \\
\text { Gamma }-17 \\
\text { Delta }-1 \\
\end{array}$ & 172 & $\begin{array}{l}\text { Alpha }-3,5 \\
\text { Beta }-0 \\
\text { Gamma }-9,9 \\
\text { Delta }-0,6\end{array}$ & $\begin{array}{l}\text { Alpha }-0 \\
\text { Beta }-0 \\
\text { Gamma }-0 \\
\text { Delta }-0\end{array}$ & 0 & $\begin{array}{l}\text { Alpha }-0 \\
\text { Beta }-0 \\
\text { Gamma }-0 \\
\text { Delta }-0\end{array}$ \\
\hline $\begin{array}{c}\text { Вьетнам } \\
\text { (снижение заболевае- } \\
\text { мости) }\end{array}$ & $\begin{array}{l}\text { National Influenza Center, Na- } \\
\text { tional Institute of Hygiene and } \\
\text { Epidemiology(NIHE) }\end{array}$ & $\begin{array}{l}\text { Alpha }-26 \\
\text { Beta }-0 \\
\text { Gamma }-0 \\
\text { Delta }-1518 \\
\end{array}$ & 1692 & $\begin{array}{l}\text { Alpha }-1,5 \\
\text { Beta }-0 \\
\text { Gamma }-0 \\
\text { Delta }-89,7 \\
\end{array}$ & $\begin{array}{l}\text { Alpha }-0 \\
\text { Beta }-0 \\
\text { Gamma }-0 \\
\text { Delta }-0\end{array}$ & 0 & $\begin{array}{l}\text { Alpha }-0 \\
\text { Beta }-0 \\
\text { Gamma }-0 \\
\text { Delta }-0 \\
\end{array}$ \\
\hline
\end{tabular}




\begin{tabular}{|c|c|c|c|c|c|c|c|}
\hline $\begin{array}{c}\text { Габон } \\
\text { (снижение заболевае- } \\
\text { мости) }\end{array}$ & $\begin{array}{l}\text { Centre de recherches médicales } \\
\text { de Lambaréné(CERMEL) }\end{array}$ & $\begin{array}{l}\text { Alpha }-46 \\
\text { Beta }-5 \\
\text { Gamma }-0 \\
\text { Delta }-27\end{array}$ & 316 & $\begin{array}{l}\text { Alpha }-14,6 \\
\text { Beta }-1,6 \\
\text { Gamma }-0 \\
\text { Delta }-8,5\end{array}$ & $\begin{array}{l}\text { Alpha }-0 \\
\text { Beta }-0 \\
\text { Gamma }-0 \\
\text { Delta }-0\end{array}$ & 0 & $\begin{array}{l}\text { Alpha }-0 \\
\text { Beta }-0 \\
\text { Gamma }-0 \\
\text { Delta }-0\end{array}$ \\
\hline $\begin{array}{c}\text { Гаити } \\
\text { (рост заболеваемости) }\end{array}$ & $\begin{array}{l}\text { Laboratoire National de Santé } \\
\text { Publique - LNSP(HAITI - } \\
\text { LNSP) }\end{array}$ & $\begin{array}{l}\text { Alpha }-1 \\
\text { Beta }-0 \\
\text { Gamma }-56 \\
\text { Delta }-1\end{array}$ & 95 & $\begin{array}{l}\text { Alpha }-1,1 \\
\text { Beta }-0 \\
\text { Gamma }-58,9 \\
\text { Delta }-1,1\end{array}$ & $\begin{array}{l}\text { Alpha }-0 \\
\text { Beta }-0 \\
\text { Gamma }-0 \\
\text { Delta }-0\end{array}$ & 0 & $\begin{array}{l}\text { Alpha }-0 \\
\text { Beta }-0 \\
\text { Gamma }-0 \\
\text { Delta }-0\end{array}$ \\
\hline $\begin{array}{c}\text { Гайана } \\
\text { (снижение заболевае- } \\
\text { мости) }\end{array}$ & $\begin{array}{l}\text { CNR Virus des Infections Res- } \\
\text { piratoires - France SUD }\end{array}$ & $\begin{array}{l}\text { Alpha }-0 \\
\text { Beta }-0 \\
\text { Gamma }-3 \\
\text { Delta }-45\end{array}$ & 60 & $\begin{array}{l}\text { Alpha }-0 \\
\text { Beta }-0 \\
\text { Gamma }-5,0 \\
\text { Delta }-75,0\end{array}$ & $\begin{array}{l}\text { Alpha }-0 \\
\text { Beta }-0 \\
\text { Gamma }-0 \\
\text { Delta }-0\end{array}$ & 0 & $\begin{array}{l}\text { Alpha }-0 \\
\text { Beta }-0 \\
\text { Gamma }-0 \\
\text { Delta }-0\end{array}$ \\
\hline $\begin{array}{c}\text { Гамбия } \\
\text { (стабилизация забо- } \\
\text { леваемости) }\end{array}$ & $\begin{array}{l}\text { MRCG at LSHTM Genomics } \\
\text { lab }\end{array}$ & $\begin{array}{l}\text { Alpha }-76 \\
\text { Beta }-0 \\
\text { Gamma }-0 \\
\text { Delta }-316\end{array}$ & 948 & $\begin{array}{l}\text { Alpha }-8,0 \\
\text { Beta }-0 \\
\text { Gamma }-0 \\
\text { Delta }-33,3\end{array}$ & $\begin{array}{l}\text { Alpha }-0 \\
\text { Beta }-0 \\
\text { Gamma }-0 \\
\text { Delta }-0\end{array}$ & 0 & $\begin{array}{l}\text { Alpha }-0 \\
\text { Beta }-0 \\
\text { Gamma }-0 \\
\text { Delta }-0\end{array}$ \\
\hline $\begin{array}{c}\text { Гана } \\
\text { (снижение заболевае- } \\
\text { мости) }\end{array}$ & $\begin{array}{l}\text { Department of Biochemistry, } \\
\text { Cell and Molecular Biology, } \\
\text { West African Centre for Cell } \\
\text { Biology of Infectious Patho- } \\
\text { gens(WACCBIP), University of } \\
\text { Ghana }\end{array}$ & $\begin{array}{l}\text { Alpha }-378 \\
\text { Beta }-22 \\
\text { Gamma }-1 \\
\text { Delta }-522 \\
\text { Omicron }-33\end{array}$ & 1817 & $\begin{array}{l}\text { Alpha }-20,8 \\
\text { Beta }-1,2 \\
\text { Gamma }-0,1 \\
\text { Delta }-28,7 \\
\text { Omicron }-1,8\end{array}$ & $\begin{array}{l}\text { Alpha }-0 \\
\text { Beta }-0 \\
\text { Gamma }-0 \\
\text { Delta }-0 \\
\text { Omicron }-33\end{array}$ & 56 & $\begin{array}{l}\text { Alpha }-0 \\
\text { Beta }-0 \\
\text { Gamma }-0 \\
\text { Delta }-0 \\
\text { Omicron - } \\
58,9\end{array}$ \\
\hline Гваделупа & $\begin{array}{l}\text { National Reference Center for } \\
\text { Viruses of Respiratory Infec- } \\
\text { tions, Institut Pasteur, Paris }\end{array}$ & $\begin{array}{l}\text { Alpha }-129 \\
\text { Beta }-4 \\
\text { Gamma }-0 \\
\text { Delta }-371\end{array}$ & 618 & $\begin{array}{l}\text { Alpha }-20,9 \\
\text { Beta }-0,6 \\
\text { Gamma }-0 \\
\text { Delta }-60,0\end{array}$ & $\begin{array}{l}\text { Alpha }-0 \\
\text { Beta }-0 \\
\text { Gamma }-0 \\
\text { Delta }-0\end{array}$ & 0 & $\begin{array}{l}\text { Alpha }-0 \\
\text { Beta }-0 \\
\text { Gamma }-0 \\
\text { Delta }-0\end{array}$ \\
\hline $\begin{array}{c}\text { Гватемала } \\
\text { (снижение заболевае- } \\
\text { мости) }\end{array}$ & $\begin{array}{l}\text { Asociación de Salud Inte- } \\
\text { gral/Clínica Familiar Luis Ángel } \\
\text { García }\end{array}$ & $\begin{array}{l}\text { Alpha }-18 \\
\text { Beta }-1 \\
\text { Gamma }-35 \\
\text { Delta }-302\end{array}$ & 1032 & $\begin{array}{l}\text { Alpha }-1,7 \\
\text { Beta }-0,1 \\
\text { Gamma }-3,4 \\
\text { Delta }-29,3\end{array}$ & $\begin{array}{l}\text { Alpha }-0 \\
\text { Beta }-0 \\
\text { Gamma }-0 \\
\text { Delta }-0\end{array}$ & 0 & $\begin{array}{l}\text { Alpha }-0 \\
\text { Beta }-0 \\
\text { Gamma }-0 \\
\text { Delta }-0\end{array}$ \\
\hline
\end{tabular}




\begin{tabular}{|c|c|c|c|c|c|c|c|}
\hline $\begin{array}{c}\text { Гвинея } \\
\text { (снижение заболевае- } \\
\text { мости) }\end{array}$ & $\begin{array}{l}\text { Centre de Recherche et de For- } \\
\text { mation en Infectiologie Guinée }\end{array}$ & $\begin{array}{l}\text { Alpha }-46 \\
\text { Beta }-0 \\
\text { Gamma }-0 \\
\text { Delta }-19\end{array}$ & 311 & $\begin{array}{l}\text { Alpha }-14,8 \\
\text { Beta }-0 \\
\text { Gamma }-0 \\
\text { Delta }-6,1\end{array}$ & $\begin{array}{l}\text { Alpha }-0 \\
\text { Beta }-0 \\
\text { Gamma }-0 \\
\text { Delta }-0\end{array}$ & 0 & $\begin{array}{l}\text { Alpha }-0 \\
\text { Beta }-0 \\
\text { Gamma }-0 \\
\text { Delta }-0\end{array}$ \\
\hline $\begin{array}{c}\text { Гвинея Биссау } \\
\text { (стабилизация забо- } \\
\text { леваемости) }\end{array}$ & $\begin{array}{l}\text { MRCG at LSHTM, Genomics } \\
\text { lab }\end{array}$ & $\begin{array}{l}\text { Alpha }-31 \\
\text { Beta }-1 \\
\text { Gamma }-0 \\
\text { Delta }-62 \\
\end{array}$ & 112 & $\begin{array}{l}\text { Alpha }-27,7 \\
\text { Beta }-0,9 \\
\text { Gamma }-0 \\
\text { Delta }-55,4 \\
\end{array}$ & $\begin{array}{l}\text { Alpha }-0 \\
\text { Beta }-0 \\
\text { Gamma }-0 \\
\text { Delta }-0\end{array}$ & 0 & $\begin{array}{l}\text { Alpha }-0 \\
\text { Beta }-0 \\
\text { Gamma }-0 \\
\text { Delta }-0\end{array}$ \\
\hline $\begin{array}{c}\text { Германия } \\
\text { (рост заболеваемости) }\end{array}$ & $\begin{array}{l}\text { CharitéUniversitätsmedizin Ber- } \\
\text { lin, InstitutfürVirologie.Institute } \\
\text { of infectious medicine \& hospi- } \\
\text { tal hygiene, CaSe-Group. }\end{array}$ & $\begin{array}{l}\text { Alpha - } 103731 \\
\text { Beta - 2252 } \\
\text { Gamma - 866 } \\
\text { Delta - } 119684 \\
\text { Omicron - 5 }\end{array}$ & 262022 & $\begin{array}{l}\text { Alpha }-39,6 \\
\text { Beta }-0,9 \\
\text { Gamma }-0,3 \\
\text { Delta }-45,7 \\
\text { Omicron }-0\end{array}$ & $\begin{array}{l}\text { Alpha }-0 \\
\text { Beta }-0 \\
\text { Gamma }-0 \\
\text { Delta }-8196 \\
\text { Omicron }-5\end{array}$ & 9127 & $\begin{array}{l}\text { Alpha }-0 \\
\text { Beta }-0 \\
\text { Gamma }-0 \\
\text { Delta }-89,8 \\
\text { Omicron }-0,1\end{array}$ \\
\hline Гибралтар & $\begin{array}{l}\text { Respiratory Virus Unit, National } \\
\text { Infection Service, Public Health } \\
\text { England }\end{array}$ & $\begin{array}{l}\text { Alpha }-216 \\
\text { Beta }-0 \\
\text { Gamma }-0 \\
\text { Delta }-848\end{array}$ & 1842 & $\begin{array}{l}\text { Alpha }-11,7 \\
\text { Beta }-0 \\
\text { Gamma }-0 \\
\text { Delta }-46,0 \\
\end{array}$ & $\begin{array}{l}\text { Alpha }-0 \\
\text { Beta }-0 \\
\text { Gamma }-0 \\
\text { Delta }-0 \\
\end{array}$ & 0 & $\begin{array}{l}\text { Alpha }-0 \\
\text { Beta }-0 \\
\text { Gamma }-0 \\
\text { Delta }-0 \\
\end{array}$ \\
\hline $\begin{array}{c}\text { Гондурас } \\
\text { (снижение заболевае- } \\
\text { мости) }\end{array}$ & $\begin{array}{l}\text { Genomics and Proteomics De- } \\
\text { partament, Gorgas Memorial In- } \\
\text { stitute For Health Studies }\end{array}$ & $\begin{array}{l}\text { Alpha }-1 \\
\text { Beta }-0 \\
\text { Gamma }-2 \\
\text { Delta }-2 \\
\end{array}$ & 116 & $\begin{array}{l}\text { Alpha }-0,9 \\
\text { Beta }-0 \\
\text { Gamma }-1,7 \\
\text { Delta }-1,7 \\
\end{array}$ & $\begin{array}{l}\text { Alpha }-0 \\
\text { Beta }-0 \\
\text { Gamma }-0 \\
\text { Delta }-0\end{array}$ & 0 & $\begin{array}{l}\text { Alpha }-0 \\
\text { Beta }-0 \\
\text { Gamma }-0 \\
\text { Delta }-0 \\
\end{array}$ \\
\hline Гонконг & $\begin{array}{l}\text { Hong Kong Department of } \\
\text { Health }\end{array}$ & $\begin{array}{l}\text { Alpha }-146 \\
\text { Beta }-113 \\
\text { Gamma }-0 \\
\text { Delta }-436 \\
\text { Omicron }-8\end{array}$ & 5128 & $\begin{array}{l}\text { Alpha }-2,8 \\
\text { Beta - 2,2 } \\
\text { Gamma - } 0 \\
\text { Delta }-8,5 \\
\text { Omicron - } 0,2\end{array}$ & $\begin{array}{l}\text { Alpha - } 0 \\
\text { Beta - } 0 \\
\text { Gamma - } 0 \\
\text { Delta }-14 \\
\text { Omicron }-8\end{array}$ & 25 & $\begin{array}{l}\text { Alpha }-0 \\
\text { Beta }-0 \\
\text { Gamma - } 0 \\
\text { Delta }-56,0 \\
\text { Omicron - } \\
32,0\end{array}$ \\
\hline $\begin{array}{c}\text { Гренада } \\
\text { (рост заболеваемости) }\end{array}$ & $\begin{array}{l}\text { The Caribbean Public Health } \\
\text { Agen-cy }\end{array}$ & $\begin{array}{l}\text { Alpha }-3 \\
\text { Beta }-0 \\
\text { Gamma }-0 \\
\text { Delta }-3\end{array}$ & 12 & $\begin{array}{l}\text { Alpha }-25,0 \\
\text { Beta }-0 \\
\text { Gamma - } 0 \\
\text { Delta }-25,0\end{array}$ & $\begin{array}{l}\text { Alpha }-0 \\
\text { Beta }-0 \\
\text { Gamma }-0 \\
\text { Delta }-0\end{array}$ & 0 & $\begin{array}{l}\text { Alpha }-0 \\
\text { Beta }-0 \\
\text { Gamma }-0 \\
\text { Delta }-0\end{array}$ \\
\hline
\end{tabular}




\begin{tabular}{|c|c|c|c|c|c|c|c|}
\hline $\begin{array}{c}\text { Греция } \\
\text { (снижение заболевае- } \\
\text { мости) }\end{array}$ & $\begin{array}{l}\text { Greek Genome Center, Biomed- } \\
\text { ical Research Foundation of the } \\
\text { Academy of Athens(BRFAA) }\end{array}$ & $\begin{array}{l}\text { Alpha }-5646 \\
\text { Beta }-58 \\
\text { Gamma }-5 \\
\text { Delta }-2987\end{array}$ & 11375 & $\begin{array}{l}\text { Alpha }-49,6 \\
\text { Beta }-0,5 \\
\text { Gamma }-0 \\
\text { Delta }-26,3\end{array}$ & $\begin{array}{l}\text { Alpha }-0 \\
\text { Beta }-0 \\
\text { Gamma }-0 \\
\text { Delta }-300\end{array}$ & 361 & $\begin{array}{l}\text { Alpha }-0 \\
\text { Beta }-0 \\
\text { Gamma }-0 \\
\text { Delta }-83,1\end{array}$ \\
\hline $\begin{array}{c}\text { Грузия } \\
\text { (стабилизация забо- } \\
\text { леваемости) }\end{array}$ & $\begin{array}{l}\text { Department for Virology, Mo- } \\
\text { lecular Biology and Genome Re- } \\
\text { search, R. G. Lugar Center for } \\
\text { Public Health Research, Nation- } \\
\text { al Center for Disease Control } \\
\text { and Public Health(NCDC) of } \\
\text { Georgia. }\end{array}$ & $\begin{array}{l}\text { Alpha }-97 \\
\text { Beta }-1 \\
\text { Gamma }-0 \\
\text { Delta }-343\end{array}$ & 530 & $\begin{array}{l}\text { Alpha }-18,3 \\
\text { Beta }-0,2 \\
\text { Gamma }-0 \\
\text { Delta }-64,73\end{array}$ & $\begin{array}{l}\text { Alpha }-0 \\
\text { Beta }-0 \\
\text { Gamma }-0 \\
\text { Delta }-51\end{array}$ & 67 & $\begin{array}{l}\text { Alpha }-0 \\
\text { Beta }-0 \\
\text { Gamma }-0 \\
\text { Delta }-76,1\end{array}$ \\
\hline Гуам & $\begin{array}{l}\text { Centers for Disease Control and } \\
\text { Preven-tion Division of Viral } \\
\text { Diseases, Pathogen Discovery }\end{array}$ & $\begin{array}{l}\text { Alpha }-105 \\
\text { Beta }-4 \\
\text { Gamma }-1 \\
\text { Delta }-151 \\
\end{array}$ & 343 & $\begin{array}{l}\text { Alpha }-30,6 \\
\text { Beta }-1,2 \\
\text { Gamma }-0,3 \\
\text { Delta }-44,0 \\
\end{array}$ & $\begin{array}{l}\text { Alpha }-0 \\
\text { Beta }-0 \\
\text { Gamma }-0 \\
\text { Delta }-0 \\
\end{array}$ & 0 & $\begin{array}{l}\text { Alpha }-0 \\
\text { Beta }-0 \\
\text { Gamma }-0 \\
\text { Delta }-0 \\
\end{array}$ \\
\hline $\begin{array}{c}\text { Дания } \\
\text { (рост заболеваемости) }\end{array}$ & $\begin{array}{l}\text { Albertsen lab, Department of } \\
\text { Chemistry and Bioscience, Aal- } \\
\text { borg University. Department of } \\
\text { Virus and Microbiological Spe- } \\
\text { cial Diagnostics, Statens Serum } \\
\text { Institut. }\end{array}$ & $\begin{array}{l}\text { Alpha }-63528 \\
\text { Beta }-128 \\
\text { Gamma }-64 \\
\text { Delta }-107021\end{array}$ & 227971 & $\begin{array}{l}\text { Alpha }-27,9 \\
\text { Beta }-0,1 \\
\text { Gamma }-0 \\
\text { Delta }-46,9\end{array}$ & $\begin{array}{l}\text { Alpha }-0 \\
\text { Beta }-0 \\
\text { Gamma }-0 \\
\text { Delta }- \\
26734\end{array}$ & 30028 & $\begin{array}{l}\text { Alpha }-0 \\
\text { Beta }-0 \\
\text { Gamma }-0 \\
\text { Delta }-89,0\end{array}$ \\
\hline $\begin{array}{c}\text { Доминика } \\
\text { (рост заболеваемости) }\end{array}$ & $\begin{array}{l}\text { Carrington Lab, Department of } \\
\text { PreClinical Sciences, Faculty of } \\
\text { Medical Sciences, The Universi- } \\
\text { ty of the West Indies, St Augus- } \\
\text { tine Campus }\end{array}$ & $\begin{array}{l}\text { Alpha }-4 \\
\text { Beta }-0 \\
\text { Gamma }-0 \\
\text { Delta }-0\end{array}$ & 9 & $\begin{array}{l}\text { Alpha }-44,4 \\
\text { Beta }-0 \\
\text { Gamma }-0 \\
\text { Delta }-0\end{array}$ & $\begin{array}{l}\text { Alpha }-0 \\
\text { Beta }-0 \\
\text { Gamma }-0 \\
\text { Delta }-0\end{array}$ & 0 & $\begin{array}{l}\text { Alpha }-0 \\
\text { Beta }-0 \\
\text { Gamma }-0 \\
\text { Delta }-0\end{array}$ \\
\hline $\begin{array}{c}\text { Доминиканская } \\
\text { Республика } \\
\text { (снижение заболевае- } \\
\text { мости) } \\
\end{array}$ & $\begin{array}{l}\text { Respiratory Viruses Branch, } \\
\text { Centers for Disease Control and } \\
\text { Prevention, USA }\end{array}$ & $\begin{array}{l}\text { Alpha }-20 \\
\text { Beta }-0 \\
\text { Gamma }-60 \\
\text { Delta }-131\end{array}$ & 568 & $\begin{array}{l}\text { Alpha }-3,5 \\
\text { Beta }-0 \\
\text { Gamma }-10,6 \\
\text { Delta }-23,1\end{array}$ & $\begin{array}{l}\text { Alpha }-0 \\
\text { Beta }-0 \\
\text { Gamma }-0 \\
\text { Delta }-0\end{array}$ & 0 & $\begin{array}{l}\text { Alpha }-0 \\
\text { Beta }-0 \\
\text { Gamma }-0 \\
\text { Delta }-0\end{array}$ \\
\hline
\end{tabular}




\begin{tabular}{|c|c|c|c|c|c|c|c|}
\hline $\begin{array}{c}\text { ДР Конго } \\
\text { (стабилизация забо- } \\
\text { леваемости) }\end{array}$ & $\begin{array}{l}\text { Pathogen Sequencing Lab, Na- } \\
\text { tional Institute for Biomedical } \\
\text { Research(INRB) }\end{array}$ & $\begin{array}{l}\text { Alpha }-16 \\
\text { Beta }-32 \\
\text { Gamma }-0 \\
\text { Delta }-228\end{array}$ & 871 & $\begin{array}{l}\text { Alpha }-1,8 \\
\text { Beta }-3,7 \\
\text { Gamma }-0 \\
\text { Delta }-26,2\end{array}$ & $\begin{array}{l}\text { Alpha }-0 \\
\text { Beta }-0 \\
\text { Gamma }-0 \\
\text { Delta }-0\end{array}$ & 0 & $\begin{array}{l}\text { Alpha }-0 \\
\text { Beta }-0 \\
\text { Gamma }-0 \\
\text { Delta }-0\end{array}$ \\
\hline $\begin{array}{c}\text { Египет } \\
\text { (рост заболеваемости) }\end{array}$ & $\begin{array}{l}\text { Main Chemical Laboratories } \\
\text { Egypt Army }\end{array}$ & $\begin{array}{l}\text { Alpha }-7 \\
\text { Beta }-0 \\
\text { Gamma }-0 \\
\text { Delta }-98 \\
\end{array}$ & 1118 & $\begin{array}{l}\text { Alpha }-0,6 \\
\text { Beta }-0 \\
\text { Gamma }-0 \\
\text { Delta }-8,8 \\
\end{array}$ & $\begin{array}{l}\text { Alpha }-0 \\
\text { Beta }-0 \\
\text { Gamma }-0 \\
\text { Delta }-0\end{array}$ & 0 & $\begin{array}{l}\text { Alpha }-0 \\
\text { Beta }-0 \\
\text { Gamma }-0 \\
\text { Delta }-0\end{array}$ \\
\hline $\begin{array}{c}\text { Замбия } \\
\text { (рост заболеваемости) }\end{array}$ & $\begin{array}{l}\text { University of Zambia, School of } \\
\text { Veterinary Medicine }\end{array}$ & $\begin{array}{l}\text { Alpha }-6 \\
\text { Beta }-220 \\
\text { Gamma }-0 \\
\text { Delta }-356\end{array}$ & 1071 & $\begin{array}{l}\text { Alpha }-0,6 \\
\text { Beta }-20,5 \\
\text { Gamma }-0 \\
\text { Delta }-33,2\end{array}$ & $\begin{array}{l}\text { Alpha }-0 \\
\text { Beta }-0 \\
\text { Gamma }-0 \\
\text { Delta }-0\end{array}$ & 0 & $\begin{array}{l}\text { Alpha }-0 \\
\text { Beta }-0 \\
\text { Gamma }-0 \\
\text { Delta }-0\end{array}$ \\
\hline $\begin{array}{c}\text { Зимбабве } \\
\text { (рост заболеваемости) }\end{array}$ & $\begin{array}{l}\text { National Microbiology Refer- } \\
\text { ence Laboratory(Quadram Insti- } \\
\text { tute Bioscience) }\end{array}$ & $\begin{array}{l}\text { Alpha }-0 \\
\text { Beta }-331 \\
\text { Gamma }-0 \\
\text { Delta }-142 \\
\end{array}$ & 709 & $\begin{array}{l}\text { Alpha }-0 \\
\text { Beta }-46,7 \\
\text { Gamma }-0 \\
\text { Delta }-20,0\end{array}$ & $\begin{array}{l}\text { Alpha }-0 \\
\text { Beta }-0 \\
\text { Gamma }-0 \\
\text { Delta }-0\end{array}$ & 0 & $\begin{array}{l}\text { Alpha }-0 \\
\text { Beta }-0 \\
\text { Gamma }-0 \\
\text { Delta }-0\end{array}$ \\
\hline $\begin{array}{c}\text { Израиль } \\
\text { (рост заболеваемости) }\end{array}$ & $\begin{array}{l}\text { Central Virology Laboratory, Is- } \\
\text { rael Ministry of Health }\end{array}$ & $\begin{array}{l}\text { Alpha }-7984 \\
\text { Beta }-244 \\
\text { Gamma }-27 \\
\text { Delta }-14933 \\
\text { Omicron }-1 \\
\end{array}$ & 29084 & $\begin{array}{l}\text { Alpha }-27,5 \\
\text { Beta }-0,8 \\
\text { Gamma }-0,1 \\
\text { Delta }-51,3 \\
\text { Omicron }-0\end{array}$ & $\begin{array}{l}\text { Alpha }-0 \\
\text { Beta }-0 \\
\text { Gamma }-0 \\
\text { Delta }-2093 \\
\text { Omicron }-1 \\
\end{array}$ & 2528 & $\begin{array}{l}\text { Alpha }-0 \\
\text { Beta }-0 \\
\text { Gamma }-0 \\
\text { Delta }-82,8 \\
\text { Omicron }-0\end{array}$ \\
\hline $\begin{array}{c}\text { Индия } \\
\text { (снижение заболевае- } \\
\text { мости) }\end{array}$ & $\begin{array}{l}\text { Department of Neurovirology, } \\
\text { National Institute of Mental } \\
\text { Health and Neuroscienc- } \\
\text { es(NIMHANS).CSIR-Centre for } \\
\text { Cellular and Molecular Biology }\end{array}$ & $\begin{array}{l}\text { Alpha }-4230 \\
\text { Beta }-246 \\
\text { Gamma }-5 \\
\text { Delta }-48858\end{array}$ & 84890 & $\begin{array}{l}\text { Alpha }-5,0 \\
\text { Beta }-0,3 \\
\text { Gamma }-0 \\
\text { Delta }-57,6\end{array}$ & $\begin{array}{l}\text { Alpha }-0 \\
\text { Beta }-0 \\
\text { Gamma }-0 \\
\text { Delta }-266\end{array}$ & 323 & $\begin{array}{l}\text { Alpha }-0 \\
\text { Beta }-0 \\
\text { Gamma }-0 \\
\text { Delta }-82,4\end{array}$ \\
\hline $\begin{array}{c}\text { Индонезия } \\
\text { (снижение заболевае- } \\
\text { мости) }\end{array}$ & $\begin{array}{l}\text { National Institute of Health Re- } \\
\text { search and Development }\end{array}$ & $\begin{array}{l}\text { Alpha }-78 \\
\text { Beta }-22 \\
\text { Gamma }-2 \\
\text { Delta }-5348 \\
\end{array}$ & 9288 & $\begin{array}{l}\text { Alpha }-0,8 \\
\text { Beta }-0,2 \\
\text { Gamma }-0 \\
\text { Delta }-57,6\end{array}$ & $\begin{array}{l}\text { Alpha }-1 \\
\text { Beta }-0 \\
\text { Gamma }-0 \\
\text { Delta }-57\end{array}$ & 67 & $\begin{array}{l}\text { Alpha }-1,5 \\
\text { Beta }-0 \\
\text { Gamma }-0 \\
\text { Delta }-85,1\end{array}$ \\
\hline
\end{tabular}




\begin{tabular}{|c|c|c|c|c|c|c|c|}
\hline $\begin{array}{c}\text { Иордания } \\
\text { (рост заболеваемости) }\end{array}$ & $\begin{array}{l}\text { Andersen lab at Scripps Re- } \\
\text { search, CA, USA }\end{array}$ & $\begin{array}{l}\text { Alpha }-143 \\
\text { Beta }-5 \\
\text { Gamma }-11 \\
\text { Delta }-379\end{array}$ & 1166 & $\begin{array}{l}\text { Alpha }-12,3 \\
\text { Beta }-0,4 \\
\text { Gamma }-0,9 \\
\text { Delta }-32,5\end{array}$ & $\begin{array}{l}\text { Alpha }-0 \\
\text { Beta }-0 \\
\text { Gamma }-0 \\
\text { Delta }-45\end{array}$ & 45 & $\begin{array}{l}\text { Alpha }-0 \\
\text { Beta }-0 \\
\text { Gamma }-0 \\
\text { Delta }-100,0\end{array}$ \\
\hline $\begin{array}{c}\text { Ирак } \\
\text { (снижение заболевае- } \\
\text { мости) }\end{array}$ & $\begin{array}{l}\text { Biology, College of Educa- } \\
\text { tionDepartment of Virology, } \\
\text { Faculty of Medicine, University } \\
\text { of Helsinki, Helsinki, Finland } \\
\text { generated and submitted to } \\
\text { GISAID }\end{array}$ & $\begin{array}{l}\text { Alpha }-74 \\
\text { Beta }-1 \\
\text { Gamma }-1 \\
\text { Delta }-13\end{array}$ & 297 & $\begin{array}{l}\text { Alpha }-24,9 \\
\text { Beta }-0,3 \\
\text { Gamma }-0,3 \\
\text { Delta }-4,4\end{array}$ & $\begin{array}{l}\text { Alpha }-0 \\
\text { Beta }-0 \\
\text { Gamma }-0 \\
\text { Delta }-0\end{array}$ & 0 & $\begin{array}{l}\text { Alpha }-0 \\
\text { Beta }-0 \\
\text { Gamma }-0 \\
\text { Delta }-0\end{array}$ \\
\hline $\begin{array}{c}\text { Иран } \\
\text { (снижение заболевае- } \\
\text { мости) }\end{array}$ & $\begin{array}{l}\text { National Reference Laboratory } \\
\text { for COVID-19, Pasteur Institute } \\
\text { of Iran }\end{array}$ & $\begin{array}{l}\text { Alpha }-113 \\
\text { Beta }-3 \\
\text { Gamma }-1 \\
\text { Delta }-23\end{array}$ & 1174 & $\begin{array}{l}\text { Alpha }-9,6 \\
\text { Beta }-0,3 \\
\text { Gamma }-0,2 \\
\text { Delta }-2,0\end{array}$ & $\begin{array}{l}\text { Alpha }-0 \\
\text { Beta }-0 \\
\text { Gamma }-0 \\
\text { Delta }-0\end{array}$ & 0 & $\begin{array}{l}\text { Alpha }-0 \\
\text { Beta }-0 \\
\text { Gamma }-0 \\
\text { Delta }-0\end{array}$ \\
\hline $\begin{array}{c}\text { Ирландия } \\
\text { (стабилизация забо- } \\
\text { леваемости) }\end{array}$ & $\begin{array}{l}\text { National Virus Reference La- } \\
\text { boratory }\end{array}$ & $\begin{array}{l}\text { Alpha }-16076 \\
\text { Beta }-79 \\
\text { Gamma }-33 \\
\text { Delta }-21479 \\
\text { Omicron }-1 \\
\end{array}$ & 42152 & $\begin{array}{l}\text { Alpha }-38,1 \\
\text { Beta }-0,2 \\
\text { Gamma }-0,1 \\
\text { Delta }-51,0 \\
\text { Omicron }-0\end{array}$ & $\begin{array}{l}\text { Alpha }-0 \\
\text { Beta }-0 \\
\text { Gamma }-0 \\
\text { Delta }-303 \\
\text { Omicron }-1\end{array}$ & 367 & $\begin{array}{l}\text { Alpha }-0 \\
\text { Beta }-0 \\
\text { Gamma }-0 \\
\text { Delta }-82,6 \\
\text { Omicron }-0,3\end{array}$ \\
\hline $\begin{array}{c}\text { Исландия } \\
\text { (снижение заболевае- } \\
\text { мости) }\end{array}$ & 26iagno genetics & $\begin{array}{l}\text { Alpha }-599 \\
\text { Beta }-1 \\
\text { Gamma }-17 \\
\text { Delta }-3767\end{array}$ & 9832 & $\begin{array}{l}\text { Alpha }-6,1 \\
\text { Beta }-0 \\
\text { Gamma }-0,2 \\
\text { Delta }-38,3\end{array}$ & $\begin{array}{l}\text { Alpha }-0 \\
\text { Beta }-0 \\
\text { Gamma }-0 \\
\text { Delta }-0 \\
\end{array}$ & 0 & $\begin{array}{l}\text { Alpha }-0 \\
\text { Beta }-0 \\
\text { Gamma }-0 \\
\text { Delta }-0 \\
\end{array}$ \\
\hline $\begin{array}{c}\text { Испания } \\
\text { (рост заболеваемости) }\end{array}$ & $\begin{array}{l}\text { Hospital Universitario } 12 \text { de Oc- } \\
\text { tubre }\end{array}$ & $\begin{array}{l}\text { Alpha }-24456 \\
\text { Beta }-347 \\
\text { Gamma }-1228 \\
\text { Delta }-30119 \\
\text { Omicron }-1\end{array}$ & 79429 & $\begin{array}{l}\text { Alpha }-30,8 \\
\text { Beta }-0,4 \\
\text { Gamma }-1,5 \\
\text { Delta }-37,9 \\
\text { Omicron }-0\end{array}$ & $\begin{array}{l}\text { Alpha }-0 \\
\text { Beta }-0 \\
\text { Gamma }-0 \\
\text { Delta }-1551 \\
\text { Omicron }-1\end{array}$ & 1897 & $\begin{array}{l}\text { Alpha }-0 \\
\text { Beta }-0 \\
\text { Gamma }-0 \\
\text { Delta }-81,8 \\
\text { Omicron }-0,1\end{array}$ \\
\hline $\begin{array}{c}\text { Италия } \\
\text { (рост заболеваемости) }\end{array}$ & $\begin{array}{l}\text { Army Medical Center, Scientific } \\
\text { Department, Virology Laborato- } \\
\text { ry }\end{array}$ & $\begin{array}{l}\text { Alpha }-26439 \\
\text { Beta }-126 \\
\text { Gamma }-2617 \\
\text { Delta }-31123 \\
\text { Omicron }-4 \\
\end{array}$ & 77354 & $\begin{array}{l}\text { Alpha }-34,2 \\
\text { Beta }-0,2 \\
\text { Gamma }-3,4 \\
\text { Delta }-40,2 \\
\text { Omicron }-0 \\
\end{array}$ & $\begin{array}{l}\text { Alpha }-0 \\
\text { Beta }-0 \\
\text { Gamma }-0 \\
\text { Delta }-2635 \\
\text { Omicron }-4 \\
\end{array}$ & 3021 & $\begin{array}{l}\text { Alpha }-0 \\
\text { Beta }-0 \\
\text { Gamma }-0 \\
\text { Delta }-87,2 \\
\text { Omicron }-0,1 \\
\end{array}$ \\
\hline
\end{tabular}




\begin{tabular}{|c|c|c|c|c|c|c|c|}
\hline $\begin{array}{c}\text { Кабо-Верде } \\
\text { (рост заболеваемости) }\end{array}$ & Institut Pasteur de Dakar & \begin{tabular}{|l} 
Alpha -4 \\
Beta -0 \\
Gamma -0 \\
Delta -0
\end{tabular} & 47 & $\begin{array}{l}\text { Alpha }-8,5 \\
\text { Beta }-0 \\
\text { Gamma }-0 \\
\text { Delta }-0\end{array}$ & $\begin{array}{l}\text { Alpha }-0 \\
\text { Beta }-0 \\
\text { Gamma }-0 \\
\text { Delta }-0\end{array}$ & 0 & $\begin{array}{l}\text { Alpha }-0 \\
\text { Beta }-0 \\
\text { Gamma }-0 \\
\text { Delta }-0\end{array}$ \\
\hline $\begin{array}{c}\text { Казахстан } \\
\text { (снижение заболевае- } \\
\text { мости) }\end{array}$ & $\begin{array}{l}\text { Reference laboratory for the } \\
\text { control of viral infections }\end{array}$ & $\begin{array}{l}\text { Alpha }-163 \\
\text { Beta }-0 \\
\text { Gamma }-0 \\
\text { Delta }-167 \\
\end{array}$ & 542 & $\begin{array}{l}\text { Alpha }-30,1 \\
\text { Beta }-0 \\
\text { Gamma }-0 \\
\text { Delta }-30,8 \\
\end{array}$ & $\begin{array}{l}\text { Alpha }-0 \\
\text { Beta }-0 \\
\text { Gamma }-0 \\
\text { Delta }-0\end{array}$ & 0 & $\begin{array}{l}\text { Alpha }-0 \\
\text { Beta }-0 \\
\text { Gamma }-0 \\
\text { Delta }-0 \\
\end{array}$ \\
\hline Каймановы Острова & $\begin{array}{l}\text { Carrington Lab, Department of } \\
\text { PreClinical Sciences, Building } \\
\text { 36, First Floor Biochemistry } \\
\text { Unit, Faculty of Medical Scienc- } \\
\text { es, The University of the West } \\
\text { Indies }\end{array}$ & $\begin{array}{l}\text { Alpha }-35 \\
\text { Beta }-1 \\
\text { Gamma }-1 \\
\text { Delta }-37\end{array}$ & 97 & $\begin{array}{l}\text { Alpha }-36,1 \\
\text { Beta }-1,0 \\
\text { Gamma }-1,0 \\
\text { Delta }-38,1\end{array}$ & $\begin{array}{l}\text { Alpha }-0 \\
\text { Beta }-0 \\
\text { Gamma }-0 \\
\text { Delta }-0\end{array}$ & 0 & $\begin{array}{l}\text { Alpha }-0 \\
\text { Beta }-0 \\
\text { Gamma }-0 \\
\text { Delta }-0\end{array}$ \\
\hline $\begin{array}{c}\text { Камбоджа } \\
\text { (снижение заболевае- } \\
\text { мости) }\end{array}$ & $\begin{array}{l}\text { Virology Unit, Institut Pasteur } \\
\text { du Cambodge }\end{array}$ & $\begin{array}{l}\text { Alpha }-805 \\
\text { Beta }-0 \\
\text { Gamma }-1 \\
\text { Delta }-803\end{array}$ & 1680 & $\begin{array}{l}\text { Alpha }-47,9 \\
\text { Beta }-0 \\
\text { Gamma }-0,1 \\
\text { Delta }-47,8\end{array}$ & $\begin{array}{l}\text { Alpha }-0 \\
\text { Beta }-0 \\
\text { Gamma }-0 \\
\text { Delta }-185\end{array}$ & 196 & $\begin{array}{l}\text { Alpha }-0 \\
\text { Beta }-0 \\
\text { Gamma }-0 \\
\text { Delta }-94,4\end{array}$ \\
\hline $\begin{array}{c}\text { Камерун } \\
\text { (снижение заболевае- } \\
\text { мости) }\end{array}$ & $\begin{array}{l}\text { CREMER(Centre de Recher- } \\
\text { cherches sur les Maladies Emer- } \\
\text { gentes et Ré-émergentes) }\end{array}$ & $\begin{array}{l}\text { Alpha }-12 \\
\text { Beta }-10 \\
\text { Gamma }-1 \\
\text { Delta }-282 \\
\end{array}$ & 556 & $\begin{array}{l}\text { Alpha }-2,2 \\
\text { Beta }-1,8 \\
\text { Gamma }-0,2 \\
\text { Delta }-50,7 \\
\end{array}$ & $\begin{array}{l}\text { Alpha }-0 \\
\text { Beta }-0 \\
\text { Gamma }-0 \\
\text { Delta }-0\end{array}$ & 0 & $\begin{array}{l}\text { Alpha }-0 \\
\text { Beta }-0 \\
\text { Gamma }-0 \\
\text { Delta }-0 \\
\end{array}$ \\
\hline $\begin{array}{c}\text { Канада } \\
\text { (стабилизация забо- } \\
\text { леваемости) }\end{array}$ & $\begin{array}{l}\text { Laboratoire de santé publique du } \\
\text { Québec }\end{array}$ & $\begin{array}{l}\text { Alpha }-41477 \\
\text { Beta }-1346 \\
\text { Gamma }-16024 \\
\text { Delta }-80355 \\
\text { Omicron }-3 \\
\end{array}$ & 200865 & $\begin{array}{l}\text { Alpha }-20,6 \\
\text { Beta }-0,7 \\
\text { Gamma }-8,0 \\
\text { Delta }-40,0 \\
\text { Omicron }-0\end{array}$ & $\begin{array}{l}\text { Alpha }-0 \\
\text { Beta }-0 \\
\text { Gamma }-0 \\
\text { Delta }-754 \\
\text { Omicron }-3\end{array}$ & 985 & $\begin{array}{l}\text { Alpha }-0 \\
\text { Beta }-0 \\
\text { Gamma }-0 \\
\text { Delta }-76,5 \\
\text { Omicron }-0,3\end{array}$ \\
\hline Канарские острова & $\begin{array}{l}\text { SeqCOVID-SPAIN consorti- } \\
\text { um/IBV(CSIC) }\end{array}$ & $\begin{array}{l}\text { Alpha }-123 \\
\text { Beta }-0 \\
\text { Gamma }-0 \\
\text { Delta }-0 \\
\end{array}$ & 454 & $\begin{array}{l}\text { Alpha }-27,1 \\
\text { Beta }-0 \\
\text { Gamma }-0 \\
\text { Delta }-0 \\
\end{array}$ & $\begin{array}{l}\text { Alpha }-0 \\
\text { Beta }-0 \\
\text { Gamma }-0 \\
\text { Delta }-0\end{array}$ & 0 & $\begin{array}{l}\text { Alpha }-0 \\
\text { Beta }-0 \\
\text { Gamma }-0 \\
\text { Delta }-0 \\
\end{array}$ \\
\hline
\end{tabular}




\begin{tabular}{|c|c|c|c|c|c|c|c|}
\hline $\begin{array}{c}\text { Катар } \\
\text { (рост заболеваемости) }\end{array}$ & $\begin{array}{l}\text { Biomedical Research Cen- } \\
\text { ter(BRC), Qatar University / Qa- } \\
\text { tar Genome Project(QGP) }\end{array}$ & $\begin{array}{l}\text { Alpha }-231 \\
\text { Beta }-612 \\
\text { Gamma }-0 \\
\text { Delta }-1343\end{array}$ & 4126 & $\begin{array}{l}\text { Alpha }-5,6 \\
\text { Beta }-14,8 \\
\text { Gamma }-0 \\
\text { Delta }-32,5\end{array}$ & $\begin{array}{l}\text { Alpha }-0 \\
\text { Beta }-0 \\
\text { Gamma }-0 \\
\text { Delta }-0\end{array}$ & 0 & $\begin{array}{l}\text { Alpha }-0 \\
\text { Beta }-0 \\
\text { Gamma }-0 \\
\text { Delta }-0\end{array}$ \\
\hline $\begin{array}{c}\text { Кения } \\
\text { (рост заболеваемости) }\end{array}$ & $\begin{array}{l}\text { KEMRI-Wellcome Trust Re- } \\
\text { search Programme/KEMRI- } \\
\text { CGMR-C Kilifi }\end{array}$ & $\begin{array}{l}\text { Alpha }-933 \\
\text { Beta }-211 \\
\text { Gamma }-0 \\
\text { Delta }-1727\end{array}$ & 5081 & $\begin{array}{l}\text { Alpha }-18,4 \\
\text { Beta }-4,2 \\
\text { Gamma }-0 \\
\text { Delta }-34,0\end{array}$ & $\begin{array}{l}\text { Alpha }-0 \\
\text { Beta }-0 \\
\text { Gamma }-0 \\
\text { Delta }-3\end{array}$ & 11 & $\begin{array}{l}\text { Alpha }-0 \\
\text { Beta }-0 \\
\text { Gamma }-0 \\
\text { Delta }-27,3\end{array}$ \\
\hline $\begin{array}{c}\text { Кипр } \\
\text { (рост заболеваемости) }\end{array}$ & $\begin{array}{l}\text { Department of Molecular Virol- } \\
\text { ogy, Cyprus Institute of Neurol- } \\
\text { ogy and Genetics }\end{array}$ & $\begin{array}{l}\text { Alpha }-10 \\
\text { Beta }-0 \\
\text { Gamma }-0 \\
\text { Delta }-1\end{array}$ & 147 & $\begin{array}{l}\text { Alpha }-6,8 \\
\text { Beta }-0 \\
\text { Gamma }-0 \\
\text { Delta }-0,7\end{array}$ & $\begin{array}{l}\text { Alpha }-0 \\
\text { Beta }-0 \\
\text { Gamma }-0 \\
\text { Delta }-0\end{array}$ & 0 & $\begin{array}{l}\text { Alpha }-0 \\
\text { Beta }-0 \\
\text { Gamma }-0 \\
\text { Delta }-0\end{array}$ \\
\hline $\begin{array}{c}\text { Китай } \\
\text { (рост заболеваемости) }\end{array}$ & $\begin{array}{l}\text { National Institute for Viral Dis- } \\
\text { ease Control and Prevention }\end{array}$ & $\begin{array}{l}\text { Alpha }-18 \\
\text { Beta }-3 \\
\text { Gamma }-2 \\
\text { Delta }-100\end{array}$ & 1285 & $\begin{array}{l}\text { Alpha }-1,4 \\
\text { Beta }-0,2 \\
\text { Gamma }-0,2 \\
\text { Delta }-7,8\end{array}$ & $\begin{array}{l}\text { Alpha }-0 \\
\text { Beta }-0 \\
\text { Gamma }-0 \\
\text { Delta }-0\end{array}$ & 0 & $\begin{array}{l}\text { Alpha }-0 \\
\text { Beta }-0 \\
\text { Gamma }-0 \\
\text { Delta }-0\end{array}$ \\
\hline $\begin{array}{c}\text { Колумбия } \\
\text { (снижение заболевае- } \\
\text { мости) }\end{array}$ & $\begin{array}{l}\text { Instituto Nacional de Salud- Di- } \\
\text { rección de Investigación en } \\
\text { Salud Pública }\end{array}$ & $\begin{array}{l}\text { Alpha }-144 \\
\text { Beta }-2 \\
\text { Gamma }-846 \\
\text { Delta }-1387\end{array}$ & 8175 & $\begin{array}{l}\text { Alpha }-1,8 \\
\text { Beta }-0 \\
\text { Gamma }-10,3 \\
\text { Delta }-17,0 \\
\end{array}$ & $\begin{array}{l}\text { Alpha }-0 \\
\text { Beta }-0 \\
\text { Gamma }-0 \\
\text { Delta }-57\end{array}$ & 100 & $\begin{array}{l}\text { Alpha }-0 \\
\text { Beta }-0 \\
\text { Gamma }-0 \\
\text { Delta }-57,0\end{array}$ \\
\hline $\begin{array}{l}\text { Коморские острова } \\
\text { (рост заболеваемости) }\end{array}$ & $\begin{array}{l}\text { KEMRI-Wellcome Trust Re- } \\
\text { search Programme/KEMRI- } \\
\text { CGMR-C Kilifi }\end{array}$ & $\begin{array}{l}\text { Alpha }-0 \\
\text { Beta }-6 \\
\text { Gamma }-0 \\
\text { Delta }-11 \\
\end{array}$ & 17 & $\begin{array}{l}\text { Alpha }-0 \\
\text { Beta }-35,3 \\
\text { Gamma }-0 \\
\text { Delta }-64,7\end{array}$ & $\begin{array}{l}\text { Alpha }-0 \\
\text { Beta }-0 \\
\text { Gamma }-0 \\
\text { Delta }-0\end{array}$ & 0 & $\begin{array}{l}\text { Alpha }-0 \\
\text { Beta }-0 \\
\text { Gamma }-0 \\
\text { Delta }-0\end{array}$ \\
\hline Косово & $\begin{array}{l}\text { Charité Universitätsmedizin Ber- } \\
\text { lin, Institut für Virologie }\end{array}$ & $\begin{array}{l}\text { Alpha }-26 \\
\text { Beta }-0 \\
\text { Gamma }-0 \\
\text { Delta }-839\end{array}$ & 892 & $\begin{array}{l}\text { Alpha }-2,9 \\
\text { Beta }-0 \\
\text { Gamma }-0 \\
\text { Delta }-94,1\end{array}$ & $\begin{array}{l}\text { Alpha }-0 \\
\text { Beta }-0 \\
\text { Gamma }-0 \\
\text { Delta }-0\end{array}$ & 0 & $\begin{array}{l}\text { Alpha }-0 \\
\text { Beta }-0 \\
\text { Gamma }-0 \\
\text { Delta }-0\end{array}$ \\
\hline $\begin{array}{c}\text { Коста-Рика } \\
\text { (снижение заболевае- } \\
\text { мости) }\end{array}$ & $\begin{array}{l}\text { Inciensa, Instituto Costarricense } \\
\text { de Investigación y Enseñanza en } \\
\text { Nutrición y Salud }\end{array}$ & $\begin{array}{l}\text { Alpha }-145 \\
\text { Beta }-13 \\
\text { Gamma }-160 \\
\text { Delta }-689\end{array}$ & 1677 & $\begin{array}{l}\text { Alpha }-8,6 \\
\text { Beta }-0,8 \\
\text { Gamma }-9,5 \\
\text { Delta }-41,1\end{array}$ & $\begin{array}{l}\text { Alpha }-0 \\
\text { Beta }-0 \\
\text { Gamma }-0 \\
\text { Delta }-1\end{array}$ & 4 & $\begin{array}{l}\text { Alpha }-0 \\
\text { Beta }-0 \\
\text { Gamma }-0 \\
\text { Delta }-25,0\end{array}$ \\
\hline
\end{tabular}




\begin{tabular}{|c|c|c|c|c|c|c|c|}
\hline $\begin{array}{c}\text { Кот Д'Ивуар } \\
\text { (снижение заболевае- } \\
\text { мости) }\end{array}$ & $\begin{array}{l}\text { Molecular diagnostic unit for vi- } \\
\text { ral haemorrhagic fevers and } \\
\text { emerging viruses, Bouaké CHU } \\
\text { Laboratory }\end{array}$ & $\begin{array}{l}\text { Alpha }-33 \\
\text { Beta }-4 \\
\text { Gamma }-0 \\
\text { Delta }-0\end{array}$ & 236 & $\begin{array}{l}\text { Alpha }-14,0 \\
\text { Beta }-1,7 \\
\text { Gamma }-0 \\
\text { Delta }-0\end{array}$ & $\begin{array}{l}\text { Alpha }-0 \\
\text { Beta }-0 \\
\text { Gamma }-0 \\
\text { Delta }-0\end{array}$ & 0 & $\begin{array}{l}\text { Alpha }-0 \\
\text { Beta }-0 \\
\text { Gamma }-0 \\
\text { Delta }-0\end{array}$ \\
\hline $\begin{array}{c}\text { Кувейт } \\
\text { (снижение заболевае- } \\
\text { мости) }\end{array}$ & $\begin{array}{l}\text { Virology Unit, Department of } \\
\text { Microbiology, Faculty of Medi- } \\
\text { cine, Kuwait }\end{array}$ & $\begin{array}{l}\text { Alpha }-24 \\
\text { Beta }-1 \\
\text { Gamma }-0 \\
\text { Delta }-191\end{array}$ & 354 & $\begin{array}{l}\text { Alpha }-6,8 \\
\text { Beta }-0,3 \\
\text { Gamma }-0 \\
\text { Delta }-54,0\end{array}$ & $\begin{array}{l}\text { Alpha }-0 \\
\text { Beta }-0 \\
\text { Gamma }-0 \\
\text { Delta }-0\end{array}$ & 0 & $\begin{array}{l}\text { Alpha }-0 \\
\text { Beta }-0 \\
\text { Gamma }-0 \\
\text { Delta }-0\end{array}$ \\
\hline Кюрасао & $\begin{array}{l}\text { National Institute for Public } \\
\text { Health and the Environ- } \\
\text { ment(RIVM) }\end{array}$ & $\begin{array}{l}\text { Alpha }-318 \\
\text { Beta }-0 \\
\text { Gamma }-14 \\
\text { Delta }-495\end{array}$ & 949 & $\begin{array}{l}\text { Alpha }-33,5 \\
\text { Beta }-0 \\
\text { Gamma }-1,5 \\
\text { Delta }-52,2\end{array}$ & $\begin{array}{l}\text { Alpha }-0 \\
\text { Beta }-0 \\
\text { Gamma }-0 \\
\text { Delta }-18\end{array}$ & 24 & $\begin{array}{l}\text { Alpha }-0 \\
\text { Beta }-0 \\
\text { Gamma }-0 \\
\text { Delta }-75,0\end{array}$ \\
\hline $\begin{array}{c}\text { Латвия } \\
\text { (снижение заболевае- } \\
\text { мости) }\end{array}$ & $\begin{array}{l}\text { Latvian Biomedical Research } \\
\text { and Study Centre }\end{array}$ & $\begin{array}{l}\text { Alpha }-3191 \\
\text { Beta }-10 \\
\text { Gamma }-2 \\
\text { Delta }-73\end{array}$ & 5728 & $\begin{array}{l}\text { Alpha }-55,7 \\
\text { Beta }-0,2 \\
\text { Gamma }-0 \\
\text { Delta }-1,3\end{array}$ & $\begin{array}{l}\text { Alpha }-0 \\
\text { Beta }-0 \\
\text { Gamma }-0 \\
\text { Delta }-0\end{array}$ & 0 & $\begin{array}{l}\text { Alpha }-0 \\
\text { Beta }-0 \\
\text { Gamma }-0 \\
\text { Delta }-0\end{array}$ \\
\hline $\begin{array}{c}\text { Лесото } \\
\text { (рост заболеваемости) }\end{array}$ & $\begin{array}{l}\text { National Institute for Communi- } \\
\text { cable Diseases of the National } \\
\text { Health Laboratory Service }\end{array}$ & $\begin{array}{l}\text { Alpha }-0 \\
\text { Beta }-14 \\
\text { Gamma }-0 \\
\text { Delta }-0 \\
\end{array}$ & 18 & $\begin{array}{l}\text { Alpha }-0 \\
\text { Beta }-77,8 \\
\text { Gamma }-0 \\
\text { Delta }-0 \\
\end{array}$ & $\begin{array}{l}\text { Alpha }-0 \\
\text { Beta }-0 \\
\text { Gamma }-0 \\
\text { Delta }-0\end{array}$ & 0 & $\begin{array}{l}\text { Alpha }-0 \\
\text { Beta }-0 \\
\text { Gamma }-0 \\
\text { Delta }-0\end{array}$ \\
\hline $\begin{array}{c}\text { Либерия } \\
\text { (стабилизация забо- } \\
\text { леваемости) }\end{array}$ & $\begin{array}{l}\text { Center for Infection and Immun- } \\
\text { ity, Columbia University }\end{array}$ & $\begin{array}{l}\text { Alpha }-4 \\
\text { Beta }-6 \\
\text { Gamma }-0 \\
\text { Delta }-56\end{array}$ & 77 & $\begin{array}{l}\text { Alpha }-5,2 \\
\text { Beta }-7,8 \\
\text { Gamma }-0 \\
\text { Delta }-72,7 \\
\end{array}$ & $\begin{array}{l}\text { Alpha }-0 \\
\text { Beta }-0 \\
\text { Gamma }-0 \\
\text { Delta }-0\end{array}$ & 0 & $\begin{array}{l}\text { Alpha }-0 \\
\text { Beta }-0 \\
\text { Gamma }-0 \\
\text { Delta }-0\end{array}$ \\
\hline $\begin{array}{c}\text { Ливан } \\
\text { (рост заболеваемости) }\end{array}$ & $\begin{array}{l}\text { Laboratory of Molecular Biolo- } \\
\text { gy and Cancer Immunolo- } \\
\text { gy,Lebanese University Public } \\
\text { Health England }\end{array}$ & $\begin{array}{l}\text { Alpha }-851 \\
\text { Beta }-0 \\
\text { Gamma }-0 \\
\text { Delta }-80\end{array}$ & 1081 & $\begin{array}{l}\text { Alpha }-78,7 \\
\text { Beta }-0 \\
\text { Gamma }-0 \\
\text { Delta }-7,4\end{array}$ & $\begin{array}{l}\text { Alpha }-0 \\
\text { Beta }-0 \\
\text { Gamma }-0 \\
\text { Delta }-0\end{array}$ & 0 & $\begin{array}{l}\text { Alpha }-0 \\
\text { Beta }-0 \\
\text { Gamma }-0 \\
\text { Delta }-0\end{array}$ \\
\hline $\begin{array}{c}\text { Ливия } \\
\text { (рост заболеваемости) }\end{array}$ & Erasmus Medical Center & $\begin{array}{l}\text { Alpha }-1 \\
\text { Beta }-0 \\
\text { Gamma }-0 \\
\text { Delta }-0\end{array}$ & 22 & $\begin{array}{l}\text { Alpha }-4,5 \\
\text { Beta }-0 \\
\text { Gamma }-0 \\
\text { Delta }-0\end{array}$ & $\begin{array}{l}\text { Alpha }-0 \\
\text { Beta }-0 \\
\text { Gamma }-0 \\
\text { Delta }-0\end{array}$ & 0 & $\begin{array}{l}\text { Alpha -0 } \\
\text { Beta -0 } \\
\text { Gamma - 0 } \\
\text { Delta -0 }\end{array}$ \\
\hline
\end{tabular}




\begin{tabular}{|c|c|c|c|c|c|c|c|}
\hline $\begin{array}{c}\text { Литва } \\
\text { (снижение заболевае- } \\
\text { мости) }\end{array}$ & $\begin{array}{l}\text { Vilnius University Hospital San- } \\
\text { taros Klinikos, Center of La- } \\
\text { boratory Medicine }\end{array}$ & $\begin{array}{l}\text { Alpha }-9347 \\
\text { Beta }-11 \\
\text { Gamma }-8 \\
\text { Delta }-9166\end{array}$ & 23508 & $\begin{array}{l}\text { Alpha }-39,8 \\
\text { Beta }-0 \\
\text { Gamma }-0 \\
\text { Delta }-39,0\end{array}$ & $\begin{array}{l}\text { Alpha }-0 \\
\text { Beta }-0 \\
\text { Gamma }-0 \\
\text { Delta }-333\end{array}$ & 780 & $\begin{array}{l}\text { Alpha }-0 \\
\text { Beta }-0 \\
\text { Gamma }-0 \\
\text { Delta }-42,7\end{array}$ \\
\hline $\begin{array}{c}\text { Лихтенштейн } \\
\text { (рост заболеваемости) }\end{array}$ & $\begin{array}{l}\text { Bergthaler laboratory, CeMM } \\
\text { Research Center for Molecular } \\
\text { Medicine of the Austrian Acad- } \\
\text { emy of Sciences }\end{array}$ & $\begin{array}{l}\text { Alpha }-19 \\
\text { Beta }-0 \\
\text { Gamma }-1 \\
\text { Delta }-103\end{array}$ & 181 & $\begin{array}{l}\text { Alpha }-10,5 \\
\text { Beta }-0 \\
\text { Gamma }-0,9 \\
\text { Delta }-56,9 \\
\end{array}$ & $\begin{array}{l}\text { Alpha }-0 \\
\text { Beta }-0 \\
\text { Gamma }-0 \\
\text { Delta }-50\end{array}$ & 62 & $\begin{array}{l}\text { Alpha }-0 \\
\text { Beta }-0 \\
\text { Gamma }-0 \\
\text { Delta }-80,6\end{array}$ \\
\hline $\begin{array}{c}\text { Люксембург } \\
\text { (рост заболеваемости) }\end{array}$ & $\begin{array}{l}\text { Laboratoire national de santé, } \\
\text { Microbiology, Microbial Ge- } \\
\text { nomics Platform }\end{array}$ & $\begin{array}{l}\text { Alpha }-4899 \\
\text { Beta }-911 \\
\text { Gamma }-1049 \\
\text { Delta }-6002\end{array}$ & 17534 & $\begin{array}{l}\text { Alpha }-27,9 \\
\text { Beta }-5,2 \\
\text { Gamma }-6,0 \\
\text { Delta }-34,2\end{array}$ & $\begin{array}{l}\text { Alpha }-0 \\
\text { Beta }-0 \\
\text { Gamma }-0 \\
\text { Delta }-610\end{array}$ & 747 & $\begin{array}{l}\text { Alpha }-0 \\
\text { Beta }-0 \\
\text { Gamma }-0 \\
\text { Delta }-81,7\end{array}$ \\
\hline $\begin{array}{c}\text { Маври́кий } \\
\text { (снижение заболевае- } \\
\text { мости) }\end{array}$ & $\begin{array}{l}\text { CNR Virus des Infections Res- } \\
\text { piratoires - France SUD }\end{array}$ & $\begin{array}{l}\text { Alpha }-1 \\
\text { Beta }-7 \\
\text { Gamma }-0 \\
\text { Delta }-67\end{array}$ & 386 & $\begin{array}{l}\text { Alpha }-0,3 \\
\text { Beta }-1,8 \\
\text { Gamma }-0 \\
\text { Delta }-17,4\end{array}$ & $\begin{array}{l}\text { Alpha }-0 \\
\text { Beta }-0 \\
\text { Gamma }-0 \\
\text { Delta }-0\end{array}$ & 0 & $\begin{array}{l}\text { Alpha }-0 \\
\text { Beta }-0 \\
\text { Gamma }-0 \\
\text { Delta }-0\end{array}$ \\
\hline $\begin{array}{c}\text { Мадагаскар } \\
\text { (снижение заболевае- } \\
\text { мости) }\end{array}$ & $\begin{array}{l}\text { Virology Unit, Institut Pasteur } \\
\text { de Madagascar }\end{array}$ & $\begin{array}{l}\text { Alpha }-25 \\
\text { Beta }-206 \\
\text { Gamma }-0 \\
\text { Delta }-0\end{array}$ & 722 & $\begin{array}{l}\text { Alpha }-3,5 \\
\text { Beta }-28,5 \\
\text { Gamma }-0 \\
\text { Delta }-0\end{array}$ & $\begin{array}{l}\text { Alpha }-0 \\
\text { Beta }-0 \\
\text { Gamma }-0 \\
\text { Delta }-0\end{array}$ & 0 & $\begin{array}{l}\text { Alpha }-0 \\
\text { Beta }-0 \\
\text { Gamma }-0 \\
\text { Delta }-0\end{array}$ \\
\hline Майотта & $\begin{array}{l}\text { National Reference Center for } \\
\text { Viruses of Respiratory Infec- } \\
\text { tions, Institut Pasteur, Paris }\end{array}$ & $\begin{array}{l}\text { Alpha }-2 \\
\text { Beta }-394 \\
\text { Gamma }-0 \\
\text { Delta }-75\end{array}$ & 817 & $\begin{array}{l}\text { Alpha }-0,2 \\
\text { Beta }-48,2 \\
\text { Gamma }-0 \\
\text { Delta }-9,2\end{array}$ & $\begin{array}{l}\text { Alpha }-0 \\
\text { Beta }-0 \\
\text { Gamma }-0 \\
\text { Delta }-9\end{array}$ & 14 & $\begin{array}{l}\text { Alpha }-0 \\
\text { Beta }-0 \\
\text { Gamma }-0 \\
\text { Delta }-64,3\end{array}$ \\
\hline $\begin{array}{c}\text { Малайзия } \\
\text { (снижение заболевае- } \\
\text { мости) }\end{array}$ & $\begin{array}{l}\text { Institute for Medical Research, } \\
\text { Infectious Disease Research } \\
\text { Centre, National Institutes of } \\
\text { Health, Ministry of Health Ma- } \\
\text { laysia }\end{array}$ & $\begin{array}{l}\text { Alpha }-33 \\
\text { Beta }-258 \\
\text { Gamma }-0 \\
\text { Delta }-3887\end{array}$ & 5686 & $\begin{array}{l}\text { Alpha }-0,6 \\
\text { Beta }-4,5 \\
\text { Gamma }-0 \\
\text { Delta }-68,4\end{array}$ & $\begin{array}{l}\text { Alpha }-0 \\
\text { Beta }-1 \\
\text { Gamma }-0 \\
\text { Delta }-62\end{array}$ & 67 & $\begin{array}{l}\text { Alpha }-0 \\
\text { Beta }-1,5 \\
\text { Gamma }-0 \\
\text { Delta }-92,5\end{array}$ \\
\hline $\begin{array}{c}\text { Малави } \\
\text { (рост заболеваемости) }\end{array}$ & $\begin{array}{l}\text { KRISP, KZN Research Innova- } \\
\text { tion and Sequencing Platform }\end{array}$ & $\begin{array}{l}\text { Alpha }-5 \\
\text { Beta }-333 \\
\text { Gamma }-0 \\
\text { Delta }-216\end{array}$ & 615 & $\begin{array}{l}\text { Alpha }-0,8 \\
\text { Beta }-54,1 \\
\text { Gamma }-0 \\
\text { Delta }-35,1\end{array}$ & $\begin{array}{l}\text { Alpha }-0 \\
\text { Beta }-0 \\
\text { Gamma }-0 \\
\text { Delta }-0\end{array}$ & 0 & $\begin{array}{l}\text { Alpha }-0 \\
\text { Beta }-0 \\
\text { Gamma }-0 \\
\text { Delta }-0\end{array}$ \\
\hline
\end{tabular}




\begin{tabular}{|c|c|c|c|c|c|c|c|}
\hline $\begin{array}{c}\text { Мали } \\
\text { (рост заболеваемости) }\end{array}$ & $\begin{array}{l}\text { Northwestern University - Cen- } \\
\text { ter for Pathogen Genomics and } \\
\text { Microbial Evolution }\end{array}$ & $\begin{array}{l}\text { Alpha }-1 \\
\text { Beta }-0 \\
\text { Gamma }-0 \\
\text { Delta }-2\end{array}$ & 72 & $\begin{array}{l}\text { Alpha }-1,4 \\
\text { Beta }-0 \\
\text { Gamma }-0 \\
\text { Delta }-2,8\end{array}$ & $\begin{array}{l}\text { Alpha }-0 \\
\text { Beta }-0 \\
\text { Gamma }-0 \\
\text { Delta }-0\end{array}$ & 0 & $\begin{array}{l}\text { Alpha }-0 \\
\text { Beta }-0 \\
\text { Gamma }-0 \\
\text { Delta }-0\end{array}$ \\
\hline $\begin{array}{c}\text { Мальдивы } \\
\text { (стабилизация забо- } \\
\text { леваемости) }\end{array}$ & $\begin{array}{l}\text { Indira Gandhi Memorial Hospi- } \\
\text { tal }\end{array}$ & $\begin{array}{l}\text { Alpha }-14 \\
\text { Beta }-0 \\
\text { Gamma }-0 \\
\text { Delta }-627\end{array}$ & 669 & $\begin{array}{l}\text { Alpha }-2,1 \\
\text { Beta }-0 \\
\text { Gamma }-0 \\
\text { Delta }-93,7\end{array}$ & $\begin{array}{l}\text { Alpha }-0 \\
\text { Beta }-0 \\
\text { Gamma }-0 \\
\text { Delta }-66\end{array}$ & 81 & $\begin{array}{l}\text { Alpha }-0 \\
\text { Beta }-0 \\
\text { Gamma }-0 \\
\text { Delta }-81,5\end{array}$ \\
\hline $\begin{array}{c}\text { Мальта } \\
\text { (рост заболеваемости) }\end{array}$ & $\begin{array}{l}\text { Molecular Diagnostics Patholo- } \\
\text { gy Department Mater Dei Hospi- } \\
\text { tal Malta }\end{array}$ & $\begin{array}{l}\text { Alpha }-148 \\
\text { Beta }-3 \\
\text { Gamma }-33 \\
\text { Delta }-63\end{array}$ & 299 & $\begin{array}{l}\text { Alpha }-49,5 \\
\text { Beta }-1,0 \\
\text { Gamma }-11,0 \\
\text { Delta }-21,1\end{array}$ & $\begin{array}{l}\text { Alpha }-0 \\
\text { Beta }-0 \\
\text { Gamma }-0 \\
\text { Delta }-0\end{array}$ & 0 & $\begin{array}{l}\text { Alpha }-0 \\
\text { Beta }-0 \\
\text { Gamma }-0 \\
\text { Delta }-0\end{array}$ \\
\hline $\begin{array}{c}\text { Марокко } \\
\text { (рост заболеваемости) }\end{array}$ & Laboratoire de Biotechnologie & $\begin{array}{l}\text { Alpha }-137 \\
\text { Beta }-1 \\
\text { Gamma }-0 \\
\text { Delta }-138\end{array}$ & 551 & $\begin{array}{l}\text { Alpha }-24,9 \\
\text { Beta }-0,2 \\
\text { Gamma }-0 \\
\text { Delta }-25,0\end{array}$ & $\begin{array}{l}\text { Alpha }-0 \\
\text { Beta }-0 \\
\text { Gamma }-0 \\
\text { Delta }-0\end{array}$ & 0 & $\begin{array}{l}\text { Alpha }-0 \\
\text { Beta }-0 \\
\text { Gamma }-0 \\
\text { Delta }-0\end{array}$ \\
\hline Мартиника & $\begin{array}{l}\text { CNR Virus des Infections Res- } \\
\text { piratoires - France SUD }\end{array}$ & $\begin{array}{l}\text { Alpha }-258 \\
\text { Beta }-2 \\
\text { Gamma }-1 \\
\text { Delta }-433\end{array}$ & 713 & $\begin{array}{l}\text { Alpha }-36,2 \\
\text { Beta }-0,3 \\
\text { Gamma }-0,1 \\
\text { Delta }-60,7\end{array}$ & $\begin{array}{l}\text { Alpha }-0 \\
\text { Beta }-0 \\
\text { Gamma }-0 \\
\text { Delta }-26\end{array}$ & 26 & $\begin{array}{l}\text { Alpha }-0 \\
\text { Beta }-0 \\
\text { Gamma }-0 \\
\text { Delta }-100,0\end{array}$ \\
\hline $\begin{array}{c}\text { Мексика } \\
\text { (снижение заболевае- } \\
\text { мости) }\end{array}$ & $\begin{array}{l}\text { Instituto de } 31 \text { iagnostic y Refer- } \\
\text { enciaEpidemiologicos(INDRE) }\end{array}$ & $\begin{array}{l}\text { Alpha }-1798 \\
\text { Beta }-19 \\
\text { Gamma }-2731 \\
\text { Delta }-19263\end{array}$ & 38952 & $\begin{array}{l}\text { Alpha }-4,6 \\
\text { Beta }-0,1 \\
\text { Gamma }-7,0 \\
\text { Delta }-49,5\end{array}$ & $\begin{array}{l}\text { Alpha }-0 \\
\text { Beta }-0 \\
\text { Gamma }-0 \\
\text { Delta }-629\end{array}$ & 731 & $\begin{array}{l}\text { Alpha }-0 \\
\text { Beta }-0 \\
\text { Gamma }-0 \\
\text { Delta }-86,0\end{array}$ \\
\hline $\begin{array}{c}\text { Мозамбик } \\
\text { (рост заболеваемости) }\end{array}$ & $\begin{array}{l}\text { KRISP, KZN Research Innova- } \\
\text { tion and Sequencing Platform, } \\
\text { South Africa }\end{array}$ & $\begin{array}{l}\text { Alpha }-2 \\
\text { Beta }-362 \\
\text { Gamma }-0 \\
\text { Delta }-332\end{array}$ & 883 & $\begin{array}{l}\text { Alpha }-0,2 \\
\text { Beta }-41,0 \\
\text { Gamma }-0 \\
\text { Delta }-37,6\end{array}$ & $\begin{array}{l}\text { Alpha }-0 \\
\text { Beta }-0 \\
\text { Gamma }-0 \\
\text { Delta }-0\end{array}$ & 0 & $\begin{array}{l}\text { Alpha }-0 \\
\text { Beta }-0 \\
\text { Gamma }-0 \\
\text { Delta }-0\end{array}$ \\
\hline $\begin{array}{c}\text { Молдавия } \\
\text { (снижение заболевае- } \\
\text { мости) }\end{array}$ & ONCOGENE LLC & $\begin{array}{l}\text { Alpha }-37 \\
\text { Beta }-0 \\
\text { Gamma }-0 \\
\text { Delta }-11\end{array}$ & 67 & $\begin{array}{l}\text { Alpha }-55,2 \\
\text { Beta }-0 \\
\text { Gamma }-0 \\
\text { Delta }-16,4\end{array}$ & $\begin{array}{l}\text { Alpha }-0 \\
\text { Beta }-0 \\
\text { Gamma }-0 \\
\text { Delta }-0\end{array}$ & 0 & $\begin{array}{l}\text { Alpha }-0 \\
\text { Beta }-0 \\
\text { Gamma }-0 \\
\text { Delta }-0\end{array}$ \\
\hline
\end{tabular}




\begin{tabular}{|c|c|c|c|c|c|c|c|}
\hline $\begin{array}{c}\text { Монако } \\
\text { (рост заболеваемости) }\end{array}$ & $\begin{array}{l}\text { National Reference Center for } \\
\text { Viruses of Respiratory Infec- } \\
\text { tions, Institut Pasteur, Paris }\end{array}$ & $\begin{array}{l}\text { Alpha }-3 \\
\text { Beta }-1 \\
\text { Gamma }-0 \\
\text { Delta }-70\end{array}$ & 78 & $\begin{array}{l}\text { Alpha }-3,8 \\
\text { Beta }-1,3 \\
\text { Gamma }-0 \\
\text { Delta }-89,7\end{array}$ & $\begin{array}{l}\text { Alpha }-0 \\
\text { Beta }-0 \\
\text { Gamma }-0 \\
\text { Delta }-0\end{array}$ & 0 & $\begin{array}{l}\text { Alpha }-0 \\
\text { Beta }-0 \\
\text { Gamma }-0 \\
\text { Delta }-0\end{array}$ \\
\hline $\begin{array}{c}\text { Монголия } \\
\text { (снижение заболевае- } \\
\text { мости) }\end{array}$ & $\begin{array}{l}\text { National Centre for Communica- } \\
\text { tion Disease (NCCD) National } \\
\text { Influenza Center }\end{array}$ & $\begin{array}{l}\text { Alpha }-0 \\
\text { Beta }-0 \\
\text { Gamma }-0 \\
\text { Delta }-1 \\
\end{array}$ & 28 & $\begin{array}{l}\text { Alpha }-0 \\
\text { Beta }-0 \\
\text { Gamma }-0 \\
\text { Delta }-3,6 \\
\end{array}$ & $\begin{array}{l}\text { Alpha }-0 \\
\text { Beta }-0 \\
\text { Gamma }-0 \\
\text { Delta }-0\end{array}$ & 0 & $\begin{array}{l}\text { Alpha }-0 \\
\text { Beta }-0 \\
\text { Gamma }-0 \\
\text { Delta }-0\end{array}$ \\
\hline Монтсеррат & $\begin{array}{l}\text { Carrington Lab, Department of } \\
\text { Preclinical Sciences, Faculty of } \\
\text { Medical Sciences, The Universi- } \\
\text { ty of the West Indies }\end{array}$ & $\begin{array}{l}\text { Alpha }-2 \\
\text { Beta }-0 \\
\text { Gamma }-1 \\
\text { Delta }-7\end{array}$ & 10 & $\begin{array}{l}\text { Alpha }-20,0 \\
\text { Beta }-0 \\
\text { Gamma }-10,0 \\
\text { Delta }-70,0\end{array}$ & $\begin{array}{l}\text { Alpha }-0 \\
\text { Beta }-0 \\
\text { Gamma }-0 \\
\text { Delta }-0\end{array}$ & 0 & $\begin{array}{l}\text { Alpha }-0 \\
\text { Beta }-0 \\
\text { Gamma }-0 \\
\text { Delta }-0\end{array}$ \\
\hline $\begin{array}{c}\text { Мьянма } \\
\text { (снижение заболевае- } \\
\text { мости) }\end{array}$ & DSMRC & $\begin{array}{l}\text { Alpha }-2 \\
\text { Beta }-0 \\
\text { Gamma }-0 \\
\text { Delta }-33 \\
\end{array}$ & 90 & $\begin{array}{l}\text { Alpha }-2,2 \\
\text { Beta }-0 \\
\text { Gamma }-0 \\
\text { Delta }-36,7\end{array}$ & $\begin{array}{l}\text { Alpha }-0 \\
\text { Beta }-0 \\
\text { Gamma }-0 \\
\text { Delta }-0\end{array}$ & 0 & $\begin{array}{l}\text { Alpha }-0 \\
\text { Beta }-0 \\
\text { Gamma }-0 \\
\text { Delta }-0\end{array}$ \\
\hline $\begin{array}{c}\text { Намибия } \\
\text { (рост заболеваемости) }\end{array}$ & $\begin{array}{l}\text { National Institute for Communi- } \\
\text { cable Diseases of the National } \\
\text { Health Laboratory Service }\end{array}$ & $\begin{array}{l}\text { Alpha }-3 \\
\text { Beta }-161 \\
\text { Gamma }-2 \\
\text { Delta }-110 \\
\end{array}$ & 389 & $\begin{array}{l}\text { Alpha }-0,8 \\
\text { Beta }-41,4 \\
\text { Gamma }-0,6 \\
\text { Delta }-28,3 \\
\end{array}$ & $\begin{array}{l}\text { Alpha }-0 \\
\text { Beta }-0 \\
\text { Gamma }-0 \\
\text { Delta }-0\end{array}$ & 0 & $\begin{array}{l}\text { Alpha }-0 \\
\text { Beta }-0 \\
\text { Gamma }-0 \\
\text { Delta }-0\end{array}$ \\
\hline $\begin{array}{c}\text { Непал } \\
\text { (снижение заболевае- } \\
\text { мости) }\end{array}$ & $\begin{array}{l}\text { Molecular and Genomics Re- } \\
\text { search Lab, Dhulikhel Hospital, } \\
\text { Kathmandu University Hospi- } \\
\text { talSchool of Public Health, The } \\
\text { University of Hong Kong }\end{array}$ & $\begin{array}{l}\text { Alpha }-12 \\
\text { Beta }-0 \\
\text { Gamma }-0 \\
\text { Delta }-238\end{array}$ & 285 & $\begin{array}{l}\text { Alpha }-4,2 \\
\text { Beta }-0 \\
\text { Gamma }-0 \\
\text { Delta }-83,5\end{array}$ & $\begin{array}{l}\text { Alpha }-0 \\
\text { Beta }-0 \\
\text { Gamma }-0 \\
\text { Delta }-0\end{array}$ & 0 & $\begin{array}{l}\text { Alpha }-0 \\
\text { Beta }-0 \\
\text { Gamma }-0 \\
\text { Delta }-0\end{array}$ \\
\hline $\begin{array}{c}\text { Нигер } \\
\text { (снижение заболевае- } \\
\text { мости) }\end{array}$ & $\begin{array}{l}\text { National Reference Laboratory, } \\
\text { Nigeria Centre for Disease Con- } \\
\text { trol }\end{array}$ & $\begin{array}{l}\text { Alpha }-2 \\
\text { Beta }-0 \\
\text { Gamma }-0 \\
\text { Delta }-0 \\
\end{array}$ & 43 & $\begin{array}{l}\text { Alpha }-4,7 \\
\text { Beta }-0 \\
\text { Gamma }-0 \\
\text { Delta }-0 \\
\end{array}$ & $\begin{array}{l}\text { Alpha }-0 \\
\text { Beta }-0 \\
\text { Gamma }-0 \\
\text { Delta }-0 \\
\end{array}$ & 0 & $\begin{array}{l}\text { Alpha }-0 \\
\text { Beta }-0 \\
\text { Gamma }-0 \\
\text { Delta }-0\end{array}$ \\
\hline $\begin{array}{c}\text { Нигерия } \\
\text { (снижение заболевае- } \\
\text { мости) }\end{array}$ & $\begin{array}{l}\text { African Centre of Excellence for } \\
\text { Genomics of Infectious Diseas- } \\
\text { es(ACEGID), Redeemer's Uni- } \\
\text { versity }\end{array}$ & $\begin{array}{l}\text { Alpha }-255 \\
\text { Beta }-2 \\
\text { Gamma }-0 \\
\text { Delta }-1795\end{array}$ & 3268 & $\begin{array}{l}\text { Alpha }-7,8 \\
\text { Beta - 0,1 } \\
\text { Gamma - 0 } \\
\text { Delta }-54,9\end{array}$ & $\begin{array}{l}\text { Alpha }-0 \\
\text { Beta }-0 \\
\text { Gamma -0 } \\
\text { Delta -0 }\end{array}$ & 1 & $\begin{array}{l}\text { Alpha -0 } \\
\text { Beta -0 } \\
\text { Gamma -0 } \\
\text { Delta }-0\end{array}$ \\
\hline
\end{tabular}




\begin{tabular}{|c|c|c|c|c|c|c|c|}
\hline $\begin{array}{c}\text { Нидерланды } \\
\text { (снижение заболевае- } \\
\text { мости) }\end{array}$ & $\begin{array}{l}\text { National Institute for Public } \\
\text { Health and the Environ- } \\
\text { ment(RIVM) }\end{array}$ & $\begin{array}{l}\text { Alpha - 30000 } \\
\text { Beta - } 707 \\
\text { Gamma - 590 } \\
\text { Delta - } 29537 \\
\text { Omicron - } 13\end{array}$ & 74472 & $\begin{array}{l}\text { Alpha }-40,3 \\
\text { Beta }-0,9 \\
\text { Gamma }-0,8 \\
\text { Delta }-39,7 \\
\text { Omicron }-0\end{array}$ & $\begin{array}{l}\text { Alpha }-0 \\
\text { Beta }-0 \\
\text { Gamma }-0 \\
\text { Delta }-2016 \\
\text { Omicron }-1\end{array}$ & 2395 & $\begin{array}{l}\text { Alpha }-0 \\
\text { Beta }-0 \\
\text { Gamma }-0 \\
\text { Delta }-84,2 \\
\text { Omicron }-0\end{array}$ \\
\hline $\begin{array}{c}\text { Новая Зеландия } \\
\text { (снижение заболевае- } \\
\text { мости) }\end{array}$ & $\begin{array}{l}\text { Institute of Environmental Sci- } \\
\text { ence and Research(ESR) }\end{array}$ & $\begin{array}{l}\text { Alpha }-152 \\
\text { Beta }-31 \\
\text { Gamma }-7 \\
\text { Delta }-3385\end{array}$ & 4694 & $\begin{array}{l}\text { Alpha }-3,2 \\
\text { Beta }-0,7 \\
\text { Gamma }-0,1 \\
\text { Delta }-72,1\end{array}$ & $\begin{array}{l}\text { Alpha }-0 \\
\text { Beta }-0 \\
\text { Gamma }-0 \\
\text { Delta }-424\end{array}$ & 458 & $\begin{array}{l}\text { Alpha }-0 \\
\text { Beta }-0 \\
\text { Gamma }-0 \\
\text { Delta }-92,6\end{array}$ \\
\hline $\begin{array}{c}\text { Норвегия } \\
\text { (рост заболеваемости) }\end{array}$ & $\begin{array}{l}\text { Norwegian Institute of Public } \\
\text { Health, Department of Virology }\end{array}$ & $\begin{array}{l}\text { Alpha }-13835 \\
\text { Beta }-411 \\
\text { Gamma }-12 \\
\text { Delta }-12979\end{array}$ & 32865 & $\begin{array}{l}\text { Alpha }-42,1 \\
\text { Beta }-1,3 \\
\text { Gamma }-0 \\
\text { Delta }-39,5\end{array}$ & $\begin{array}{l}\text { Alpha }-0 \\
\text { Beta }-0 \\
\text { Gamma }-0 \\
\text { Delta }-364\end{array}$ & 401 & $\begin{array}{l}\text { Alpha }-0 \\
\text { Beta }-0 \\
\text { Gamma }-0 \\
\text { Delta }-90,8\end{array}$ \\
\hline $\begin{array}{c}\text { ОАЭ } \\
\text { (снижение заболевае- } \\
\text { мости) }\end{array}$ & $\begin{array}{l}\text { Wellcome Sanger Institute for } \\
\text { the COVID-19 Genomics } \\
\text { UK(COG-UK) Consortium }\end{array}$ & $\begin{array}{l}\text { Alpha }-363 \\
\text { Beta }-43 \\
\text { Gamma }-1 \\
\text { Delta }-28\end{array}$ & 2627 & $\begin{array}{l}\text { Alpha }-13,8 \\
\text { Beta }-1,6 \\
\text { Gamma }-0 \\
\text { Delta }-1,1 \\
\end{array}$ & $\begin{array}{l}\text { Alpha }-0 \\
\text { Beta }-0 \\
\text { Gamma }-0 \\
\text { Delta }-0 \\
\end{array}$ & 0 & $\begin{array}{l}\text { Alpha }-0 \\
\text { Beta }-0 \\
\text { Gamma }-0 \\
\text { Delta }-0 \\
\end{array}$ \\
\hline $\begin{array}{c}\text { Оман } \\
\text { (рост заболеваемости) }\end{array}$ & $\begin{array}{l}\text { Oman-National Influenza Cen- } \\
\text { ter }\end{array}$ & $\begin{array}{l}\text { Alpha }-160 \\
\text { Beta }-9 \\
\text { Gamma }-0 \\
\text { Delta }-159\end{array}$ & 883 & $\begin{array}{l}\text { Alpha }-18,1 \\
\text { Beta }-1,0 \\
\text { Gamma }-0 \\
\text { Delta }-18,0\end{array}$ & $\begin{array}{l}\text { Alpha }-0 \\
\text { Beta }-0 \\
\text { Gamma }-0 \\
\text { Delta }-0 \\
\end{array}$ & 0 & $\begin{array}{l}\text { Alpha }-0 \\
\text { Beta }-0 \\
\text { Gamma }-0 \\
\text { Delta }-0 \\
\end{array}$ \\
\hline $\begin{array}{c}\text { Пакистан } \\
\text { (рост заболеваемости) }\end{array}$ & $\begin{array}{l}\text { Department of Virology, Public } \\
\text { Health Laboratories Division }\end{array}$ & $\begin{array}{l}\text { Alpha }-458 \\
\text { Beta }-75 \\
\text { Gamma }-1 \\
\text { Delta }-749 \\
\end{array}$ & 1566 & $\begin{array}{l}\text { Alpha }-29,2 \\
\text { Beta }-4,8 \\
\text { Gamma }-0,1 \\
\text { Delta }-47,8 \\
\end{array}$ & $\begin{array}{l}\text { Alpha }-0 \\
\text { Beta }-0 \\
\text { Gamma }-0 \\
\text { Delta }-33 \\
\end{array}$ & 39 & $\begin{array}{l}\text { Alpha }-0 \\
\text { Beta }-0 \\
\text { Gamma }-0 \\
\text { Delta }-84,6\end{array}$ \\
\hline $\begin{array}{c}\text { Палестина } \\
\text { (рост заболеваемости) }\end{array}$ & $\begin{array}{l}\text { Biochemistry and Molecular Bi- } \\
\text { ology Department-Faculty of } \\
\text { Medicine, Al-Quds University }\end{array}$ & $\begin{array}{l}\text { Alpha }-22 \\
\text { Beta }-0 \\
\text { Gamma }-0 \\
\text { Delta }-0\end{array}$ & 132 & $\begin{array}{l}\text { Alpha }-16,7 \\
\text { Beta }-0 \\
\text { Gamma }-0 \\
\text { Delta }-0\end{array}$ & $\begin{array}{l}\text { Alpha }-0 \\
\text { Beta }-0 \\
\text { Gamma }-0 \\
\text { Delta }-0 \\
\end{array}$ & 0 & $\begin{array}{l}\text { Alpha }-0 \\
\text { Beta }-0 \\
\text { Gamma }-0 \\
\text { Delta }-0\end{array}$ \\
\hline $\begin{array}{c}\text { Панама } \\
\text { (стабилизация забо- } \\
\text { леваемости) }\end{array}$ & $\begin{array}{l}\text { Gorgas memorial Institute For } \\
\text { Health Studies }\end{array}$ & $\begin{array}{l}\text { Alpha }-26 \\
\text { Beta }-2 \\
\text { Gamma }-30 \\
\text { Delta }-1\end{array}$ & 1262 & $\begin{array}{l}\text { Alpha }-2,1 \\
\text { Beta }-0,2 \\
\text { Gamma }-2,4 \\
\text { Delta }-0,1\end{array}$ & $\begin{array}{l}\text { Alpha }-0 \\
\text { Beta }-0 \\
\text { Gamma }-0 \\
\text { Delta }-0\end{array}$ & 0 & $\begin{array}{l}\text { Alpha }-0 \\
\text { Beta }-0 \\
\text { Gamma }-0 \\
\text { Delta }-0\end{array}$ \\
\hline
\end{tabular}




\begin{tabular}{|c|c|c|c|c|c|c|c|}
\hline $\begin{array}{c}\text { Папуа Новая Гвинея } \\
\text { (снижение заболевае- } \\
\text { мости) }\end{array}$ & $\begin{array}{l}\text { Queensland Health Forensic and } \\
\text { Scientific Services }\end{array}$ & $\begin{array}{l}\text { Alpha }-0 \\
\text { Beta }-0 \\
\text { Gamma }-0 \\
\text { Delta }-717\end{array}$ & 2396 & $\begin{array}{l}\text { Alpha }-0 \\
\text { Beta }-0 \\
\text { Gamma }-0 \\
\text { Delta }-29,9\end{array}$ & $\begin{array}{l}\text { Alpha }-0 \\
\text { Beta }-0 \\
\text { Gamma }-0 \\
\text { Delta }-0\end{array}$ & 0 & $\begin{array}{l}\text { Alpha }-0 \\
\text { Beta }-0 \\
\text { Gamma }-0 \\
\text { Delta }-0\end{array}$ \\
\hline $\begin{array}{c}\text { Парагвай } \\
\text { (рост заболеваемости) }\end{array}$ & $\begin{array}{l}\text { Laboratorio Central de Salud } \\
\text { Publica de Paraguay }\end{array}$ & $\begin{array}{l}\text { Alpha }-6 \\
\text { Beta }-0 \\
\text { Gamma }-104 \\
\text { Delta }-100\end{array}$ & 787 & $\begin{array}{l}\text { Alpha }-0,8 \\
\text { Beta }-0 \\
\text { Gamma }-13,2 \\
\text { Delta }-12,7\end{array}$ & $\begin{array}{l}\text { Alpha }-0 \\
\text { Beta }-0 \\
\text { Gamma }-0 \\
\text { Delta }-0\end{array}$ & 0 & $\begin{array}{l}\text { Alpha }-0 \\
\text { Beta }-0 \\
\text { Gamma }-0 \\
\text { Delta }-0 \\
\end{array}$ \\
\hline $\begin{array}{c}\text { Перу } \\
\text { (снижение заболевае- } \\
\text { мости) }\end{array}$ & $\begin{array}{l}\text { Laboratorio de Referencia } \\
\text { Nacional de Biotecnología y Bi- } \\
\text { ología Molecular. Instituto } \\
\text { Nacional de SaludPerú }\end{array}$ & $\begin{array}{l}\text { Alpha }-24 \\
\text { Beta }-0 \\
\text { Gamma }-1969 \\
\text { Delta }-2906\end{array}$ & 10985 & $\begin{array}{l}\text { Alpha }-0,2 \\
\text { Beta }-0 \\
\text { Gamma }-18,9 \\
\text { Delta }-26,5\end{array}$ & $\begin{array}{l}\text { Alpha }-0 \\
\text { Beta }-0 \\
\text { Gamma }-1 \\
\text { Delta }-35\end{array}$ & 372 & $\begin{array}{l}\text { Alpha }-0 \\
\text { Beta }-0 \\
\text { Gamma }-0,3 \\
\text { Delta }-9,4\end{array}$ \\
\hline $\begin{array}{c}\text { Польша } \\
\text { (рост заболеваемости) }\end{array}$ & $\begin{array}{l}\text { genXone SA, Research \& De- } \\
\text { velopment Laboratory }\end{array}$ & $\begin{array}{l}\text { Alpha }-15369 \\
\text { Beta }-44 \\
\text { Gamma }-25 \\
\text { Delta }-13542\end{array}$ & 31995 & $\begin{array}{l}\text { Alpha }-48,0 \\
\text { Beta }-0,1 \\
\text { Gamma }-0,1 \\
\text { Delta }-42,3\end{array}$ & $\begin{array}{l}\text { Alpha }-0 \\
\text { Beta }-0 \\
\text { Gamma }-0 \\
\text { Delta }-2730\end{array}$ & 3561 & $\begin{array}{l}\text { Alpha }-0 \\
\text { Beta }-0 \\
\text { Gamma }-0 \\
\text { Delta }-76,7\end{array}$ \\
\hline $\begin{array}{c}\text { Португалия } \\
\text { (рост заболеваемости) }\end{array}$ & $\begin{array}{l}\text { Instituto Nacional de } \\
\text { Saude(INSA) }\end{array}$ & $\begin{array}{l}\text { Alpha - 5016 } \\
\text { Beta - } 118 \\
\text { Gamma - } 203 \\
\text { Delta - } 12495 \\
\text { Omicron - } 13 \\
\end{array}$ & 22036 & $\begin{array}{l}\text { Alpha - 22,8 } \\
\text { Beta - 0,5 } \\
\text { Gamma - 0,9 } \\
\text { Delta - 56,7 } \\
\text { Omicron - } 0,1 \\
\end{array}$ & $\begin{array}{l}\text { Alpha }-0 \\
\text { Beta }-0 \\
\text { Gamma }-0 \\
\text { Delta }-1025 \\
\text { Omicron }-13\end{array}$ & 1172 & $\begin{array}{l}\text { Alpha }-0 \\
\text { Beta }-0 \\
\text { Gamma }-0 \\
\text { Delta }-87,5 \\
\text { Omicron }-1,1\end{array}$ \\
\hline Пуэрто Рико & $\begin{array}{l}\text { Centers for Disease Control and } \\
\text { Prevention Division of Viral } \\
\text { Diseases, Pathogen Discovery }\end{array}$ & $\begin{array}{l}\text { Alpha }-947 \\
\text { Beta }-1 \\
\text { Gamma }-68 \\
\text { Delta }-2504\end{array}$ & 4560 & $\begin{array}{l}\text { Alpha }-20,8 \\
\text { Beta }-0 \\
\text { Gamma }-1,5 \\
\text { Delta }-54,9\end{array}$ & $\begin{array}{l}\text { Alpha }-0 \\
\text { Beta }-0 \\
\text { Gamma }-0 \\
\text { Delta }-9\end{array}$ & 13 & $\begin{array}{l}\text { Alpha }-0 \\
\text { Beta }-0 \\
\text { Gamma }-0 \\
\text { Delta }-69,2\end{array}$ \\
\hline $\begin{array}{c}\text { Республика } \\
\text { Джибути } \\
\text { (снижение заболевае- } \\
\text { мости) } \\
\end{array}$ & $\begin{array}{l}\text { Naval Medical Research Center } \\
\text { Biological Defense Research } \\
\text { Di-rectorate }\end{array}$ & $\begin{array}{l}\text { Alpha }-79 \\
\text { Beta }-7 \\
\text { Gamma }-0 \\
\text { Delta }-60\end{array}$ & 366 & $\begin{array}{l}\text { Alpha }-21,6 \\
\text { Beta }-1,9 \\
\text { Gamma }-0 \\
\text { Delta }-16,4\end{array}$ & $\begin{array}{l}\text { Alpha }-0 \\
\text { Beta }-0 \\
\text { Gamma }-0 \\
\text { Delta }-0 \\
\end{array}$ & 0 & $\begin{array}{l}\text { Alpha }-0 \\
\text { Beta }-0 \\
\text { Gamma }-0 \\
\text { Delta }-0\end{array}$ \\
\hline $\begin{array}{c}\text { Республика Конго } \\
\text { (снижение заболевае- } \\
\text { мости) }\end{array}$ & Institute of Tropical Medicine & $\begin{array}{l}\text { Alpha }-33 \\
\text { Beta }-4 \\
\text { Gamma }-1 \\
\text { Delta }-89\end{array}$ & 334 & $\begin{array}{l}\text { Alpha }-10,0 \\
\text { Beta }-1,3 \\
\text { Gamma }-0,3 \\
\text { Delta }-26,6\end{array}$ & $\begin{array}{l}\text { Alpha }-0 \\
\text { Beta }-0 \\
\text { Gamma }-0 \\
\text { Delta }-4\end{array}$ & 8 & $\begin{array}{l}\text { Alpha }-0 \\
\text { Beta }-0 \\
\text { Gamma }-0 \\
\text { Delta }-50,0\end{array}$ \\
\hline
\end{tabular}




\begin{tabular}{|c|c|c|c|c|c|c|c|}
\hline $\begin{array}{c}\text { Республика } \\
\text { Сальвадор } \\
\text { (стабилизация забо- } \\
\text { леваемости) }\end{array}$ & $\begin{array}{l}\text { Genomics and Proteomics De- } \\
\text { partament, Gorgas Memorial In- } \\
\text { stitute For Health Studies }\end{array}$ & $\begin{array}{l}\text { Alpha }-7 \\
\text { Beta }-0 \\
\text { Gamma }-1 \\
\text { Delta }-2\end{array}$ & 244 & $\begin{array}{l}\text { Alpha }-2,9 \\
\text { Beta }-0 \\
\text { Gamma }-0,4 \\
\text { Delta }-0,8\end{array}$ & $\begin{array}{l}\text { Alpha }-0 \\
\text { Beta }-0 \\
\text { Gamma }-0 \\
\text { Delta }-0\end{array}$ & 0 & $\begin{array}{l}\text { Alpha }-0 \\
\text { Beta }-0 \\
\text { Gamma }-0 \\
\text { Delta }-0\end{array}$ \\
\hline $\begin{array}{c}\text { Республика Чад } \\
\text { (стабилизацияе забо- } \\
\text { леваемости) } \\
\end{array}$ & $\begin{array}{l}\text { Pathogen Genomics Lab, Na- } \\
\text { tional Institute for Biomedical } \\
\text { Research (INRB) }\end{array}$ & Alpha - 1 & 9 & Alpha $-11,1$ & Alpha - 0 & 0 & Alpha - 0 \\
\hline Реюньон & $\begin{array}{l}\text { CNR Virus des Infections Res- } \\
\text { piratoires - France SUD }\end{array}$ & $\begin{array}{l}\text { Alpha }-128 \\
\text { Beta }-2663 \\
\text { Gamma }-0 \\
\text { Delta }-1413 \\
\text { Omicron }-1\end{array}$ & 4609 & $\begin{array}{l}\text { Alpha }-2,8 \\
\text { Beta }-57,8 \\
\text { Gamma }-0 \\
\text { Delta }-30,7 \\
\text { Omicron }-0\end{array}$ & $\begin{array}{l}\text { Alpha }-0 \\
\text { Beta }-0 \\
\text { Gamma }-0 \\
\text { Delta }-84 \\
\text { Omicron }-1\end{array}$ & 85 & $\begin{array}{l}\text { Alpha }-0 \\
\text { Beta }-0 \\
\text { Gamma }-0 \\
\text { Delta }-98,8 \\
\text { Omicron }-1,2\end{array}$ \\
\hline $\begin{array}{c}\text { Россия } \\
\text { (снижение заболевае- } \\
\text { мости) }\end{array}$ & $\begin{array}{l}\text { WHO National Influenza Centre } \\
\text { Russian Federation.Center for } \\
\text { Precision Genome Editing and } \\
\text { Genetic Technologies for Bio- } \\
\text { medicine, Pirogov Medical Uni- } \\
\text { versity, Moscow, Russian Fed- } \\
\text { eration.Federal Budget Institu- } \\
\text { tion of Science, State Research } \\
\text { Center for Applied Microbiolo- } \\
\text { gy \& Biotechnology.Group of } \\
\text { Genetic Engeneering and Bio- } \\
\text { technology, Federal Budget In- } \\
\text { stitution of Science 'Central Re- } \\
\text { search Institute of Epidemiolo- } \\
\text { gy' of The Federal Service on } \\
\text { Customers' Rights Protection } \\
\text { and Human Well--being Surveil- } \\
\text { lance.State Research Center of } \\
\text { Virology and Biotechnology } \\
\text { VECTOR, Department of Col- } \\
\text { lection of Microorganisms. }\end{array}$ & $\begin{array}{l}\text { Alpha }-397 \\
\text { Beta }-30 \\
\text { Gamma }-1 \\
\text { Delta }-5536\end{array}$ & 10861 & $\begin{array}{l}\text { Alpha }-3,7 \\
\text { Beta }-0,3 \\
\text { Gamma }-0 \\
\text { Delta }-51,0\end{array}$ & $\begin{array}{l}\text { Alpha }-0 \\
\text { Beta }-0 \\
\text { Gamma }-0 \\
\text { Delta }-121\end{array}$ & 136 & $\begin{array}{l}\text { Alpha }-0 \\
\text { Beta }-0 \\
\text { Gamma }-0 \\
\text { Delta }-89,0\end{array}$ \\
\hline
\end{tabular}




\begin{tabular}{|c|c|c|c|c|c|c|c|}
\hline $\begin{array}{c}\text { Руанда } \\
\text { (снижение заболевае- } \\
\text { мости) }\end{array}$ & GIGA Medical Genomics & $\begin{array}{l}\text { Alpha }-10 \\
\text { Beta }-50 \\
\text { Gamma }-0 \\
\text { Delta }-293\end{array}$ & 707 & $\begin{array}{l}\text { Alpha }-1,4 \\
\text { Beta }-7,1 \\
\text { Gamma }-0 \\
\text { Delta }-41,4\end{array}$ & $\begin{array}{l}\text { Alpha }-0 \\
\text { Beta }-0 \\
\text { Gamma }-0 \\
\text { Delta }-0\end{array}$ & 0 & $\begin{array}{l}\text { Alpha }-0 \\
\text { Beta }-0 \\
\text { Gamma }-0 \\
\text { Delta }-0\end{array}$ \\
\hline $\begin{array}{c}\text { Румыния } \\
\text { (снижение заболевае- } \\
\text { мости) }\end{array}$ & $\begin{array}{l}\text { National Institute of Infectious } \\
\text { Diseases-Prof. Dr. Matei Bals } \\
\text { Molecular Diagnostics Laborato- } \\
\text { ry }\end{array}$ & $\begin{array}{l}\text { Alpha }-1657 \\
\text { Beta }-8 \\
\text { Gamma }-17 \\
\text { Delta }-4680 \\
\end{array}$ & 7722 & $\begin{array}{l}\text { Alpha }-21,5 \\
\text { Beta }-0,1 \\
\text { Gamma }-0,2 \\
\text { Delta }-60,6\end{array}$ & $\begin{array}{l}\text { Alpha }-0 \\
\text { Beta }-0 \\
\text { Gamma }-0 \\
\text { Delta }-88\end{array}$ & 91 & $\begin{array}{l}\text { Alpha }-0 \\
\text { Beta }-0 \\
\text { Gamma }-0 \\
\text { Delta }-96,7\end{array}$ \\
\hline $\begin{array}{c}\text { Саудовская Аравия } \\
\text { (снижение заболевае- } \\
\text { мости) }\end{array}$ & $\begin{array}{l}\text { Infectious Diseases, King Faisal } \\
\text { Hospital Research Center }\end{array}$ & $\begin{array}{l}\text { Alpha }-19 \\
\text { Beta }-17 \\
\text { Gamma }-0 \\
\text { Delta }-14\end{array}$ & 1169 & $\begin{array}{l}\text { Alpha }-1,6 \\
\text { Beta }-1,5 \\
\text { Gamma }-0 \\
\text { Delta }-1,2 \\
\end{array}$ & $\begin{array}{l}\text { Alpha }-0 \\
\text { Beta }-0 \\
\text { Gamma }-0 \\
\text { Delta }-0\end{array}$ & 0 & $\begin{array}{l}\text { Alpha }-0 \\
\text { Beta }-0 \\
\text { Gamma }-0 \\
\text { Delta }-0\end{array}$ \\
\hline $\begin{array}{c}\text { Северная } \\
\text { Македония } \\
\text { (снижение заболевае- } \\
\text { мости) } \\
\end{array}$ & $\begin{array}{l}\text { Institute of Public Health of Re- } \\
\text { public of North Macedonia La- } \\
\text { boratory of Virology and Mo- } \\
\text { lecular Diagnostics }\end{array}$ & $\begin{array}{l}\text { Alpha }-273 \\
\text { Beta }-1 \\
\text { Gamma }-0 \\
\text { Delta }-86 \\
\end{array}$ & 750 & $\begin{array}{l}\text { Alpha }-36,4 \\
\text { Beta }-0,1 \\
\text { Gamma }-0 \\
\text { Delta }-11,5 \\
\end{array}$ & $\begin{array}{l}\text { Alpha }-0 \\
\text { Beta }-0 \\
\text { Gamma }-0 \\
\text { Delta }-37\end{array}$ & 37 & $\begin{array}{l}\text { Alpha }-0 \\
\text { Beta }-0 \\
\text { Gamma }-0 \\
\text { Delta }-100,0\end{array}$ \\
\hline $\begin{array}{c}\text { Северные } \\
\text { Марианские острова }\end{array}$ & $\begin{array}{l}\text { Centers for Disease Control and } \\
\text { Prevention Division of Viral } \\
\text { Diseases, Pathogen Discovery }\end{array}$ & $\begin{array}{l}\text { Alpha }-3 \\
\text { Beta }-0 \\
\text { Gamma }-0 \\
\text { Delta }-89 \\
\end{array}$ & 222 & $\begin{array}{l}\text { Alpha }-1,4 \\
\text { Beta }-0 \\
\text { Gamma }-0 \\
\text { Delta }-40,1 \\
\end{array}$ & $\begin{array}{l}\text { Alpha }-0 \\
\text { Beta }-0 \\
\text { Gamma }-0 \\
\text { Delta }-0 \\
\end{array}$ & 1 & $\begin{array}{l}\text { Alpha }-0 \\
\text { Beta }-0 \\
\text { Gamma }-0 \\
\text { Delta }-0 \\
\end{array}$ \\
\hline $\begin{array}{c}\text { Сейшелы } \\
\text { (снижение заболевае- } \\
\text { мости) }\end{array}$ & $\begin{array}{l}\text { KEMRI- Wellcome Trust Re- } \\
\text { search Programme,Kilifi }\end{array}$ & $\begin{array}{l}\text { Alpha }-5 \\
\text { Beta }-28 \\
\text { Gamma }-1 \\
\text { Delta }-497 \\
\end{array}$ & 543 & $\begin{array}{l}\text { Alpha }-0,9 \\
\text { Beta }-5,2 \\
\text { Gamma }-0,2 \\
\text { Delta }-90,8 \\
\end{array}$ & $\begin{array}{l}\text { Alpha }-0 \\
\text { Beta }-0 \\
\text { Gamma }-0 \\
\text { Delta }-0 \\
\end{array}$ & 0 & $\begin{array}{l}\text { Alpha }-0 \\
\text { Beta }-0 \\
\text { Gamma }-0 \\
\text { Delta }-0 \\
\end{array}$ \\
\hline $\begin{array}{c}\text { Сенегал } \\
\text { (рост заболеваемости) }\end{array}$ & IRESSEF GENOMICS LAB & $\begin{array}{l}\text { Alpha }-35 \\
\text { Beta }-0 \\
\text { Gamma }-0 \\
\text { Delta }-99\end{array}$ & 685 & $\begin{array}{l}\text { Alpha }-5,1 \\
\text { Beta }-0 \\
\text { Gamma }-0 \\
\text { Delta }-14,5\end{array}$ & $\begin{array}{l}\text { Alpha }-0 \\
\text { Beta }-0 \\
\text { Gamma }-0 \\
\text { Delta }-1\end{array}$ & 4 & $\begin{array}{l}\text { Alpha }-0 \\
\text { Beta }-0 \\
\text { Gamma }-0 \\
\text { Delta }-25,0\end{array}$ \\
\hline Сент-Бартелеми & $\begin{array}{l}\text { National Reference Center for } \\
\text { Viruses of Respiratory Infec- } \\
\text { tions, Institut Pasteur, Paris } \\
\text { Institut Pasteur de la Guadeloupe }\end{array}$ & $\begin{array}{l}\text { Alpha }-0 \\
\text { Beta }-0 \\
\text { Gamma }-0 \\
\text { Delta }-12\end{array}$ & 14 & $\begin{array}{l}\text { Alpha }-0 \\
\text { Beta }-0 \\
\text { Gamma }-0 \\
\text { Delta }-85,7\end{array}$ & $\begin{array}{l}\text { Alpha }-0 \\
\text { Beta }-0 \\
\text { Gamma }-0 \\
\text { Delta }-0\end{array}$ & 2 & $\begin{array}{l}\text { Alpha -0 } \\
\text { Beta - 0 } \\
\text { Gamma - } 0 \\
\text { Delta -0 }\end{array}$ \\
\hline Сент-Винсент и & Carrington Lab, Department of & Alpha -0 & 38 & Alpha - 0 & Alpha - 0 & 0 & Alpha -0 \\
\hline
\end{tabular}




\begin{tabular}{|c|c|c|c|c|c|c|c|}
\hline $\begin{array}{c}\text { Гренадины } \\
\text { (стабилизация забо- } \\
\text { леваемости) }\end{array}$ & $\begin{array}{l}\text { PreClinical Sciences, Faculty of } \\
\text { Medical Sciences, The Universi- } \\
\text { ty of the West Indies }\end{array}$ & $\begin{array}{l}\text { Beta }-0 \\
\text { Gamma }-8 \\
\text { Delta }-2\end{array}$ & & $\begin{array}{l}\text { Beta }-0 \\
\text { Gamma }-21,1 \\
\text { Delta }-5,3\end{array}$ & $\begin{array}{l}\text { Beta }-0 \\
\text { Gamma }-0 \\
\text { Delta }-0\end{array}$ & & $\begin{array}{l}\text { Beta }-0 \\
\text { Gamma }-0 \\
\text { Delta }-0\end{array}$ \\
\hline $\begin{array}{c}\text { Сент-Люсия } \\
\text { (рост заболеваемости) }\end{array}$ & $\begin{array}{l}\text { Carrington Lab, Department of } \\
\text { PreClinical Sciences }\end{array}$ & $\begin{array}{l}\text { Alpha }-34 \\
\text { Beta }-0 \\
\text { Gamma }-0 \\
\text { Delta }-7\end{array}$ & 52 & $\begin{array}{l}\text { Alpha }-65,4 \\
\text { Beta }-0 \\
\text { Gamma }-0 \\
\text { Delta }-13,5\end{array}$ & $\begin{array}{l}\text { Alpha }-0 \\
\text { Beta }-0 \\
\text { Gamma }-0 \\
\text { Delta }-0 \\
\end{array}$ & 0 & $\begin{array}{l}\text { Alpha }-0 \\
\text { Beta }-0 \\
\text { Gamma }-0 \\
\text { Delta }-0 \\
\end{array}$ \\
\hline $\begin{array}{c}\text { Сербия } \\
\text { (снижение заболевае- } \\
\text { мости) }\end{array}$ & $\begin{array}{l}\text { Institute of microbiology and } \\
\text { Immunology, Faculty of Medi- } \\
\text { cine, University of Belgrade }\end{array}$ & $\begin{array}{l}\text { Alpha }-78 \\
\text { Beta }-0 \\
\text { Gamma }-1 \\
\text { Delta }-58\end{array}$ & 532 & $\begin{array}{l}\text { Alpha }-14,7 \\
\text { Beta }-0 \\
\text { Gamma }-0,2 \\
\text { Delta }-10,9\end{array}$ & $\begin{array}{l}\text { Alpha }-0 \\
\text { Beta }-0 \\
\text { Gamma }-0 \\
\text { Delta }-0\end{array}$ & 0 & $\begin{array}{l}\text { Alpha }-0 \\
\text { Beta }-0 \\
\text { Gamma }-0 \\
\text { Delta }-0\end{array}$ \\
\hline $\begin{array}{c}\text { Сингапур } \\
\text { (снижение заболевае- } \\
\text { мости) }\end{array}$ & $\begin{array}{l}\text { National Public Health Labora- } \\
\text { tory, National Centre for Infec- } \\
\text { tious Diseases }\end{array}$ & $\begin{array}{l}\text { Alpha }-190 \\
\text { Beta }-203 \\
\text { Gamma }-8 \\
\text { Delta }-7750\end{array}$ & 10151 & $\begin{array}{l}\text { Alpha }-1,9 \\
\text { Beta }-2,0 \\
\text { Gamma }-0,1 \\
\text { Delta }-76,3\end{array}$ & $\begin{array}{l}\text { Alpha }-0 \\
\text { Beta }-0 \\
\text { Gamma }-0 \\
\text { Delta }-808\end{array}$ & 850 & $\begin{array}{l}\text { Alpha }-0 \\
\text { Beta }-0 \\
\text { Gamma }-0 \\
\text { Delta }-95,1\end{array}$ \\
\hline Синт-Мартен & $\begin{array}{l}\text { National Institute for Public } \\
\text { Health and the Environ- } \\
\text { ment(RIVM) }\end{array}$ & $\begin{array}{l}\text { Alpha }-430 \\
\text { Beta }-1 \\
\text { Gamma }-1 \\
\text { Delta }-1231\end{array}$ & 1749 & $\begin{array}{l}\text { Alpha }-24,6 \\
\text { Beta }-0,1 \\
\text { Gamma }-0,1 \\
\text { Delta }-70,4\end{array}$ & $\begin{array}{l}\text { Alpha }-0 \\
\text { Beta }-0 \\
\text { Gamma }-0 \\
\text { Delta }-4 \\
\end{array}$ & 0 & $\begin{array}{l}\text { Alpha }-0 \\
\text { Beta }-0 \\
\text { Gamma }-0 \\
\text { Delta }-50,0\end{array}$ \\
\hline $\begin{array}{c}\text { Словакия } \\
\text { (снижение заболевае- } \\
\text { мости) }\end{array}$ & $\begin{array}{l}\text { Faculty of Natural Sciences, } \\
\text { Comenius University }\end{array}$ & $\begin{array}{l}\text { Alpha }-4582 \\
\text { Beta }-31 \\
\text { Gamma }-0 \\
\text { Delta }-8683 \\
\end{array}$ & 13672 & $\begin{array}{l}\text { Alpha }-33,5 \\
\text { Beta }-0,2 \\
\text { Gamma }-0 \\
\text { Delta }-63,5\end{array}$ & $\begin{array}{l}\text { Alpha }-0 \\
\text { Beta }-0 \\
\text { Gamma }-0 \\
\text { Delta }-553\end{array}$ & 821 & $\begin{array}{l}\text { Alpha }-0 \\
\text { Beta }-0 \\
\text { Gamma }-0 \\
\text { Delta }-67,4\end{array}$ \\
\hline $\begin{array}{c}\text { Словения } \\
\text { (снижение заболевае- } \\
\text { мости) }\end{array}$ & $\begin{array}{l}\text { Institute of Microbiology and } \\
\text { Immunology, Faculty of Medi- } \\
\text { cine, University of Ljubljana }\end{array}$ & $\begin{array}{l}\text { Alpha }-8511 \\
\text { Beta }-31 \\
\text { Gamma }-11 \\
\text { Delta }-13439\end{array}$ & 33748 & $\begin{array}{l}\text { Alpha }-25,2 \\
\text { Beta }-0,1 \\
\text { Gamma }-0 \\
\text { Delta }-39,8\end{array}$ & $\begin{array}{l}\text { Alpha }-0 \\
\text { Beta }-0 \\
\text { Gamma }-0 \\
\text { Delta }-0\end{array}$ & 0 & $\begin{array}{l}\text { Alpha }-0 \\
\text { Beta }-0 \\
\text { Gamma }-0 \\
\text { Delta }-0\end{array}$ \\
\hline $\begin{array}{c}\text { Сомали } \\
\text { (снижение заболевае- } \\
\text { мости) }\end{array}$ & $\begin{array}{l}\text { African Centre of Excellence for } \\
\text { Genomics of Infectious Diseas- } \\
\text { es(ACEGID), Redeemer's Uni- } \\
\text { versity }\end{array}$ & $\begin{array}{l}\text { Alpha }-7 \\
\text { Beta }-4 \\
\text { Gamma }-0 \\
\text { Delta }-0\end{array}$ & 37 & $\begin{array}{l}\text { Alpha }-18,9 \\
\text { Beta }-10,8 \\
\text { Gamma }-0 \\
\text { Delta }-0\end{array}$ & $\begin{array}{l}\text { Alpha }-0 \\
\text { Beta }-0 \\
\text { Gamma }-0 \\
\text { Delta }-0 \\
\end{array}$ & 0 & $\begin{array}{l}\text { Alpha }-0 \\
\text { Beta }-0 \\
\text { Gamma }-0 \\
\text { Delta }-0 \\
\end{array}$ \\
\hline $\begin{array}{c}\text { Судан } \\
\text { (снижение заболевае- }\end{array}$ & $\begin{array}{l}\text { National Institute for Communi- } \\
\text { cable Diseases of the National }\end{array}$ & $\begin{array}{l}\text { Alpha - } 2 \\
\text { Beta }-13\end{array}$ & 116 & $\begin{array}{l}\text { Alpha }-1,7 \\
\text { Beta }-11,2\end{array}$ & $\begin{array}{l}\text { Alpha -0 } \\
\text { Beta }-0\end{array}$ & 0 & $\begin{array}{l}\text { Alpha }-0 \\
\text { Beta }-0\end{array}$ \\
\hline
\end{tabular}




\begin{tabular}{|c|c|c|c|c|c|c|c|}
\hline мости) & Health Laboratory Service & $\begin{array}{l}\text { Gamma }-0 \\
\text { Delta }-0\end{array}$ & & $\begin{array}{l}\text { Gamma }-0 \\
\text { Delta }-0\end{array}$ & $\begin{array}{l}\text { Gamma }-0 \\
\text { Delta }-0\end{array}$ & & $\begin{array}{l}\text { Gamma }-0 \\
\text { Delta }-0\end{array}$ \\
\hline $\begin{array}{c}\text { Суринам } \\
\text { (снижение заболевае- } \\
\text { мости) }\end{array}$ & $\begin{array}{l}\text { National Institute for Public } \\
\text { Health and the Environ- } \\
\text { ment(RIVM) }\end{array}$ & $\begin{array}{l}\text { Alpha }-47 \\
\text { Beta }-5 \\
\text { Gamma }-377 \\
\text { Delta }-150\end{array}$ & 804 & $\begin{array}{l}\text { Alpha }-5,8 \\
\text { Beta }-0,6 \\
\text { Gamma }-46,9 \\
\text { Delta }-18,7\end{array}$ & $\begin{array}{l}\text { Alpha }-0 \\
\text { Beta }-0 \\
\text { Gamma }-0 \\
\text { Delta }-0\end{array}$ & 0 & $\begin{array}{l}\text { Alpha }-0 \\
\text { Beta }-0 \\
\text { Gamma }-0 \\
\text { Delta }-0\end{array}$ \\
\hline $\begin{array}{c}\text { США } \\
\text { (рост заболеваемости) }\end{array}$ & $\begin{array}{l}\text { Colorado Department of Public } \\
\text { Health \& Environment.Maine } \\
\text { Health and Environmental Test- } \\
\text { ing Laboratory.California De- } \\
\text { partment of Public Health. } \\
\text { UCSD EXCITE. }\end{array}$ & $\begin{array}{l}\text { Alpha }-236883 \\
\text { Beta }-3037 \\
\text { Gamma }-29109 \\
\text { Delta }-1011486\end{array}$ & 1776726 & $\begin{array}{l}\text { Alpha }-13,3 \\
\text { Beta }-0,2 \\
\text { Gamma }-1,6 \\
\text { Delta }-56,9\end{array}$ & $\begin{array}{l}\text { Alpha }-1 \\
\text { Beta }-0 \\
\text { Gamma }-0 \\
\text { Delta }- \\
50631\end{array}$ & 65579 & $\begin{array}{l}\text { Alpha }-0 \\
\text { Beta }-0 \\
\text { Gamma }-0 \\
\text { Delta }-77,2\end{array}$ \\
\hline $\begin{array}{c}\text { Сьерра-Леоне } \\
\text { (снижение заболевае- } \\
\text { мости) }\end{array}$ & $\begin{array}{l}\text { Central Public Health Reference } \\
\text { Laboratory }\end{array}$ & $\begin{array}{l}\text { Alpha }-0 \\
\text { Beta }-0 \\
\text { Gamma }-0 \\
\text { Delta }-22\end{array}$ & 59 & $\begin{array}{l}\text { Alpha }-0 \\
\text { Beta }-0 \\
\text { Gamma }-0 \\
\text { Delta }-37,3\end{array}$ & $\begin{array}{l}\text { Alpha }-0 \\
\text { Beta }-0 \\
\text { Gamma }-0 \\
\text { Delta }-0\end{array}$ & 0 & $\begin{array}{l}\text { Alpha }-0 \\
\text { Beta }-0 \\
\text { Gamma }-0 \\
\text { Delta }-0\end{array}$ \\
\hline $\begin{array}{c}\text { Таиланд } \\
\text { (снижение заболевае- } \\
\text { мости) }\end{array}$ & $\begin{array}{l}\text { COVID-19 Network Investiga- } \\
\text { tions(CONI) Alliance }\end{array}$ & $\begin{array}{l}\text { Alpha }-2020 \\
\text { Beta }-109 \\
\text { Gamma }-1 \\
\text { Delta }-4943\end{array}$ & 8355 & $\begin{array}{l}\text { Alpha }-24,2 \\
\text { Beta }-1,3 \\
\text { Gamma }-0 \\
\text { Delta }-59,2\end{array}$ & $\begin{array}{l}\text { Alpha }-0 \\
\text { Beta }-0 \\
\text { Gamma }-0 \\
\text { Delta }-92\end{array}$ & 98 & $\begin{array}{l}\text { Alpha }-0 \\
\text { Beta }-0 \\
\text { Gamma }-0 \\
\text { Delta }-93,9\end{array}$ \\
\hline Тайвань & $\begin{array}{l}\text { Microbial Genomics Core Lab, } \\
\text { National Taiwan University } \\
\text { Centers of Genomic and Preci- } \\
\text { sion Medicine }\end{array}$ & $\begin{array}{l}\text { Alpha }-56 \\
\text { Beta }-4 \\
\text { Gamma }-6 \\
\text { Delta }-15\end{array}$ & 263 & $\begin{array}{l}\text { Alpha }-21,3 \\
\text { Beta }-1,5 \\
\text { Gamma }-2,3 \\
\text { Delta }-5,7\end{array}$ & $\begin{array}{l}\text { Alpha }-0 \\
\text { Beta }-0 \\
\text { Gamma }-0 \\
\text { Delta }-0 \\
\end{array}$ & 0 & $\begin{array}{l}\text { Alpha }-0 \\
\text { Beta }-0 \\
\text { Gamma }-0 \\
\text { Delta }-0 \\
\end{array}$ \\
\hline Теркс и Кайкос & $\begin{array}{l}\text { Carrington Lab, Department of } \\
\text { Preclinical Sciences, Faculty of } \\
\text { Medical Sciences, The Universi- } \\
\text { ty of the West Indies, St Augus- } \\
\text { tine Campus }\end{array}$ & $\begin{array}{l}\text { Alpha }-5 \\
\text { Beta }-0 \\
\text { Gamma }-0 \\
\text { Delta }-4\end{array}$ & 16 & $\begin{array}{l}\text { Alpha }-31,3 \\
\text { Beta }-0 \\
\text { Gamma }-0 \\
\text { Delta }-25,0\end{array}$ & $\begin{array}{l}\text { Alpha }-0 \\
\text { Beta }-0 \\
\text { Gamma }-0 \\
\text { Delta }-0\end{array}$ & 0 & $\begin{array}{l}\text { Alpha }-0 \\
\text { Beta }-0 \\
\text { Gamma }-0 \\
\text { Delta }-0\end{array}$ \\
\hline Тимор-Лешти & $\begin{array}{l}\text { Microbiological Diagnostic Unit } \\
\text { - Public Health Laboratory } \\
\text { (MDU-PHL) }\end{array}$ & $\begin{array}{l}\text { Alpha }-0 \\
\text { Beta }-0 \\
\text { Gamma }-0 \\
\text { Delta }-33\end{array}$ & 356 & $\begin{array}{l}\text { Alpha }-0 \\
\text { Beta }-0 \\
\text { Gamma }-0 \\
\text { Delta }-9,3\end{array}$ & $\begin{array}{l}\text { Alpha }-0 \\
\text { Beta }-0 \\
\text { Gamma }-0 \\
\text { Delta }-0\end{array}$ & 0 & $\begin{array}{l}\text { Alpha }-0 \\
\text { Beta }-0 \\
\text { Gamma }-0 \\
\text { Delta }-0\end{array}$ \\
\hline
\end{tabular}




\begin{tabular}{|c|c|c|c|c|c|c|c|}
\hline $\begin{array}{c}\text { Того } \\
\text { (рост заболеваемости) }\end{array}$ & \begin{tabular}{|l} 
Unité Mixte Internationale \\
TransVIHMI(UMI 233 IRD - \\
U1175 INSERM - Université de \\
Montpellier) IRD(Institut de re- \\
cherche pour le développement)
\end{tabular} & $\begin{array}{l}\text { Alpha }-34 \\
\text { Beta }-6 \\
\text { Gamma }-1 \\
\text { Delta }-130\end{array}$ & 362 & $\begin{array}{l}\text { Alpha }-9,4 \\
\text { Beta }-1,7 \\
\text { Gamma }-0,3 \\
\text { Delta }-35,9\end{array}$ & $\begin{array}{l}\text { Alpha }-0 \\
\text { Beta }-0 \\
\text { Gamma }-0 \\
\text { Delta }-0\end{array}$ & 0 & $\begin{array}{l}\text { Alpha }-0 \\
\text { Beta }-0 \\
\text { Gamma }-0 \\
\text { Delta }-0\end{array}$ \\
\hline $\begin{array}{c}\text { Тринидад и Тобаго } \\
\text { (рост заболеваемости) }\end{array}$ & $\begin{array}{l}\text { Carrington Lab, Department of } \\
\text { PreClinical Sciences, Faculty of } \\
\text { Medical Sciences, The Universi- } \\
\text { ty of the West Indies }\end{array}$ & $\begin{array}{l}\text { Alpha }-9 \\
\text { Beta }-0 \\
\text { Gamma }-473 \\
\text { Delta }-114 \\
\end{array}$ & 982 & $\begin{array}{l}\text { Alpha }-0,9 \\
\text { Beta }-0 \\
\text { Gamma }-48,2 \\
\text { Delta }-11,6 \\
\end{array}$ & $\begin{array}{l}\text { Alpha }-0 \\
\text { Beta }-0 \\
\text { Gamma }-0 \\
\text { Delta }-0 \\
\end{array}$ & 28 & $\begin{array}{l}\text { Alpha }-0 \\
\text { Beta }-0 \\
\text { Gamma }-0 \\
\text { Delta }-0\end{array}$ \\
\hline $\begin{array}{c}\text { Тунис } \\
\text { (рост заболеваемости) }\end{array}$ & $\begin{array}{l}\text { Laboratoire de linique linique - } \\
\text { Institut Pasteur de Tunis }\end{array}$ & $\begin{array}{l}\text { Alpha }-6 \\
\text { Beta }-3 \\
\text { Gamma }-0 \\
\text { Delta }-1 \\
\end{array}$ & 132 & $\begin{array}{l}\text { Alpha }-4,5 \\
\text { Beta }-2,3 \\
\text { Gamma }-0 \\
\text { Delta }-0,8 \\
\end{array}$ & $\begin{array}{l}\text { Alpha }-0 \\
\text { Beta }-0 \\
\text { Gamma }-0 \\
\text { Delta }-0\end{array}$ & 0 & $\begin{array}{l}\text { Alpha }-0 \\
\text { Beta }-0 \\
\text { Gamma }-0 \\
\text { Delta }-0\end{array}$ \\
\hline $\begin{array}{c}\text { Турция } \\
\text { (снижение заболевае- } \\
\text { мости) }\end{array}$ & Ministry of Health Turkey & $\begin{array}{l}\text { Alpha }-1917 \\
\text { Beta }-503 \\
\text { Gamma }-211 \\
\text { Delta }-51794 \\
\end{array}$ & 72532 & $\begin{array}{l}\text { Alpha }-2,6 \\
\text { Beta }-0,7 \\
\text { Gamma }-0,3 \\
\text { Delta }-71,4 \\
\end{array}$ & $\begin{array}{l}\text { Alpha }-0 \\
\text { Beta }-0 \\
\text { Gamma }-0 \\
\text { Delta }-2505\end{array}$ & 3314 & $\begin{array}{l}\text { Alpha }-0 \\
\text { Beta }-0 \\
\text { Gamma }-0 \\
\text { Delta }-75,6\end{array}$ \\
\hline $\begin{array}{c}\text { Уганда } \\
\text { (рост заболеваемости) }\end{array}$ & $\begin{array}{l}\text { MRC/UVRI \& LSHTM Uganda } \\
\text { Research Unit }\end{array}$ & $\begin{array}{l}\text { Alpha }-17 \\
\text { Beta }-15 \\
\text { Gamma }-0 \\
\text { Delta }-340 \\
\end{array}$ & 820 & \begin{tabular}{|l|} 
Alpha $-2,1$ \\
Beta $-1,8$ \\
Gamma -0 \\
Delta $-41,5$ \\
\end{tabular} & $\begin{array}{l}\text { Alpha }-0 \\
\text { Beta }-0 \\
\text { Gamma }-0 \\
\text { Delta }-0 \\
\end{array}$ & 0 & $\begin{array}{l}\text { Alpha }-0 \\
\text { Beta }-0 \\
\text { Gamma }-0 \\
\text { Delta }-0 \\
\end{array}$ \\
\hline $\begin{array}{c}\text { Узбекистан } \\
\text { (снижение заболевае- } \\
\text { мости) }\end{array}$ & $\begin{array}{l}\text { Biotechnology laboratory, Cen- } \\
\text { ter for advanced technology }\end{array}$ & $\begin{array}{l}\text { Alpha }-2 \\
\text { Beta }-0 \\
\text { Gamma }-0 \\
\text { Delta }-47 \\
\end{array}$ & 90 & $\begin{array}{l}\text { Alpha }-2,2 \\
\text { Beta }-0 \\
\text { Gamma }-0 \\
\text { Delta }-52,2 \\
\end{array}$ & $\begin{array}{l}\text { Alpha }-0 \\
\text { Beta }-0 \\
\text { Gamma }-0 \\
\text { Delta }-0 \\
\end{array}$ & 0 & $\begin{array}{l}\text { Alpha }-0 \\
\text { Beta }-0 \\
\text { Gamma }-0 \\
\text { Delta }-0\end{array}$ \\
\hline $\begin{array}{c}\text { Украина } \\
\text { (снижение заболевае- } \\
\text { мости) }\end{array}$ & $\begin{array}{l}\text { Department of Respiratory and } \\
\text { other Viral Infections of } \\
\text { L.V.Gromashevsky Institute of } \\
\text { Epidemiology \& Infectious Dis- } \\
\text { eases NAMS of Ukraine, JSC } \\
\text { "Farmak" } \\
\end{array}$ & $\begin{array}{l}\text { Alpha }-116 \\
\text { Beta }-0 \\
\text { Gamma }-0 \\
\text { Delta }-226\end{array}$ & 535 & $\begin{array}{l}\text { Alpha }-31,7 \\
\text { Beta }-0 \\
\text { Gamma }-0 \\
\text { Delta }-42,2\end{array}$ & $\begin{array}{l}\text { Alpha }-0 \\
\text { Beta }-0 \\
\text { Gamma }-0 \\
\text { Delta }-0\end{array}$ & 0 & $\begin{array}{l}\text { Alpha }-0 \\
\text { Beta }-0 \\
\text { Gamma }-0 \\
\text { Delta }-0\end{array}$ \\
\hline Уоллис и Футуна & $\begin{array}{l}\text { CNR Virus des Infections Res- } \\
\text { piratoires - France SUD }\end{array}$ & $\begin{array}{l}\text { Alpha }-10 \\
\text { Beta }-0\end{array}$ & 10 & $\begin{array}{l}\text { Alpha - 100,0 } \\
\text { Beta }-0\end{array}$ & $\begin{array}{l}\text { Alpha -0 } \\
\text { Beta }-0\end{array}$ & 0 & $\begin{array}{l}\text { Alpha -0 } \\
\text { Beta }-0\end{array}$ \\
\hline
\end{tabular}




\begin{tabular}{|c|c|c|c|c|c|c|c|}
\hline & & $\begin{array}{l}\text { Gamma }-0 \\
\text { Delta }-0 \\
\end{array}$ & & $\begin{array}{l}\text { Gamma }-0 \\
\text { Delta }-0 \\
\end{array}$ & $\begin{array}{l}\text { Gamma - } 0 \\
\text { Delta - } 0\end{array}$ & & $\begin{array}{l}\text { Gamma }-0 \\
\text { Delta }-0\end{array}$ \\
\hline $\begin{array}{c}\text { Уругвай } \\
\text { (рост заболеваемости) }\end{array}$ & $\begin{array}{l}\text { Centro de Innovación en Vigi- } \\
\text { lancia Epidemiológica(CiVE), } \\
\text { Institut Pasteur Montevideo, } \\
\text { Uruguay }\end{array}$ & $\begin{array}{l}\text { Alpha }-0 \\
\text { Beta }-0 \\
\text { Gamma }-174 \\
\text { Delta }-0 \\
\end{array}$ & 739 & $\begin{array}{l}\text { Alpha }-0 \\
\text { Beta }-0 \\
\text { Gamma }-23,5 \\
\text { Delta }-0 \\
\end{array}$ & $\begin{array}{l}\text { Alpha }-0 \\
\text { Beta }-0 \\
\text { Gamma }-0 \\
\text { Delta }-0 \\
\end{array}$ & 0 & $\begin{array}{l}\text { Alpha }-0 \\
\text { Beta }-0 \\
\text { Gamma }-0 \\
\text { Delta }-0\end{array}$ \\
\hline Фарерские острова & $\begin{array}{l}\text { Faroese National Reference La- } \\
\text { boratory for Fish and Animal } \\
\text { Diseases }\end{array}$ & $\begin{array}{l}\text { Alpha }-2 \\
\text { Beta }-0 \\
\text { Gamma }-1 \\
\text { Delta }-0\end{array}$ & 42 & $\begin{array}{l}\text { Alpha }-4,8 \\
\text { Beta }-0 \\
\text { Gamma }-2,4 \\
\text { Delta }-0\end{array}$ & $\begin{array}{l}\text { Alpha }-0 \\
\text { Beta }-0 \\
\text { Gamma }-0 \\
\text { Delta }-0\end{array}$ & 0 & $\begin{array}{l}\text { Alpha }-0 \\
\text { Beta }-0 \\
\text { Gamma }-0 \\
\text { Delta }-0\end{array}$ \\
\hline $\begin{array}{c}\text { Фиджи } \\
\text { (рост заболеваемости) }\end{array}$ & $\begin{array}{l}\text { Microbiological Diagnostic Unit } \\
\text { - Public Health Laboratory } \\
\text { (MDU-PHL) }\end{array}$ & $\begin{array}{l}\text { Alpha }-4 \\
\text { Beta }-0 \\
\text { Gamma }-0 \\
\text { Delta }-507 \\
\end{array}$ & 531 & $\begin{array}{l}\text { Alpha }-0,8 \\
\text { Beta }-0 \\
\text { Gamma }-0 \\
\text { Delta }-95,5 \\
\end{array}$ & $\begin{array}{l}\text { Alpha }-0 \\
\text { Beta }-0 \\
\text { Gamma }-0 \\
\text { Delta }-0\end{array}$ & 0 & $\begin{array}{l}\text { Alpha }-0 \\
\text { Beta }-0 \\
\text { Gamma }-0 \\
\text { Delta }-0\end{array}$ \\
\hline $\begin{array}{c}\text { Филиппины } \\
\text { (снижение заболевае- } \\
\text { мости) }\end{array}$ & Philippine Genome Center & $\begin{array}{l}\text { Alpha }-2719 \\
\text { Beta }-3182 \\
\text { Gamma }-5 \\
\text { Delta }-3220\end{array}$ & 12767 & $\begin{array}{l}\text { Alpha }-21,3 \\
\text { Beta }-24,9 \\
\text { Gamma }-0 \\
\text { Delta }-25,2\end{array}$ & $\begin{array}{l}\text { Alpha }-0 \\
\text { Beta }-0 \\
\text { Gamma }-0 \\
\text { Delta }-0\end{array}$ & 0 & $\begin{array}{l}\text { Alpha }-0 \\
\text { Beta }-0 \\
\text { Gamma }-0 \\
\text { Delta }-0\end{array}$ \\
\hline $\begin{array}{c}\text { Финляндия } \\
\text { (рост заболеваемости) }\end{array}$ & $\begin{array}{l}\text { Department of Virology, Faculty } \\
\text { of Medicine, University of Hel- } \\
\text { sinki }\end{array}$ & $\begin{array}{l}\text { Alpha }-6177 \\
\text { Beta }-1149 \\
\text { Gamma }-20 \\
\text { Delta }-9234 \\
\end{array}$ & 21846 & $\begin{array}{l}\text { Alpha }-28,3 \\
\text { Beta }-5,3 \\
\text { Gamma }-0,1 \\
\text { Delta }-42,3 \\
\end{array}$ & $\begin{array}{l}\text { Alpha }-0 \\
\text { Beta }-0 \\
\text { Gamma }-0 \\
\text { Delta }-0 \\
\end{array}$ & 0 & $\begin{array}{l}\text { Alpha }-0 \\
\text { Beta }-0 \\
\text { Gamma }-0 \\
\text { Delta }-0 \\
\end{array}$ \\
\hline $\begin{array}{c}\text { Франция } \\
\text { (рост заболеваемости) }\end{array}$ & $\begin{array}{l}\text { CNR Virus des Infections Res- } \\
\text { piratoires - France SUD }\end{array}$ & $\begin{array}{l}\text { Alpha }-34979 \\
\text { Beta }-3399 \\
\text { Gamma }-741 \\
\text { Delta }-78571\end{array}$ & 146631 & $\begin{array}{l}\text { Alpha }-23,9 \\
\text { Beta }-2,3 \\
\text { Gamma }-0,5 \\
\text { Delta }-53,6\end{array}$ & $\begin{array}{l}\text { Alpha }-2 \\
\text { Beta }-0 \\
\text { Gamma }-0 \\
\text { Delta }-4567\end{array}$ & 6072 & $\begin{array}{l}\text { Alpha }-0 \\
\text { Beta }-0 \\
\text { Gamma }-0 \\
\text { Delta }-75,2\end{array}$ \\
\hline $\begin{array}{c}\text { Французская } \\
\text { Гвиана }\end{array}$ & $\begin{array}{l}\text { National Reference Center for } \\
\text { Viruses of Respiratory Infec- } \\
\text { tions, Institut Pasteur, Paris }\end{array}$ & $\begin{array}{l}\text { Alpha }-61 \\
\text { Beta }-2 \\
\text { Gamma }-414 \\
\text { Delta }-291 \\
\end{array}$ & 962 & $\begin{array}{l}\text { Alpha }-6,3 \\
\text { Beta }-0,2 \\
\text { Gamma }-43,0 \\
\text { Delta }-30,2\end{array}$ & $\begin{array}{l}\text { Alpha }-0 \\
\text { Beta }-0 \\
\text { Gamma }-0 \\
\text { Delta }-13\end{array}$ & 14 & $\begin{array}{l}\text { Alpha }-0 \\
\text { Beta }-0 \\
\text { Gamma }-0 \\
\text { Delta }-92,9\end{array}$ \\
\hline $\begin{array}{c}\text { Французская Поли- } \\
\text { незия }\end{array}$ & $\begin{array}{l}\text { National Reference Center for } \\
\text { Viruses of Respiratory Infec- } \\
\text { tions, Institut Pasteur, Paris }\end{array}$ & $\begin{array}{l}\text { Alpha }-0 \\
\text { Beta }-0 \\
\text { Gamma }-0 \\
\end{array}$ & 89 & $\begin{array}{l}\text { Alpha }-0 \\
\text { Beta }-0 \\
\text { Gamma }-0 \\
\end{array}$ & $\begin{array}{l}\text { Alpha }-0 \\
\text { Beta }-0 \\
\text { Gamma }-0 \\
\end{array}$ & 0 & $\begin{array}{l}\text { Alpha }-0 \\
\text { Beta }-0 \\
\text { Gamma }-0 \\
\end{array}$ \\
\hline
\end{tabular}




\begin{tabular}{|c|c|c|c|c|c|c|c|}
\hline & & Delta -30 & & Delta $-33,7$ & Delta -0 & & Delta -0 \\
\hline $\begin{array}{c}\text { Хорватия } \\
\text { (стабилизация забо- } \\
\text { леваемости) }\end{array}$ & $\begin{array}{l}\text { Croatian Institute of Public } \\
\text { Health }\end{array}$ & $\begin{array}{l}\text { Alpha }-4471 \\
\text { Beta }-28 \\
\text { Gamma }-7 \\
\text { Delta }-6419\end{array}$ & 12090 & $\begin{array}{l}\text { Alpha }-37,0 \\
\text { Beta }-0,2 \\
\text { Gamma }-0,1 \\
\text { Delta }-53,1\end{array}$ & $\begin{array}{l}\text { Alpha }-0 \\
\text { Beta }-0 \\
\text { Gamma }-0 \\
\text { Delta }-388\end{array}$ & 513 & $\begin{array}{l}\text { Alpha }-0 \\
\text { Beta }-0 \\
\text { Gamma }-0 \\
\text { Delta }-75,6\end{array}$ \\
\hline $\begin{array}{c}\text { Центральноафри- } \\
\text { канская } \\
\text { Республика } \\
\text { (снижение заболевае- } \\
\text { мости) }\end{array}$ & $\begin{array}{l}\text { Pathogen Sequencing Lab, Na- } \\
\text { tional Institute for Biomedical } \\
\text { Research(INRB) }\end{array}$ & $\begin{array}{l}\text { Alpha }-12 \\
\text { Beta }-1 \\
\text { Gamma }-0 \\
\text { Delta }-17\end{array}$ & 127 & $\begin{array}{l}\text { Alpha }-9,4 \\
\text { Beta }-0,8 \\
\text { Gamma }-0 \\
\text { Delta }-13,4\end{array}$ & $\begin{array}{l}\text { Alpha }-0 \\
\text { Beta }-0 \\
\text { Gamma }-0 \\
\text { Delta }-0\end{array}$ & 0 & $\begin{array}{l}\text { Alpha }-0 \\
\text { Beta }-0 \\
\text { Gamma }-0 \\
\text { Delta }-0\end{array}$ \\
\hline $\begin{array}{c}\text { Черногория } \\
\text { (снижение заболевае- } \\
\text { мости) }\end{array}$ & $\begin{array}{l}\text { Charité Universitätsmedizin Ber- } \\
\text { lin, Institut für Virologie }\end{array}$ & $\begin{array}{l}\text { Alpha }-55 \\
\text { Beta }-0 \\
\text { Gamma }-3 \\
\text { Delta }-178\end{array}$ & 260 & $\begin{array}{l}\text { Alpha }-21,2 \\
\text { Beta }-0 \\
\text { Gamma }-1,2 \\
\text { Delta }-68,5\end{array}$ & $\begin{array}{l}\text { Alpha }-0 \\
\text { Beta }-0 \\
\text { Gamma }-0 \\
\text { Delta }-0\end{array}$ & 0 & $\begin{array}{l}\text { Alpha }-0 \\
\text { Beta }-0 \\
\text { Gamma }-0 \\
\text { Delta }-0\end{array}$ \\
\hline $\begin{array}{c}\text { Чехия } \\
\text { (рост заболеваемости) }\end{array}$ & $\begin{array}{l}\text { The National Institute of Public } \\
\text { Health }\end{array}$ & $\begin{array}{l}\text { Alpha }-4459 \\
\text { Beta }-74 \\
\text { Gamma }-21 \\
\text { Delta }-9803 \\
\text { Omicron }-1\end{array}$ & 15874 & $\begin{array}{l}\text { Alpha }-28,1 \\
\text { Beta }-0,5 \\
\text { Gamma }-0,1 \\
\text { Delta }-61,8 \\
\text { Omicron }-0\end{array}$ & $\begin{array}{l}\text { Alpha }-0 \\
\text { Beta }-0 \\
\text { Gamma }-0 \\
\text { Delta }-475 \\
\text { Omicron }-1\end{array}$ & 543 & $\begin{array}{l}\text { Alpha }-0 \\
\text { Beta }-0 \\
\text { Gamma }-0 \\
\text { Delta }-87,5 \\
\text { Omicron }-0,2\end{array}$ \\
\hline $\begin{array}{c}\text { Чили } \\
\text { (снижение заболевае- } \\
\text { мости) }\end{array}$ & $\begin{array}{l}\text { Instituto de Salud Publica de } \\
\text { Chile }\end{array}$ & $\begin{array}{l}\text { Alpha }-190 \\
\text { Beta }-4 \\
\text { Gamma }-4417 \\
\text { Delta }-6641 \\
\end{array}$ & 16273 & $\begin{array}{l}\text { Alpha }-1,2 \\
\text { Beta }-0 \\
\text { Gamma }-27,1 \\
\text { Delta }-40,8 \\
\end{array}$ & $\begin{array}{l}\text { Alpha }-0 \\
\text { Beta }-0 \\
\text { Gamma }-0 \\
\text { Delta }-653\end{array}$ & 788 & $\begin{array}{l}\text { Alpha }-0 \\
\text { Beta }-0 \\
\text { Gamma }-0 \\
\text { Delta }-82,9\end{array}$ \\
\hline $\begin{array}{c}\text { Швейцария } \\
\text { (рост заболеваемости) }\end{array}$ & $\begin{array}{l}\text { Department of Biosystems Sci- } \\
\text { ence and Engineering, ETH Zü- } \\
\text { rich. }\end{array}$ & $\begin{array}{l}\text { Alpha }-21842 \\
\text { Beta }-327 \\
\text { Gamma }-263 \\
\text { Delta }-43799\end{array}$ & 91244 & $\begin{array}{l}\text { Alpha }-23,9 \\
\text { Beta }-0,4 \\
\text { Gamma }-0,3 \\
\text { Delta }-48,0\end{array}$ & $\begin{array}{l}\text { Alpha }-0 \\
\text { Beta }-0 \\
\text { Gamma }-0 \\
\text { Delta }-6841\end{array}$ & 8313 & $\begin{array}{l}\text { Alpha }-0 \\
\text { Beta }-0 \\
\text { Gamma }-0 \\
\text { Delta }-82,3\end{array}$ \\
\hline $\begin{array}{c}\text { Швеция } \\
\text { (рост заболеваемости) }\end{array}$ & $\begin{array}{l}\text { The Public Health Agency of } \\
\text { Sweden }\end{array}$ & $\begin{array}{l}\text { Alpha }-68304 \\
\text { Beta }-2575 \\
\text { Gamma }-185 \\
\text { Delta }-43530 \\
\text { Omicron }-1\end{array}$ & 131146 & $\begin{array}{l}\text { Alpha }-52,1 \\
\text { Beta }-2,0 \\
\text { Gamma }-0,1 \\
\text { Delta }-33,2 \\
\text { Omicron }-0\end{array}$ & $\begin{array}{l}\text { Alpha }-0 \\
\text { Beta }-0 \\
\text { Gamma }-0 \\
\text { Delta }-5212 \\
\text { Omicron }-1\end{array}$ & 5725 & $\begin{array}{l}\text { Alpha }-0 \\
\text { Beta }-0 \\
\text { Gamma }-0 \\
\text { Delta }-91,0 \\
\text { Omicron }-0\end{array}$ \\
\hline Шри-Ланка & Centre for Dengue Research and & Alpha - 398 & 1881 & Alpha $-21,2$ & Alpha - 0 & 91 & Alpha -0 \\
\hline
\end{tabular}




\begin{tabular}{|c|c|c|c|c|c|c|c|}
\hline $\begin{array}{c}\text { (снижение заболевае- } \\
\text { мости) }\end{array}$ & $\begin{array}{l}\text { AICBU, Department of Immu- } \\
\text { nology and Molecular Medicine }\end{array}$ & \begin{tabular}{|l|} 
Beta -6 \\
Gamma -0 \\
Delta -1076
\end{tabular} & & $\begin{array}{l}\text { Beta }-0,3 \\
\text { Gamma }-0 \\
\text { Delta }-57,2\end{array}$ & $\begin{array}{l}\text { Beta }-0 \\
\text { Gamma }-0 \\
\text { Delta }-84\end{array}$ & & $\begin{array}{l}\text { Beta }-0 \\
\text { Gamma }-0 \\
\text { Delta }-92,3\end{array}$ \\
\hline $\begin{array}{c}\text { Эквадор } \\
\text { (снижение заболевае- } \\
\text { мости) }\end{array}$ & $\begin{array}{l}\text { Instituto Nacional de Investi- } \\
\text { gaciónenSaludPública, INSPI }\end{array}$ & $\begin{array}{l}\text { Alpha }-225 \\
\text { Beta }-0 \\
\text { Gamma }-310 \\
\text { Delta }-1023 \\
\end{array}$ & 3552 & $\begin{array}{l}\text { Alpha }-6,3 \\
\text { Beta }-0 \\
\text { Gamma }-8,7 \\
\text { Delta }-28,8 \\
\end{array}$ & $\begin{array}{l}\text { Alpha }-0 \\
\text { Beta }-0 \\
\text { Gamma }-1 \\
\text { Delta }-157 \\
\end{array}$ & 170 & $\begin{array}{l}\text { Alpha }-0 \\
\text { Beta }-0 \\
\text { Gamma }-0,6 \\
\text { Delta }-92,4\end{array}$ \\
\hline $\begin{array}{c}\text { Экваториальная } \\
\text { Гвинея } \\
\text { (рост заболеваемости) }\end{array}$ & $\begin{array}{l}\text { Swiss Tropical and Public } \\
\text { Health Institute }\end{array}$ & $\begin{array}{l}\text { Alpha }-1 \\
\text { Beta }-14 \\
\text { Gamma }-0 \\
\text { Delta }-14\end{array}$ & 207 & $\begin{array}{l}\text { Alpha }-0,5 \\
\text { Beta }-6,8 \\
\text { Gamma }-0 \\
\text { Delta }-6,8\end{array}$ & $\begin{array}{l}\text { Alpha }-0 \\
\text { Beta }-0 \\
\text { Gamma }-0 \\
\text { Delta }-0\end{array}$ & 0 & $\begin{array}{l}\text { Alpha }-0 \\
\text { Beta }-0 \\
\text { Gamma }-0 \\
\text { Delta }-0\end{array}$ \\
\hline $\begin{array}{c}\text { Эсватини } \\
\text { (рост заболеваемости) }\end{array}$ & $\begin{array}{l}\text { Nhlangano Health Cen- } \\
\text { tre(National Institute for Com- } \\
\text { municable Diseases of the Na- } \\
\text { tional Health Laboratory Ser- } \\
\text { vice) }\end{array}$ & $\begin{array}{l}\text { Alpha }-0 \\
\text { Beta }-28 \\
\text { Gamma }-0 \\
\text { Delta }-81\end{array}$ & 123 & $\begin{array}{l}\text { Alpha }-0 \\
\text { Beta }-22,8 \\
\text { Gamma }-0 \\
\text { Delta }-65,9\end{array}$ & $\begin{array}{l}\text { Alpha }-0 \\
\text { Beta }-0 \\
\text { Gamma }-0 \\
\text { Delta }-0\end{array}$ & 0 & $\begin{array}{l}\text { Alpha }-0 \\
\text { Beta }-0 \\
\text { Gamma }-0 \\
\text { Delta }-0\end{array}$ \\
\hline $\begin{array}{c}\text { Эстония } \\
\text { (снижение заболевае- } \\
\text { мости) }\end{array}$ & $\begin{array}{l}\text { Laboratory of Communicable } \\
\text { Diseases(Estonia); Eurofins Ge- } \\
\text { nomics Europe Sequencing } \\
\text { GmbH }\end{array}$ & $\begin{array}{l}\text { Alpha }-3197 \\
\text { Beta }-37 \\
\text { Gamma }-0 \\
\text { Delta }-2896\end{array}$ & 7413 & $\begin{array}{l}\text { Alpha }-43,1 \\
\text { Beta }-0,5 \\
\text { Gamma }-0 \\
\text { Delta }-39,1\end{array}$ & $\begin{array}{l}\text { Alpha }-0 \\
\text { Beta }-0 \\
\text { Gamma }-0 \\
\text { Delta }-14\end{array}$ & 48 & $\begin{array}{l}\text { Alpha }-0 \\
\text { Beta }-0 \\
\text { Gamma }-0 \\
\text { Delta }-29,2\end{array}$ \\
\hline $\begin{array}{c}\text { Эфиопия } \\
\text { (снижение заболевае- } \\
\text { мости) }\end{array}$ & $\begin{array}{l}\text { International Centre for Genetic } \\
\text { Engineering and Biotechnolo- } \\
\text { gy(ICGEB) and ARGO Open } \\
\text { Lab for Genome Sequencing }\end{array}$ & $\begin{array}{l}\text { Alpha }-28 \\
\text { Beta }-2 \\
\text { Gamma }-1 \\
\text { Delta }-424 \\
\end{array}$ & 524 & $\begin{array}{l}\text { Alpha }-5,3 \\
\text { Beta }-0,4 \\
\text { Gamma }-0,2 \\
\text { Delta }-80,9 \\
\end{array}$ & $\begin{array}{l}\text { Alpha }-0 \\
\text { Beta }-0 \\
\text { Gamma }-0 \\
\text { Delta }-0 \\
\end{array}$ & 0 & $\begin{array}{l}\text { Alpha }-0 \\
\text { Beta }-0 \\
\text { Gamma }-0 \\
\text { Delta }-0 \\
\end{array}$ \\
\hline $\begin{array}{c}\text { ЮАР } \\
\text { (рост заболеваемости) }\end{array}$ & $\begin{array}{l}\text { KRISP, KZN Research Innova- } \\
\text { tion and Sequencing Platform. }\end{array}$ & $\begin{array}{l}\text { Alpha }-224 \\
\text { Beta }-6838 \\
\text { Gamma }-1 \\
\text { Delta }-10792 \\
\text { Omicron }-172\end{array}$ & 24044 & $\begin{array}{l}\text { Alpha }-0,9 \\
\text { Beta }-28,4 \\
\text { Gamma }-0 \\
\text { Delta }-44,9 \\
\text { Omicron }-0,7\end{array}$ & $\begin{array}{l}\text { Alpha }-0 \\
\text { Beta }-0 \\
\text { Gamma }-0 \\
\text { Delta }-45 \\
\text { Omicron - } \\
172 \\
\end{array}$ & 248 & $\begin{array}{l}\text { Alpha }-0 \\
\text { Beta }-0 \\
\text { Gamma }-0 \\
\text { Delta }-18,1 \\
\text { Omicron - } \\
69,4\end{array}$ \\
\hline $\begin{array}{c}\text { Южная Корея } \\
\text { (рост заболеваемости) }\end{array}$ & $\begin{array}{l}\text { Division of Emerging Infectious } \\
\text { Diseases, Bureau of Infectious } \\
\text { Diseases Diagnosis Control, Ko- }\end{array}$ & $\begin{array}{l}\text { Alpha }-827 \\
\text { Beta }-36 \\
\text { Gamma }-15\end{array}$ & 20457 & $\begin{array}{l}\text { Alpha }-4,0 \\
\text { Beta }-0,2 \\
\text { Gamma }-0,1\end{array}$ & $\begin{array}{l}\text { Alpha }-0 \\
\text { Beta }-0 \\
\text { Gamma }-0\end{array}$ & 0 & $\begin{array}{l}\text { Alpha }-0 \\
\text { Beta }-0 \\
\text { Gamma }-0\end{array}$ \\
\hline
\end{tabular}




\begin{tabular}{|c|c|c|c|c|c|c|c|}
\hline & $\begin{array}{l}\text { rea Disease Control and Preven- } \\
\text { tion Agency }\end{array}$ & Delta -8615 & & Delta $-42,1$ & Delta -0 & & Delta -0 \\
\hline $\begin{array}{c}\text { Южный Судан } \\
\text { (снижение заболевае- } \\
\text { мости) }\end{array}$ & $\begin{array}{l}\text { MRC/UVRI \& LSHTM Uganda } \\
\text { Research Unit, South Sudan } \\
\text { Ministry of Health, WHO South } \\
\text { Sudan }\end{array}$ & $\begin{array}{l}\text { Alpha }-2 \\
\text { Beta }-3 \\
\text { Gamma }-0 \\
\text { Delta }-29 \\
\end{array}$ & 89 & $\begin{array}{l}\text { Alpha }-2,2 \\
\text { Beta }-3,4 \\
\text { Gamma }-0 \\
\text { Delta }-32,6 \\
\end{array}$ & $\begin{array}{l}\text { Alpha }-0 \\
\text { Beta }-0 \\
\text { Gamma }-0 \\
\text { Delta }-0 \\
\end{array}$ & 0 & $\begin{array}{l}\text { Alpha }-0 \\
\text { Beta }-0 \\
\text { Gamma }-0 \\
\text { Delta }-0 \\
\end{array}$ \\
\hline $\begin{array}{c}\text { Ямайка } \\
\text { (снижение заболевае- } \\
\text { мости) }\end{array}$ & $\begin{array}{l}\text { Carrington Lab, Department of } \\
\text { PreClinical Sciences, Faculty of } \\
\text { Medical Sciences, The Universi- } \\
\text { ty of the West Indies }\end{array}$ & $\begin{array}{l}\text { Alpha }-205 \\
\text { Beta }-0 \\
\text { Gamma }-0 \\
\text { Delta }-60\end{array}$ & 312 & $\begin{array}{l}\text { Alpha }-65,7 \\
\text { Beta }-0 \\
\text { Gamma }-0 \\
\text { Delta }-19,2\end{array}$ & $\begin{array}{l}\text { Alpha }-0 \\
\text { Beta }-0 \\
\text { Gamma }-0 \\
\text { Delta }-0\end{array}$ & 0 & $\begin{array}{l}\text { Alpha }-0 \\
\text { Beta }-0 \\
\text { Gamma }-0 \\
\text { Delta }-0\end{array}$ \\
\hline $\begin{array}{c}\text { Япония } \\
\text { (снижение заболевае- } \\
\text { мости) }\end{array}$ & $\begin{array}{l}\text { Pathogen Genomics Center, Na- } \\
\text { tional Institute of Infectious Dis- } \\
\text { eases }\end{array}$ & $\begin{array}{l}\text { Alpha }-48917 \\
\text { Beta }-112 \\
\text { Gamma }-130 \\
\text { Delta }-71041 \\
\text { Omicron }-2\end{array}$ & 162268 & $\begin{array}{l}\text { Alpha }-30,1 \\
\text { Beta }-0,1 \\
\text { Gamma }-0,1 \\
\text { Delta }-43,8 \\
\text { Omicron }-0\end{array}$ & $\begin{array}{l}\text { Alpha }-0 \\
\text { Beta }-0 \\
\text { Gamma }-0 \\
\text { Delta }-40 \\
\text { Omicron }-2\end{array}$ & 45 & $\begin{array}{l}\text { Alpha }-0 \\
\text { Beta }-0 \\
\text { Gamma }-0 \\
\text { Delta }-88,9 \\
\text { Omicron }-4,4\end{array}$ \\
\hline
\end{tabular}

Таблица 2 - Количество депонированных геномов вариантов Lambda GR/452Q.V1 (C.37), Mu GH (B.1.621+B.1.621.1) вируса SARS-CoV-2 в базе GISAID

\begin{tabular}{|c|c|c|c|}
\hline Страна & $\begin{array}{c}\text { Учреждение, } \\
\text { проводившее секвенирова- } \\
\text { ние }\end{array}$ & $\begin{array}{c}\text { Количество депонированных геномов } \\
\text { SARS-CoV-2 }\end{array}$ & $\begin{array}{c}\text { В том числе количество геномов, } \\
\text { депонированных за последние } 4 \text { не- } \\
\text { дели } \\
(06.11 .21-03.12 .21)\end{array}$ \\
\hline
\end{tabular}




\begin{tabular}{|c|c|c|c|c|c|c|c|}
\hline & & $\begin{array}{l}\text { Варианты: } \\
\text { Lambda (C.37) } \\
\text { Mu } \\
\text { (B.1.621+B.1.62 } \\
1.1)\end{array}$ & Всего & $\begin{array}{l}\text { Процент ге- } \\
\text { номов, отно- } \\
\text { сящихся к } \\
\text { варианту: } \\
\text { Lambda } \\
\text { (C.37) } \\
\text { Mu } \\
\text { (B.1.621+B.1. } \\
621.1 \text { ) }\end{array}$ & $\begin{array}{l}\text { Варианты: } \\
\text { Lambda } \\
\text { (С.37) } \\
\text { Mu } \\
(\text { B.1.621+B.1 } \\
.621 .1)\end{array}$ & Всего & $\begin{array}{l}\text { Процент ге- } \\
\text { номов, отно- } \\
\text { сящихся к } \\
\text { варианту: } \\
\text { Lambda } \\
\text { (C. } 37) \\
\text { Mu } \\
\text { (B.1.621+B.1. } \\
621.1 \text { ) }\end{array}$ \\
\hline $\begin{array}{c}\text { Австралия } \\
\text { (стабилизация забо- } \\
\text { леваемости) }\end{array}$ & $\begin{array}{l}\text { NSW Health Pathology - Insti- } \\
\text { tute of Clinical Pathology and } \\
\text { Medical Research; Westmead } \\
\text { Hospital; University of Sydney }\end{array}$ & Lambda -1 & 43568 & Lambda -0 & Lambda -0 & 1586 & Lambda -0 \\
\hline $\begin{array}{c}\text { Австрия } \\
\text { (снижение заболевае- } \\
\text { мости) }\end{array}$ & $\begin{array}{l}\text { Bergthaler laboratory, CeMM } \\
\text { Research Center for Molecular } \\
\text { Medicine of the Austrian Acad- } \\
\text { emy of Sciences }\end{array}$ & $\mathrm{Mu}-49$ & 69152 & $\mathrm{Mu}-0,1$ & $\mathrm{Mu}-0$ & 236 & $\mathrm{Mu}-0$ \\
\hline $\begin{array}{l}\text { Американские Вир- } \\
\text { гинские острова }\end{array}$ & UW Virology Lab & $\mathrm{Mu}-6$ & 428 & $\mathrm{Mu}-1,4$ & $\mathrm{Mu}-0$ & 0 & $\mathrm{Mu}-0$ \\
\hline $\begin{array}{c}\text { Ангола } \\
\text { (снижение заболевае- } \\
\text { мости) } \\
\end{array}$ & $\begin{array}{l}\text { KRISP, KZN Research Innova- } \\
\text { tion and Sequencing Platform }\end{array}$ & Lambda - 3 & 1055 & Lambda - 0,3 & Lambda -0 & 0 & Lambda - 0 \\
\hline $\begin{array}{c}\text { Аргентина } \\
\text { (рост заболеваемости) }\end{array}$ & $\begin{array}{l}\text { Instituto Nacional Enfermedad- } \\
\text { esInfecciosasC.G.Malbran }\end{array}$ & $\begin{array}{l}\text { Lambda }-952 \\
\mathrm{Mu}-19\end{array}$ & 11141 & $\begin{array}{l}\text { Lambda }-8,5 \\
\mathrm{Mu}-0,2\end{array}$ & $\begin{array}{l}\text { Lambda }-3 \\
\mathrm{Mu}-0\end{array}$ & 17 & $\begin{array}{l}\text { Lambda - } \\
17,6 \\
\mathrm{Mu}-0\end{array}$ \\
\hline Аpyбa & $\begin{array}{l}\text { National Institute for Public } \\
\text { Health and the Environment } \\
\text { (RIVM) }\end{array}$ & $\begin{array}{l}\text { Lambda }-2 \\
\mathrm{Mu}-94\end{array}$ & 2867 & $\begin{array}{l}\text { Lambda }-0,1 \\
\mathrm{Mu}-3,3\end{array}$ & $\begin{array}{l}\text { Lambda }-0 \\
\text { Mu }-0\end{array}$ & 33 & $\begin{array}{l}\text { Lambda }-0 \\
\mathrm{Mu}-0\end{array}$ \\
\hline
\end{tabular}




\begin{tabular}{|c|c|c|c|c|c|c|c|}
\hline $\begin{array}{c}\text { Барбадос } \\
\text { (снижение заболевае- } \\
\text { мости) }\end{array}$ & $\begin{array}{l}\text { Carrington Lab, Department of } \\
\text { PreClinical Sciences, Building } \\
\text { 36, First Floor Biochemistry } \\
\text { Unit, Faculty of Medical Scienc- } \\
\text { es, The University of the West } \\
\text { Indies }\end{array}$ & $\mathrm{Mu}-1$ & 78 & $\mathrm{Mu}-1,3$ & $\mathrm{Mu}-0$ & 0 & $\mathrm{Mu}-0$ \\
\hline $\begin{array}{c}\text { Боливия } \\
\text { (снижение заболевае- } \\
\text { мости) }\end{array}$ & $\begin{array}{l}\text { Microbiologia Molecular, Insti- } \\
\text { tuto SELADIS, Universidad } \\
\text { Mayor de San Andrés }\end{array}$ & $\begin{array}{l}\text { Lambda }-2 \\
\mathrm{Mu}-2\end{array}$ & 155 & $\begin{array}{l}\text { Lambda }-1,3 \\
\mathrm{Mu}-1,3\end{array}$ & $\begin{array}{l}\text { Lambda }-0 \\
\mathrm{Mu}-0\end{array}$ & 0 & $\begin{array}{l}\text { Lambda }-0 \\
\mathrm{Mu}-0\end{array}$ \\
\hline $\begin{array}{c}\text { Бельгия } \\
\text { (снижение заболевае- } \\
\text { мости) }\end{array}$ & $\begin{array}{l}\text { KU Leuven, Rega Institute, } \\
\text { Clinical and Epidemiological } \\
\text { Virology }\end{array}$ & $\begin{array}{l}\text { Lambda }-11 \\
\mathrm{Mu}-51\end{array}$ & 67542 & $\begin{array}{l}\text { Lambda }-0 \\
\mathrm{Mu}-0,1\end{array}$ & $\begin{array}{l}\text { Lambda }-0 \\
\mathrm{Mu}-0\end{array}$ & 2459 & $\begin{array}{l}\text { Lambda }-0 \\
\mathrm{Mu}-0\end{array}$ \\
\hline Бонэйр & $\begin{array}{l}\text { National Institute for Public } \\
\text { Health and the Environ- } \\
\text { ment(RIVM) }\end{array}$ & $\mathrm{Mu}-10$ & 699 & $\mathrm{Mu}-1,4$ & $\mathrm{Mu}-0$ & 34 & $\mathrm{Mu}-0$ \\
\hline $\begin{array}{c}\text { Бразилия } \\
\text { (снижение заболевае- } \\
\text { мости) } \\
\end{array}$ & $\begin{array}{l}\text { Instituto Adolfo Lutz, Interdici- } \\
\text { plinary Procedures Center, Stra- } \\
\text { tegic Laboratory }\end{array}$ & $\begin{array}{l}\text { Lambda }-22 \\
\mathrm{Mu}-19\end{array}$ & 77541 & $\begin{array}{l}\text { Lambda }-0 \\
\mathrm{Mu}-0\end{array}$ & $\begin{array}{l}\text { Lambda }-0 \\
\mathrm{Mu}-0\end{array}$ & 902 & $\begin{array}{l}\text { Lambda }-0 \\
\mathrm{Mu}-0\end{array}$ \\
\hline $\begin{array}{c}\text { Британские Виргин- } \\
\text { ские острова }\end{array}$ & Caribbean Public Health Agency & $\mathrm{Mu}-41$ & 58 & $\mathrm{Mu}-70,7$ & $\mathrm{Mu}-0$ & 0 & $\mathrm{Mu}-0$ \\
\hline $\begin{array}{c}\text { Великобритания } \\
\text { (рост заболеваемости) }\end{array}$ & $\begin{array}{l}\text { COVID- } 19 \text { Genomics UK } \\
\text { (COG- UK) Consortium. } \\
\text { Wellcome Sanger Institute for } \\
\text { the COVID- } 19 \text { Genomics UK } \\
\text { (COG- UK) consortium. }\end{array}$ & $\begin{array}{l}\text { Lambda }-8 \\
\mathrm{Mu}-70\end{array}$ & 1341165 & $\begin{array}{l}\text { Lambda }-0 \\
\mathrm{Mu}-0\end{array}$ & $\begin{array}{l}\text { Lambda }-0 \\
\mathrm{Mu}-0\end{array}$ & 138220 & $\begin{array}{l}\text { Lambda }-0 \\
\mathrm{Mu}-0\end{array}$ \\
\hline $\begin{array}{c}\text { Венесуэла } \\
\text { (снижение заболевае- } \\
\text { мости) } \\
\end{array}$ & $\begin{array}{l}\text { Laboratorio de Virología Mo- } \\
\text { lecular }\end{array}$ & $\begin{array}{l}\text { Lambda }-2 \\
\mathrm{Mu}-5\end{array}$ & 172 & $\begin{array}{l}\text { Lambda }-1,2 \\
\mathrm{Mu}-2,9\end{array}$ & $\begin{array}{l}\text { Lambda }-0 \\
\mathrm{Mu}-0\end{array}$ & 0 & $\begin{array}{l}\text { Lambda }-0 \\
\mathrm{Mu}-0\end{array}$ \\
\hline $\begin{array}{c}\text { Гаити } \\
\text { (рост заболеваемости) }\end{array}$ & $\begin{array}{l}\text { Laboratoire National de Santé } \\
\text { Publique - LNSP(HAITI - } \\
\text { LNSP) }\end{array}$ & $\mathrm{Mu}-6$ & 95 & $\mathrm{Mu}-6,3$ & $\mathrm{Mu}-0$ & 0 & $\mathrm{Mu}-0$ \\
\hline
\end{tabular}




\begin{tabular}{|c|c|c|c|c|c|c|c|}
\hline $\begin{array}{c}\text { Гватемала } \\
\text { (снижение } \\
\text { заболеваемости) }\end{array}$ & $\begin{array}{l}\text { Asociación de Salud Inte- } \\
\text { gral/Clínica Familiar Luis Ángel } \\
\text { García }\end{array}$ & $\begin{array}{l}\text { Lambda }-3 \\
\mathrm{Mu}-4\end{array}$ & 1032 & $\begin{array}{l}\text { Lambda }-0,3 \\
\mathrm{Mu}-0,4\end{array}$ & $\begin{array}{l}\text { Lambda }-0 \\
\mathrm{Mu}-0\end{array}$ & 0 & $\begin{array}{l}\text { Lambda }-0 \\
\mathrm{Mu}-0\end{array}$ \\
\hline $\begin{array}{c}\text { Гвинея } \\
\text { (снижение заболевае- } \\
\text { мости) } \\
\end{array}$ & $\begin{array}{l}\text { Centre de Recherche et de For- } \\
\text { mation en Infectiologie Guinée }\end{array}$ & Lambda - 1 & 311 & Lambda $-0,3$ & Lambda - 0 & 0 & Lambda -0 \\
\hline $\begin{array}{c}\text { Германия } \\
(\text { рост } \\
\text { заболеваемости })\end{array}$ & $\begin{array}{l}\text { Charité Universitätsmedizin Ber- } \\
\text { lin, InstitutfürVirologie. } \\
\text { Institute of infectious medicine } \\
\text { \& hospital hygiene, CaSe-- } \\
\text { Group. }\end{array}$ & $\begin{array}{l}\text { Lambda }-102 \\
\mathrm{Mu}-15\end{array}$ & 262022 & $\begin{array}{l}\text { Lambda }-0 \\
\mathrm{Mu}-0\end{array}$ & $\begin{array}{l}\text { Lambda }-0 \\
\mathrm{Mu}-0\end{array}$ & 9127 & $\begin{array}{l}\text { Lambda }-0 \\
\mathrm{Mu}-0\end{array}$ \\
\hline Гибралтар & $\begin{array}{l}\text { Respiratory Virus Unit, National } \\
\text { Infection Service, Public Health } \\
\text { England }\end{array}$ & $\mathrm{Mu}-1$ & 1842 & $\mathrm{Mu}-0,1$ & $\mathrm{Mu}-0$ & 0 & $\mathrm{Mu}-0$ \\
\hline Гонконг & $\begin{array}{l}\text { Hong Kong Department of } \\
\text { Health }\end{array}$ & $\mathrm{Mu}-3$ & 5128 & $\mathrm{Mu}-0,1$ & $\mathrm{Mu}-0$ & 25 & $\mathrm{Mu}-0$ \\
\hline $\begin{array}{c}\text { Дания } \\
\text { (рост заболеваемости) }\end{array}$ & $\begin{array}{l}\text { Albertsen lab, Department of } \\
\text { Chemistry and Bioscience, Aal- } \\
\text { borg University. } \\
\text { Department of Virus and Micro- } \\
\text { biological Special Diagnostics, } \\
\text { Statens Serum Institut. }\end{array}$ & $\begin{array}{l}\text { Lambda }-9 \\
\mathrm{Mu}-10\end{array}$ & 227971 & $\begin{array}{l}\text { Lambda }-0 \\
\mathrm{Mu}-0\end{array}$ & $\begin{array}{l}\text { Lambda }-0 \\
\mathrm{Mu}-0\end{array}$ & 30028 & $\begin{array}{l}\text { Lambda }-0 \\
\mathrm{Mu}-0\end{array}$ \\
\hline $\begin{array}{c}\text { Доминиканская } \\
\text { Республика } \\
\text { (снижение заболевае- } \\
\text { мости) } \\
\end{array}$ & $\begin{array}{l}\text { Respiratory Viruses Branch, } \\
\text { Centers for Disease Control and } \\
\text { Prevention, USA }\end{array}$ & $\begin{array}{l}\text { Lambda }-6 \\
\mathrm{Mu}-115\end{array}$ & 568 & $\begin{array}{l}\text { Lambda }-1,1 \\
\mathrm{Mu}-20,2\end{array}$ & $\begin{array}{l}\text { Lambda }-0 \\
\mathrm{Mu}-0\end{array}$ & 0 & $\begin{array}{l}\text { Lambda }-0 \\
\mathrm{Mu}-0\end{array}$ \\
\hline $\begin{array}{c}\text { Израиль } \\
\text { (рост заболеваемости) } \\
\end{array}$ & $\begin{array}{l}\text { Central Virology Laboratory, Is- } \\
\text { rael Ministry of Health }\end{array}$ & $\begin{array}{l}\text { Lambda }-31 \\
\mathrm{Mu}-2\end{array}$ & 29084 & $\begin{array}{l}\text { Lambda }-0,1 \\
\mathrm{Mu}-0\end{array}$ & $\begin{array}{l}\text { Lambda }-0 \\
\mathrm{Mu}-0\end{array}$ & 2528 & $\begin{array}{l}\text { Lambda }-0 \\
\mathrm{Mu}-0\end{array}$ \\
\hline
\end{tabular}




\begin{tabular}{|c|c|c|c|c|c|c|c|}
\hline $\begin{array}{c}\text { Индия } \\
\text { (снижение заболевае- } \\
\text { мости) }\end{array}$ & $\begin{array}{l}\text { Department of Neurovirology, } \\
\text { National Institute of Mental } \\
\text { Health and Neurosciences } \\
\text { (NIMHANS). } \\
\text { CSIR-Centre for Cellular and } \\
\text { Molecular Biology }\end{array}$ & $\begin{array}{l}\text { Lambda }-3 \\
\mathrm{Mu}-1\end{array}$ & 84890 & $\begin{array}{l}\text { Lambda }-0 \\
\mathrm{Mu}-0\end{array}$ & $\begin{array}{l}\text { Lambda }-0 \\
\mathrm{Mu}-0\end{array}$ & 323 & $\begin{array}{l}\text { Lambda }-0 \\
\mathrm{Mu}-0\end{array}$ \\
\hline $\begin{array}{c}\text { Ирак } \\
\text { (снижение заболевае- } \\
\text { мости) }\end{array}$ & $\begin{array}{l}\text { Biology, College of Educa- } \\
\text { tionDepartment of Virology, } \\
\text { Faculty of Medicine, University } \\
\text { of Helsinki, Helsinki, Finland } \\
\text { generated and submitted to } \\
\text { GISAID }\end{array}$ & $\mathrm{Mu}-1$ & 297 & $\mathrm{Mu}-0,3$ & $\mathrm{Mu}-0$ & 0 & $\mathrm{Mu}-0$ \\
\hline $\begin{array}{c}\text { Ирландия } \\
\text { (стабилизация забо- } \\
\text { леваемости) } \\
\end{array}$ & $\begin{array}{l}\text { National Virus Reference La- } \\
\text { boratory }\end{array}$ & $\begin{array}{l}\text { Lambda }-4 \\
\mathrm{Mu}-4\end{array}$ & 42152 & $\begin{array}{l}\text { Lambda }-0 \\
\mathrm{Mu}-0\end{array}$ & $\begin{array}{l}\text { Lambda }-0 \\
\mathrm{Mu}-0\end{array}$ & 367 & $\begin{array}{l}\text { Lambda }-0 \\
\mathrm{Mu}-0\end{array}$ \\
\hline $\begin{array}{c}\text { Испания } \\
\text { (рост заболеваемости) }\end{array}$ & $\begin{array}{l}\text { Hospital Universitario } 12 \text { de Oc- } \\
\text { tubre }\end{array}$ & $\begin{array}{l}\text { Lambda }-232 \\
\mathrm{Mu}-679\end{array}$ & 79429 & $\begin{array}{l}\text { Lambda }-0,3 \\
\mathrm{Mu}-0,9\end{array}$ & $\begin{array}{l}\text { Lambda }-0 \\
\mathrm{Mu}-0\end{array}$ & 1897 & $\begin{array}{l}\text { Lambda }-0 \\
\mathrm{Mu}-0\end{array}$ \\
\hline $\begin{array}{c}\text { Италия } \\
\text { (рост заболеваемости) }\end{array}$ & $\begin{array}{l}\text { Army Medical Center, Scientific } \\
\text { Department, Virology Laborato- } \\
\text { ry }\end{array}$ & $\begin{array}{l}\text { Lambda }-18 \\
\mathrm{Mu}-83\end{array}$ & 77354 & $\begin{array}{l}\text { Lambda }-0 \\
\mathrm{Mu}-0,1\end{array}$ & $\begin{array}{l}\text { Lambda }-0 \\
\mathrm{Mu}-0\end{array}$ & 3021 & $\begin{array}{l}\text { Lambda }-0 \\
\mathrm{Mu}-0\end{array}$ \\
\hline Каймановы острова & $\begin{array}{l}\text { Carrington Lab, Department of } \\
\text { PreClinical Sciences, Building } \\
\text { 36, First Floor Bio- chemistry } \\
\text { Unit, Fac- ulty of Medical Sci- } \\
\text { ences, The University of the } \\
\text { West Indies }\end{array}$ & $\mathrm{Mu}-2$ & 97 & $\mathrm{Mu}-2,1$ & $\mathrm{Mu}-0$ & 0 & $\mathrm{Mu}-0$ \\
\hline $\begin{array}{c}\text { Канада } \\
\text { (стабилизация забо- } \\
\text { леваемости) } \\
\end{array}$ & $\begin{array}{l}\text { Laboratoire de santé publique du } \\
\text { Québec }\end{array}$ & $\begin{array}{l}\text { Lambda }-29 \\
\mathrm{Mu}-152\end{array}$ & 200865 & $\begin{array}{l}\text { Lambda }-0 \\
\mathrm{Mu}-0,1\end{array}$ & $\begin{array}{l}\text { Lambda }-0 \\
\mathrm{Mu}-0\end{array}$ & 985 & $\begin{array}{l}\text { Lambda }-0 \\
\mathrm{Mu}-0\end{array}$ \\
\hline $\begin{array}{c}\text { Катар } \\
\text { (рост заболеваемости) }\end{array}$ & $\begin{array}{l}\text { Biomedical Research Cen- } \\
\text { ter(BRC), Qatar University / Qa- } \\
\text { tar Genome Project(QGP) }\end{array}$ & $\mathrm{Mu}-1$ & 4126 & $\mathrm{Mu}-0$ & $\mathrm{Mu}-0$ & 0 & $\mathrm{Mu}-0$ \\
\hline
\end{tabular}




\begin{tabular}{|c|c|c|c|c|c|c|c|}
\hline $\begin{array}{c}\text { Китай } \\
\text { (рост заболеваемости) }\end{array}$ & $\begin{array}{l}\text { National Institute for Viral Dis- } \\
\text { ease Control and Prevention }\end{array}$ & $\mathrm{Mu}-3$ & 1285 & $\mathrm{Mu}-0$ & $\mathrm{Mu}-0$ & 0 & $\mathrm{Mu}-0$ \\
\hline $\begin{array}{c}\text { Колумбия } \\
\text { (снижение заболева- } \\
\text { емости) } \\
\end{array}$ & $\begin{array}{l}\text { Instituto Nacional de Salud- Di- } \\
\text { rección de Investigación en } \\
\text { Salud Pública }\end{array}$ & $\begin{array}{l}\text { Lambda }-104 \\
\mathrm{Mu}-3961\end{array}$ & 8175 & $\begin{array}{l}\text { Lambda }-1,3 \\
\mathrm{Mu}-48,5\end{array}$ & $\begin{array}{l}\text { Lambda }-0 \\
\mathrm{Mu}-1\end{array}$ & 100 & $\begin{array}{l}\text { Lambda }-0 \\
\mathrm{Mu}-1,0\end{array}$ \\
\hline $\begin{array}{c}\text { Коста- Рика } \\
\text { (снижение заболевае- } \\
\text { мости) } \\
\end{array}$ & $\begin{array}{l}\text { Inciensa, Instituto Costarricense } \\
\text { de Investigación y Enseñanza en } \\
\text { Nutrición y Salud }\end{array}$ & $\begin{array}{l}\text { Lambda }-16 \\
\mathrm{Mu}-65\end{array}$ & 1677 & $\begin{array}{l}\text { Lambda }-1,0 \\
\mathrm{Mu}-3,9\end{array}$ & $\begin{array}{l}\text { Lambda }-0 \\
\mathrm{Mu}-0\end{array}$ & 4 & $\begin{array}{l}\text { Lambda }-0 \\
\mathrm{Mu}-0\end{array}$ \\
\hline Кюрасао & $\begin{array}{l}\text { Dutch COVID- } 19 \text { response } \\
\text { team }\end{array}$ & $\begin{array}{l}\text { Lambda }-1 \\
\mathrm{Mu}-20\end{array}$ & 949 & $\begin{array}{l}\text { Lambda }-0,1 \\
\mathrm{Mu}-2,1\end{array}$ & $\begin{array}{l}\text { Lambda }-0 \\
\mathrm{Mu}-0\end{array}$ & 24 & $\begin{array}{l}\text { Lambda }-0 \\
\mathrm{Mu}-0\end{array}$ \\
\hline $\begin{array}{c}\text { Лихтенштейн } \\
\text { (рост заболеваемости) }\end{array}$ & $\begin{array}{l}\text { Bergthaler laboratory, CeMM } \\
\text { Research Center for Molecular } \\
\text { Medicine of the Austrian Acad- } \\
\text { emy of Sciences }\end{array}$ & $\mathrm{Mu}-1$ & 181 & $\mathrm{Mu}-0,6$ & $\mathrm{Mu}-0$ & 62 & $\mathrm{Mu}-0$ \\
\hline $\begin{array}{c}\text { Люксембург } \\
\text { (рост заболеваемости) }\end{array}$ & $\begin{array}{l}\text { Laboratoire national de santé, } \\
\text { Microbiology, Microbial Ge- } \\
\text { nomics Platform }\end{array}$ & $\begin{array}{l}\text { Lambda }-1 \\
\mathrm{Mu}-3\end{array}$ & 17534 & $\begin{array}{l}\text { Lambda }-0 \\
\mathrm{Mu}-0\end{array}$ & $\begin{array}{l}\text { Lambda }-0 \\
\mathrm{Mu}-0\end{array}$ & 747 & $\begin{array}{l}\text { Lambda }-0 \\
\mathrm{Mu}-0\end{array}$ \\
\hline Майотта & $\begin{array}{l}\text { National Reference Center for } \\
\text { Viruses of Respiratory Infec- } \\
\text { tions, Institut Pasteur, Paris }\end{array}$ & Lambda -2 & 817 & Lambda $-0,2$ & Lambda -0 & 14 & Lambda -0 \\
\hline $\begin{array}{c}\text { Мальта } \\
\text { (рост заболеваемости) }\end{array}$ & $\begin{array}{l}\text { Molecular Diagnostics Patholo- } \\
\text { gy Department Mater Dei Hospi- } \\
\text { tal Malta }\end{array}$ & $\mathrm{Mu}-1$ & 299 & $\mathrm{Mu}-0,3$ & $\mathrm{Mu}-0$ & 0 & $\mathrm{Mu}-0$ \\
\hline $\begin{array}{c}\text { Марокко } \\
\text { (рост заболеваемости) } \\
\end{array}$ & Laboratoire de Biotechnologie & $\mathrm{Mu}-1$ & 551 & $\mathrm{Mu}-0,2$ & $\mathrm{Mu}-0$ & 0 & $\mathrm{Mu}-0$ \\
\hline $\begin{array}{c}\text { Мексика } \\
\text { (снижение } \\
\text { заболеваемости) }\end{array}$ & $\begin{array}{l}\text { Instituto de diagnóstico y Refer- } \\
\text { enciaEpidemiologicos (INDRE) }\end{array}$ & $\begin{array}{l}\text { Lambda }-215 \\
\mathrm{Mu}-431\end{array}$ & 38952 & $\begin{array}{l}\text { Lambda }-0,6 \\
\mathrm{Mu}-1,1\end{array}$ & $\begin{array}{l}\text { Lambda }-0 \\
\mathrm{Mu}-1\end{array}$ & 731 & $\begin{array}{l}\text { Lambda }-0 \\
\mathrm{Mu}-0,1\end{array}$ \\
\hline $\begin{array}{c}\text { Нидерланды } \\
\text { (снижение заболевае- } \\
\text { мости) } \\
\end{array}$ & $\begin{array}{l}\text { National Institute for Public } \\
\text { Health and the Environment } \\
\text { (RIVM) }\end{array}$ & $\begin{array}{l}\text { Lambda }-12 \\
\mathrm{Mu}-73\end{array}$ & 74472 & $\begin{array}{l}\text { Lambda }-0 \\
\mathrm{Mu}-0,1\end{array}$ & $\begin{array}{l}\text { Lambda }-0 \\
\mathrm{Mu}-0\end{array}$ & 2395 & $\begin{array}{l}\text { Lambda }-0 \\
\mathrm{Mu}-0\end{array}$ \\
\hline
\end{tabular}




\begin{tabular}{|c|c|c|c|c|c|c|c|}
\hline $\begin{array}{c}\text { Норвегия } \\
\text { (рост } \\
\text { заболеваемости) }\end{array}$ & $\begin{array}{l}\text { Norwegian Institute of Public } \\
\text { Health, Department of Virology }\end{array}$ & Lambda - 1 & 32865 & Lambda -0 & Lambda - 0 & 401 & Lambda -0 \\
\hline $\begin{array}{c}\text { Панама } \\
\text { (стабилизация } \\
\text { заболеваемости) } \\
\end{array}$ & $\begin{array}{c}\text { Gorgas Memorial Laboratory of } \\
\text { Health Studies }\end{array}$ & $\begin{array}{l}\text { Lambda }-6 \\
\mathrm{Mu}-16\end{array}$ & 1262 & $\begin{array}{l}\text { Lambda }-0,5 \\
\mathrm{Mu}-1,3\end{array}$ & $\begin{array}{l}\text { Lambda }-0 \\
\mathrm{Mu}-0\end{array}$ & 0 & $\begin{array}{l}\text { Lambda }-0 \\
\mathrm{Mu}-0\end{array}$ \\
\hline $\begin{array}{c}\text { Перу } \\
\text { (снижение заболевае- } \\
\text { мости) }\end{array}$ & $\begin{array}{l}\text { Laboratorio de Referencia } \\
\text { Nacional de Biotecnología y Bi- } \\
\text { ología Molecular. Instituto } \\
\text { Nacional de SaludPerú }\end{array}$ & $\begin{array}{l}\text { Lambda }-3948 \\
\mathrm{Mu}-207\end{array}$ & 10985 & $\begin{array}{l}\text { Lambda }-35,9 \\
\mathrm{Mu}-1,9\end{array}$ & $\begin{array}{l}\text { Lambda }-4 \\
\mathrm{Mu}-1\end{array}$ & 372 & $\begin{array}{l}\text { Lambda }-1,1 \\
\mathrm{Mu}-0,3\end{array}$ \\
\hline $\begin{array}{c}\text { Польша } \\
\text { (рост заболеваемости) }\end{array}$ & $\begin{array}{l}\text { genXone SA, Research \& De- } \\
\text { velopment Laboratory }\end{array}$ & \begin{tabular}{|l|} 
Lambda -1 \\
$\mathrm{Mu}-8$ \\
\end{tabular} & 31995 & $\begin{array}{l}\text { Lambda }-0 \\
\mathrm{Mu}-0\end{array}$ & $\begin{array}{l}\text { Lambda }-0 \\
\mathrm{Mu}-0\end{array}$ & 3561 & $\begin{array}{l}\text { Lambda }-0 \\
\mathrm{Mu}-0\end{array}$ \\
\hline $\begin{array}{c}\text { Португалия } \\
\text { (рост заболеваемости) }\end{array}$ & $\begin{array}{l}\text { Instituto Nacional de Saude } \\
\text { (INSA) }\end{array}$ & $\begin{array}{l}\text { Lambda }-2 \\
\mathrm{Mu}-25\end{array}$ & 22036 & $\begin{array}{l}\text { Lambda }-0 \\
\mathrm{Mu}-0,1\end{array}$ & $\begin{array}{l}\text { Lambda }-0 \\
\mathrm{Mu}-0\end{array}$ & 1172 & $\begin{array}{l}\text { Lambda }-0 \\
\mathrm{Mu}-0\end{array}$ \\
\hline Пуэрто Рико & $\begin{array}{l}\text { Centers for Disease Control and } \\
\text { Prevention Division of Viral } \\
\text { Dis- eases, Pathogen Discovery }\end{array}$ & $\begin{array}{l}\text { Lambda }-6 \\
\mathrm{Mu}-64\end{array}$ & 4560 & $\begin{array}{l}\text { Lambda }-0,1 \\
\mathrm{Mu}-1,4\end{array}$ & $\begin{array}{l}\text { Lambda }-0 \\
\mathrm{Mu}-0\end{array}$ & 13 & $\begin{array}{l}\text { Lambda }-0 \\
\mathrm{Mu}-0\end{array}$ \\
\hline $\begin{array}{c}\text { Республика Сальва- } \\
\text { дор } \\
\text { (стабилизация забо- } \\
\text { леваемости) }\end{array}$ & $\begin{array}{l}\text { Genomics and Proteomics De- } \\
\text { partament, Gorgas Memorial In- } \\
\text { stitute For Health Studies }\end{array}$ & Lambda - 13 & 244 & Lambda $-5,3$ & Lambda - 0 & 0 & Lambda -0 \\
\hline
\end{tabular}




\begin{tabular}{|c|c|c|c|c|c|c|c|}
\hline $\begin{array}{c}\text { Россия } \\
\text { (снижение } \\
\text { заболеваемости) }\end{array}$ & $\begin{array}{l}\text { WHO National Influenza Centre } \\
\text { Russian Federation.Center for } \\
\text { Precision Genome Editing and } \\
\text { Genetic Technologies for Bio- } \\
\text { medicine, Pirogov Medical Uni- } \\
\text { versity, Moscow, Russian Fed- } \\
\text { eration.Federal Budget Institu- } \\
\text { tion of Science, State Research } \\
\text { Center for Applied Microbiolo- } \\
\text { gy \& Biotechnology.Group of } \\
\text { Genetic Engeneering and Bio- } \\
\text { technology, Federal Budget In- } \\
\text { stitution of Science 'Central Re- } \\
\text { search Institute of Epidemiolo- } \\
\text { gy' of The Federal Service on } \\
\text { Customers' Rights Protection } \\
\text { and Human Well-being Surveil- } \\
\text { lance.State Research Center of } \\
\text { Virology and Biotechnology } \\
\text { VECTOR, Department of Col- } \\
\text { lection of Microorganisms. }\end{array}$ & $\begin{array}{l}\text { Lambda }-0 \\
\mathrm{Mu}-0\end{array}$ & 10861 & $\begin{array}{l}\text { Lambda }-0 \\
\mathrm{Mu}-0\end{array}$ & $\begin{array}{l}\text { Lambda }-0 \\
\mathrm{Mu}-0\end{array}$ & 136 & $\begin{array}{l}\text { Lambda }-0 \\
\mathrm{Mu}-0\end{array}$ \\
\hline $\begin{array}{c}\text { Румыния } \\
\text { (снижение } \\
\text { заболеваемости) }\end{array}$ & $\begin{array}{l}\text { National Institute of Infectious } \\
\text { Diseases- Prof. Dr. Matei Bals } \\
\text { Molecular Diagnostics Laborato- } \\
\text { ry }\end{array}$ & $\mathrm{Mu}-1$ & 7722 & $\mathrm{Mu}-0$ & $\mathrm{Mu}-0$ & 91 & $\mathrm{Mu}-0$ \\
\hline $\begin{array}{c}\text { Сент-Винсент и } \\
\text { Гренадины }\end{array}$ & & $\mathrm{Mu}-3$ & 38 & $\mathrm{Mu}-7,9$ & $\mathrm{Mu}-0$ & 0 & $\mathrm{Mu}-0$ \\
\hline $\begin{array}{c}\text { Сент- Китс и Невис } \\
\text { (рост заболеваемости) }\end{array}$ & $\begin{array}{l}\text { Carrington Lab, Department of } \\
\text { Preclinical Sciences, Faculty of } \\
\text { Medical Sciences, The Universi- } \\
\text { ty of the West Indies }\end{array}$ & Lambda -25 & 29 & Lambda $-86,2$ & Lambda -0 & 3 & Lambda -0 \\
\hline
\end{tabular}




\begin{tabular}{|c|c|c|c|c|c|c|c|}
\hline Синт-Мартен & $\begin{array}{l}\text { National Institute for Public } \\
\text { Health and the Environment } \\
\text { (RIVM) }\end{array}$ & $\begin{array}{l}\text { Lambda - } 3 \\
\mathrm{Mu}-3\end{array}$ & 1749 & $\begin{array}{l}\text { Lambda }-0,2 \\
\mathrm{Mu}-0,2\end{array}$ & $\begin{array}{l}\text { Lambda }-0 \\
\mathrm{Mu}-0\end{array}$ & 0 & $\begin{array}{l}\text { Lambda }-0 \\
\mathrm{Mu}-0\end{array}$ \\
\hline $\begin{array}{c}\text { Словакия } \\
\text { (снижение заболевае- } \\
\text { мости) } \\
\end{array}$ & $\begin{array}{l}\text { Faculty of Natural Sciences, } \\
\text { Come- nius University }\end{array}$ & $\mathrm{Mu}-4$ & 13672 & $\mathrm{Mu}-0$ & $\mathrm{Mu}-0$ & 821 & $\mathrm{Mu}-0$ \\
\hline $\begin{array}{c}\text { Словения } \\
\text { (снижение заболевае- } \\
\text { мости) } \\
\end{array}$ & $\begin{array}{l}\text { Institute of Microbiology and } \\
\text { Immunology, Faculty of Medi- } \\
\text { cine, University of Ljubljana }\end{array}$ & $\mathrm{Mu}-4$ & 33748 & $\mathrm{Mu}-0$ & $\mathrm{Mu}-0$ & 0 & $\mathrm{Mu}-0$ \\
\hline $\begin{array}{c}\text { США } \\
\text { (рост заболеваемости) }\end{array}$ & $\begin{array}{l}\text { Colorado Department of Public } \\
\text { Health \& Environment. } \\
\text { Maine Health and Environmen- } \\
\text { tal Testing Laboratory. } \\
\text { California Department of Public } \\
\text { Health. UCSD EXCITE. }\end{array}$ & $\begin{array}{l}\text { Lambda }-1269 \\
\mathrm{Mu}-5851\end{array}$ & 1776726 & $\begin{array}{l}\text { Lambda }-0,1 \\
\mathrm{Mu}-0,3\end{array}$ & $\begin{array}{l}\text { Lambda }-0 \\
\mathrm{Mu}-2\end{array}$ & 65579 & $\begin{array}{l}\text { Lambda }-0 \\
\mathrm{Mu}-0\end{array}$ \\
\hline Тёркс и Кайкос & $\begin{array}{l}\text { Carrington Lab, Department of } \\
\text { Preclinical Sciences, Faculty of } \\
\text { Medical Sciences, The Universi- } \\
\text { ty of the West Indies }\end{array}$ & $\mathrm{Mu}-1$ & 16 & $\mathrm{Mu}-6,3$ & $\mathrm{Mu}-0$ & 0 & $\mathrm{Mu}-0$ \\
\hline $\begin{array}{c}\text { Турция } \\
\text { (снижение заболевае- } \\
\text { мости) } \\
\end{array}$ & Ministry of Health Turkey & $\begin{array}{l}\text { Lambda }-44 \\
\mathrm{Mu}-2\end{array}$ & 72532 & $\begin{array}{l}\text { Lambda }-0,1 \\
\mathrm{Mu}-0\end{array}$ & $\begin{array}{l}\text { Lambda }-0 \\
\mathrm{Mu}-0\end{array}$ & 3314 & $\begin{array}{l}\text { Lambda }-0 \\
\mathrm{Mu}-0\end{array}$ \\
\hline $\begin{array}{c}\text { Уругвай } \\
\text { (рост } \\
\text { заболеваемости) }\end{array}$ & $\begin{array}{l}\text { Centro de Innovación en Vigi- } \\
\text { lancia Epidemiológica (CiVE), } \\
\text { Institut Pasteur Montevideo, } \\
\text { Uruguay }\end{array}$ & Lambda -1 & 739 & Lambda $-0,1$ & Lambda -0 & 0 & Lambda -0 \\
\hline $\begin{array}{c}\text { Финляндия } \\
\text { (рост заболеваемости) }\end{array}$ & $\begin{array}{l}\text { Department of Virology, Faculty } \\
\text { of Medicine, University of Hel- } \\
\text { sinki }\end{array}$ & $\mathrm{Mu}-5$ & 21345 & $\mathrm{Mu}-0$ & $\mathrm{Mu}-0$ & 0 & $\mathrm{Mu}-0$ \\
\hline $\begin{array}{c}\text { Франция } \\
\text { (рост заболеваемости) }\end{array}$ & $\begin{array}{l}\text { CNR Virus des Infections Res- } \\
\text { piratoires - France SUD }\end{array}$ & $\begin{array}{l}\text { Lambda }-65 \\
\mathrm{Mu}-32\end{array}$ & 146631 & $\begin{array}{l}\text { Lambda }-0 \\
\mathrm{Mu}-0\end{array}$ & $\begin{array}{l}\text { Lambda }-0 \\
\mathrm{Mu}-0\end{array}$ & 6072 & $\begin{array}{l}\text { Lambda }-0 \\
\mathrm{Mu}-0\end{array}$ \\
\hline $\begin{array}{c}\text { Чехия } \\
\text { (рост заболеваемости) } \\
\end{array}$ & $\begin{array}{l}\text { The National Institute of Public } \\
\text { Health }\end{array}$ & $\begin{array}{l}\text { Lambda }-1 \\
\mathrm{Mu}-1\end{array}$ & 15874 & $\begin{array}{l}\text { Lambda }-0 \\
\mathrm{Mu}-0\end{array}$ & $\begin{array}{l}\text { Lambda }-0 \\
\mathrm{Mu}-0\end{array}$ & 543 & $\begin{array}{l}\text { Lambda }-0 \\
\mathrm{Mu}-0\end{array}$ \\
\hline
\end{tabular}




\begin{tabular}{|c|c|c|c|c|c|c|c|}
\hline $\begin{array}{c}\text { Чили } \\
\text { (снижение заболевае- } \\
\text { мости) }\end{array}$ & $\begin{array}{l}\text { Instituto de Salud Publica de } \\
\text { Chile }\end{array}$ & $\begin{array}{l}\text { Lambda }-1834 \\
\mathrm{Mu}-953\end{array}$ & 16273 & $\begin{array}{l}\text { Lambda }-11,3 \\
\mathrm{Mu}-5,9\end{array}$ & $\begin{array}{l}\text { Lambda }-2 \\
\mathrm{Mu}-8\end{array}$ & 788 & $\begin{array}{l}\text { Lambda }-0,3 \\
\mathrm{Mu}-1,0\end{array}$ \\
\hline $\begin{array}{c}\text { Швейцария } \\
\text { (рост } \\
\text { заболеваемости) } \\
\end{array}$ & $\begin{array}{l}\text { Department of Biosystems Sci- } \\
\text { ence and Engineering, ETH Zü- } \\
\text { rich. }\end{array}$ & $\begin{array}{l}\text { Lambda }-36 \\
\mathrm{Mu}-48\end{array}$ & 91244 & $\begin{array}{l}\text { Lambda }-0 \\
\mathrm{Mu}-0,1\end{array}$ & $\begin{array}{l}\text { Lambda }-0 \\
\mathrm{Mu}-0\end{array}$ & 8313 & $\begin{array}{l}\text { Lambda }-0 \\
\mathrm{Mu}-0\end{array}$ \\
\hline $\begin{array}{c}\text { Швеция } \\
\text { (рост } \\
\text { заболеваемости) } \\
\end{array}$ & $\begin{array}{l}\text { The Public Health Agency of } \\
\text { Sweden }\end{array}$ & $\begin{array}{l}\text { Lambda }-4 \\
\mathrm{Mu}-4\end{array}$ & 131146 & $\begin{array}{l}\text { Lambda }-0 \\
\mathrm{Mu}-0\end{array}$ & $\begin{array}{l}\text { Lambda }-0 \\
\mathrm{Mu}-0\end{array}$ & 5725 & $\begin{array}{l}\text { Lambda }-0 \\
\mathrm{Mu}-0\end{array}$ \\
\hline $\begin{array}{c}\text { Эквадор } \\
\text { (снижение заболевае- } \\
\text { мости) } \\
\end{array}$ & $\begin{array}{l}\text { Instituto Nacional de Investi- } \\
\text { gaciónenSaludPública, INSPI }\end{array}$ & $\begin{array}{l}\text { Lambda }-304 \\
\mathrm{Mu}-444\end{array}$ & 3552 & $\begin{array}{l}\text { Lambda }-8,6 \\
\mathrm{Mu}-12,5\end{array}$ & $\begin{array}{l}\text { Lambda }-0 \\
\mathrm{Mu}-9\end{array}$ & 170 & $\begin{array}{l}\text { Lambda }-0 \\
\mathrm{Mu}-5,3\end{array}$ \\
\hline $\begin{array}{c}\text { ЮАР } \\
\text { (рост заболеваемости) }\end{array}$ & $\begin{array}{l}\text { KRISP, KZN Research Innova- } \\
\text { tion and Sequencing Platform }\end{array}$ & $\begin{array}{l}\text { Lambda }-17 \\
\mathrm{Mu}-0\end{array}$ & 24044 & $\begin{array}{l}\text { Lambda }-0,1 \\
\mathrm{Mu}-0\end{array}$ & $\begin{array}{l}\text { Lambda }-0 \\
\mathrm{Mu}-0\end{array}$ & 248 & $\begin{array}{l}\text { Lambda }-0 \\
\mathrm{Mu}-0\end{array}$ \\
\hline $\begin{array}{c}\text { Южная Корея } \\
\text { (рост заболеваемости) }\end{array}$ & $\begin{array}{l}\text { Division of Emerging Infectious } \\
\text { Diseases, Bureau of Infectious } \\
\text { Diseases Diagnosis Control, Ko- } \\
\text { rea Disease Control and Preven- } \\
\text { tion Agency }\end{array}$ & $\begin{array}{l}\text { Lambda }-0 \\
\mathrm{Mu}-1\end{array}$ & 20457 & $\begin{array}{l}\text { Lambda }-0 \\
\mathrm{Mu}-0\end{array}$ & $\begin{array}{l}\text { Lambda }-0 \\
\mathrm{Mu}-0\end{array}$ & 0 & $\begin{array}{l}\text { Lambda }-0 \\
\mathrm{Mu}-0\end{array}$ \\
\hline $\begin{array}{c}\text { Ямайка } \\
\text { (снижение заболевае- } \\
\text { мости) }\end{array}$ & $\begin{array}{l}\text { Carrington Lab, Department of } \\
\text { PreClinical Sciences, Faculty of } \\
\text { Medical Sciences, The Universi- } \\
\text { ty of the West Indies }\end{array}$ & $\mathrm{Mu}-27$ & 312 & $\mathrm{Mu}-8,7$ & $\mathrm{Mu}-0$ & 0 & $\mathrm{Mu}-0$ \\
\hline $\begin{array}{c}\text { Япония } \\
\text { (снижение заболевае- } \\
\text { мости) } \\
\end{array}$ & $\begin{array}{l}\text { Pathogen Genomics Center, Na- } \\
\text { tional Institute of Infectious Dis- } \\
\text { eases }\end{array}$ & $\begin{array}{l}\text { Lambda }-5 \\
\mathrm{Mu}-5\end{array}$ & 162268 & $\begin{array}{l}\text { Lambda }-0 \\
\mathrm{Mu}-0\end{array}$ & $\begin{array}{l}\text { Lambda }-0 \\
\mathrm{Mu}-0\end{array}$ & 45 & $\begin{array}{l}\text { Lambda }-0 \\
\mathrm{Mu}-0\end{array}$ \\
\hline
\end{tabular}




\section{ВОЗ. Эпидемиологическое обновление от 30 ноября}

\section{Особое внимание: обновленная информация о вариантах SARS-CoV-2, пред- ставляющих интерес, и вариантах, вызывающих озабоченность}

\section{VOC Omicron (B.1.1.529)}

26 ноября 2021 года Техническая консультативная группа по эволюции вируса SARS-CoV-2 (TAG-VE) сообщила BO3, что вариант B.1.1.529 следует обозначить как VOC. Ему дали название Omicron. Решение обозначить его как VOC было основано на доказательствах, представленных TAG-VE, что Omicron имеет множество мутаций (в том числе 26-32 в спайковом белке), которые могут повысить его трансмиссивность и / или обеспечить некоторую степень иммунного ускользания. Впервые о варианте В.1.1.529 было сообщено в ВОЗ 24 ноября 2021 года из Южной Африки, а первый известный лабораторно подтвержденный случай был выявлен в образце, взятом 9 ноября 2021 года. 28 ноября 2021 г. ВОЗ опубликовала краткое техническое описание приоритетных действий для государств-членов. Вариант Omicron уже был выявлен в ряде стран с высокой вероятностью дальнейшего распространения. Существуют предварительные данные, свидетельствующие о том, что Omicron может иметь потенциал ускользания от иммунитета и/или, возможно, более высокую трансмиссивность по сравнению с предыдущими VOC, что может привести к дальнейшим волнам пандемии. В результате этого общий глобальный риск, связанный с новым VOC Omicron в контексте пандемии COVID-19, очень высок. Доказательства этой оценки содержат значительную неопределенность и будут обновляться по мере поступления дополнительной информации.

На основании имеющихся данных для государств-членов был рекомендован список приоритетных действий, в том числе:

- Усилить эпиднадзор и мероприятия по определению последовательности, чтобы понять масштабы циркуляции вариантов SARS-CoV-2, включая Omicron.

- Отправлять полные последовательности генома и связанные метаданные в общедоступную базу данных, такую как GISAID.

- По возможности использовать несостоятельность мишени гена S (SGTF) в некоторых тестах полимеразной цепной реакции (ПЦР) в качестве маркера инфекции Omicron.

- Сообщать ВОЗ о первых случаях / кластерах заражения вариантом Omicron через механизм Международных медико-санитарных правил (2005 г.); указывать относительную распространенность Оmicron среди секвенированных образцов и / или, если возможно, количество SGTF из числа протестированных образцов.

- Продолжать регулярно, своевременно и прозрачно сообщать основанную на фактах информацию о других вариантах.

- Как можно быстрее ускорить охват вакцинацией против COVID-19, особенно среди тех, кто не вакцинирован или частично вакцинирован и относится к группе населения, имеющей высокий приоритет для вакцинации.

- Использовать подход, основанный на оценке риска, для своевременной корректировки мер по международным поездкам и сообщать в ВОЗ о применении ограниченных по времени мер, влияющих на международные поездки и торговлю.

- Мероприятия по снижению трансмиссии SARS-CoV-2 - использование хорошо подогнанных масок, физическое дистанцирование, гигиена рук, адекватная вентиляция помещений и недопущение скоплений людей. 
- Обеспечение возможности эффективной корректировки мер общественного здравоохранения и социальных мер в зависимости от местного сценария трансмиссии.

- Подготовиться и обеспечить сохранение основных медицинских услуг, включая необходимые ресурсы здравоохранения, когда спрос на медицинские услуги высок. В настоящее время ВОЗ координирует работу с большим количеством исследователей по всему миру, чтобы лучше понять Omicron. Исследования, проводимые в настоящее время или в ближайшее время, включают оценку трансмиссивности, клинических проявлений, включая тяжесть, риск повторного заражения, а также эффективность вакцин, диагностических тестов и терапевтических средств против этого варианта.

\section{Географическое распространение и преобладание VOC}

Текущая глобальная эпидемиология SARS-CoV-2 характеризуется преобладанием дельта-варианта, при этом распространенность других вариантов продолжает снижаться среди геномных последовательностей, представленных в общедоступных наборах данных или обнаруженных в ВО3 (рисунок 13). Вариант Delta вытеснил другие варианты, включая другие VOC, в большинстве стран. Омикрон, который был идентифицирован недавно, пока зарегистрирован в ограниченном числе стран (Рисунок 14). В настоящее время имеются данные о его распространении на несколько стран в четырех регионах ВОЗ. Хотя большинство случаев, выявленных в этих странах, связаны с поездками, ситуация может измениться по мере поступления дополнительной информации. Из 839119 последовательностей, загруженных в GISAID за последние 60 дней, 837253 (99,8\%) были Delta, 314 $(<0,1 \%)$ Gamma, $160(<0,1 \%)$ Alpha, $159(<0,1 \%)$ Omicron, $14(<0,1 \%)$ Beta и $<0,1 \%$ включали другие циркулирующие варианты (включая VOI Mu и Lambda). По-прежнему наблюдаются различия на субрегиональном и страновом уровнях; особенно в некоторых странах Южной Америки, где распространение варианта Дельта было более постепенным, а другие варианты (например, гамма, лямбда, $\mathrm{Mu}$ ) по-прежнему составляют значительную часть определенных последовательностей. В Южной Африке, где впервые был обнаружен Омикрон, недавно произошло резкое увеличение числа случаев заболевания во многих провинциях, что совпало с обнаружением варианта Омикрон.

Рис 13. Распространение VOCs Alpha, Beta, Gamma и Delta в последние 60 дней к 30 ноября 2021 

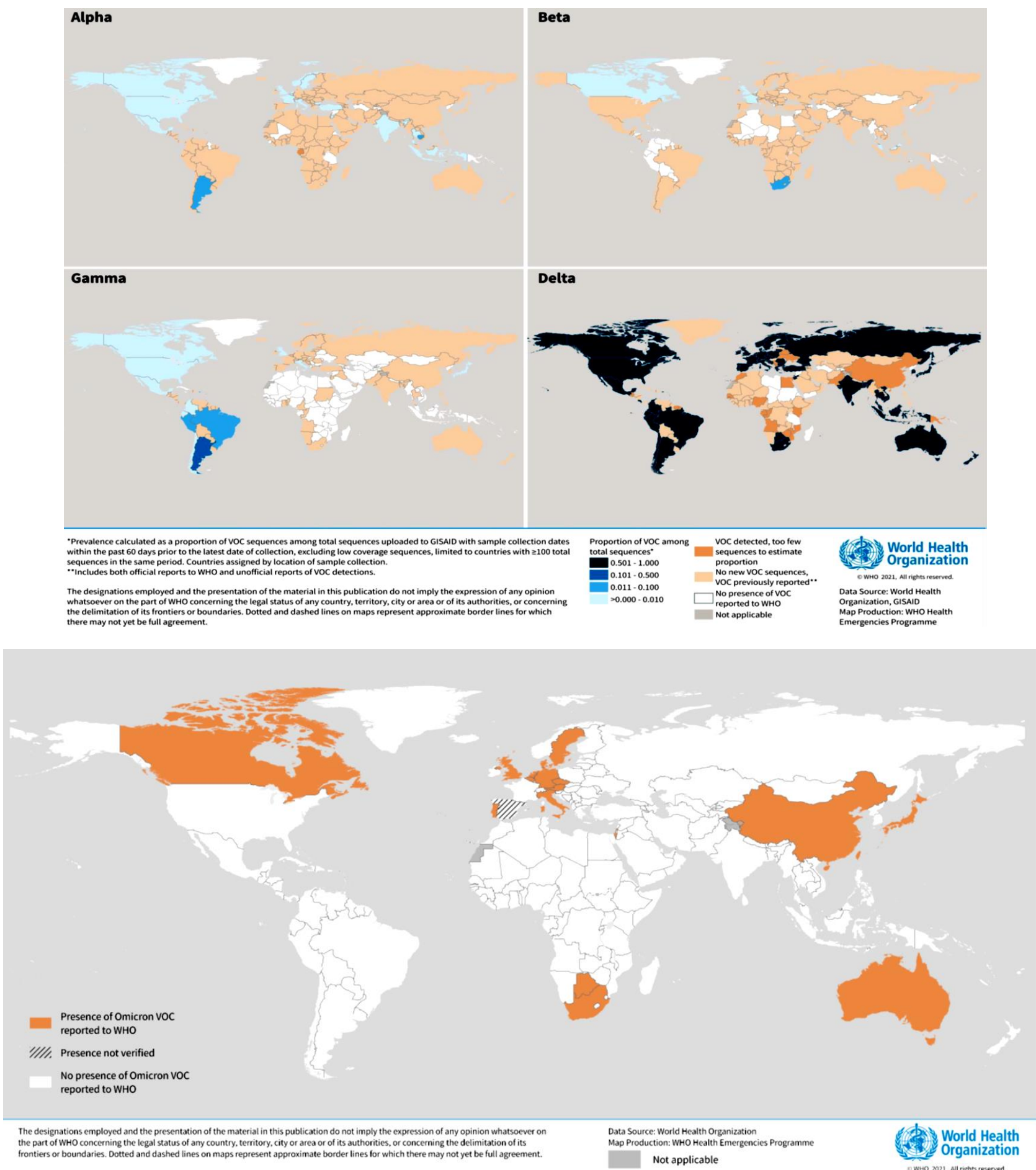

\section{Рис 14. Выявление VOC Omicron, на 30 ноября 2021 года}

\section{Фенотипические характеристики}

Имеющиеся данные о фенотипических проявлениях VOC обобщены в таблице 3, a также в предыдущих выпусках еженедельного эпидемиологического бюллетеня по COVID-19. После последнего подробного обновления 16 ноября появилось несколько новых публикаций по фенотипическим характеристикам VOC.

Ретроспективное когортное исследование (еще не прошедшее экспертную оценку) было проведено в городе Белу-Оризонти, Бразилия, для оценки влияния гамма-варианта на госпитализацию и смертность. Гамма-вариант стал доминирующим вариантом в стране 
с января 2021 года после его появления в штате Амазонас в декабре 2020 года. Социальнодемографические характеристики широко варьировались по стране и до появления гаммаварианта; смертность среди госпитализированных в городские больницы была ниже, чем среди госпитализированных в сельской местности. В исследование были включены в общей сложности 42443 пациента, у которых был положительный результат на SARS-CoV-2 в ОТ-ПЦР в период с 13 марта 2020 года по 9 сентября 2021 года. Используя многомерный логистический регрессионный анализ с поправкой на ковариаты, такие как пол, этническая принадлежность, возраст, социально-экономический статус, сопутствующие заболевания и тяжесть симптомов, сопоставляли внутрибольничную смертность между периодами, при сравнении первого периода, 13 марта - 18 октября 2020 г., со вторым периодом, 19 октября - 14 февраля 2021 г (OR = 1,08, 95\% ДИ 0,98-1,19, p = 0,117). Однако госпитальная летальность была выше в третьем периоде с 15 февраля по 9 сентября 2021 г. (OR $=1,95,95 \%$ ДИ $=1,79-2,11, \mathrm{p}<0,001)$ по сравнению с первым периодом. Это говорит о том, что смертность была выше в периоды передачи гамма-варианта, однако неизвестно, связано ли это с более патогенным действием вируса или явилось результатом повышенной нагрузки на систему здравоохранения.

В рецензируемом ретроспективном исследовании, проведенном в Израиле в период с февраля 2020 года по октябрь 2021 года, изучались тенденции в заболеваемости, заболеваемости и смертности от COVID-19. Четвертый всплеск заболеваемости по всей стране, зарегистрированный с июня по сентябрь 2021 года, был вызван вариантом Дельта и характеризовался самым высоким уровнем инфицирования - более 11000 случаев в день; количество тяжелых госпитализаций из-за COVID-19 в четвертый период было ниже по сравнению с теми, о которых сообщалось во время предыдущих трех всплесков (например, максимум 8 на 100000 населения в четвертом всплеске против максимум 16 на 100000 населения во втором периоде). Во время четвертого всплеска были зарегистрированы более высокие показатели смертности среди людей, которые не были полностью вакцинированы, по сравнению с теми, кто был полностью вакцинирован $(0,1$ смертей на 100000 населения у полностью вакцинированных лиц против более 0,7 смертей на 100000 населения у частично вакцинированных лиц). Большинство мер общественного здравоохранения и социальных мер были отменены в апреле и мае 2021 года, что, возможно, способствовало более высокому уровню трансмиссии во время четвертого всплеска. Авторы пришли к выводу, что сокращение госпитализаций и смертности в четвертом периоде по сравнению с предыдущими волнами, вероятно, отражает более высокий охват вакцинацией.

CDC (US) было проведено исследование (еще не прошедшее экспертную оценку) по оценке маркеров выделения вируса среди 95 заключенных с различным прививочным статусом (82\% полностью вакцинированы, $16 \%$ не вакцинированы и $2 \%$ частично вакцинированы) во время вспышки Delta-варианта в федеральной тюрьме (18 июля - 9 августа 2021 г.). У небольшого числа участников (3\% полностью вакцинированных и 12\% не полностью вакцинированных) была задокументированная ранее инфекция SARS-CoV-2. Cpeди лиц, у которых в анамнезе не было инфекции, не было различий в средней продолжительности положительной реакции ОТ-ПЦР между полностью вакцинированными и не полностью вакцинированными (13 дней; $\mathrm{p}=0,50)$. Средняя продолжительность заболевания среди тех, у кого в анамнезе была предыдущая инфекция, независимо от их вакцинационного статуса, была короче, 10 дней, но без каких-либо доказательств разницы по сравнению с пациентами без предыдущей инфекции $(\mathrm{p}=0,12)$. Не было обнаружено различий в средней продолжительности положительной реакции ОТ-ПЦР в зависимости от 
типа вакцины (13 дней; $\mathrm{p}=0,39)$. Точно так же не было различий в продолжительности выделения вирусной культуры между полностью и не полностью вакцинированными (в среднем 5 дней для обеих групп). Наконец, не было доказательств разницы в величине $\mathrm{Ct}$ в зависимости от статуса вакцинации, типа вакцины, времени после вакцинации или известного предшествующего заражения ( $\mathrm{p}>0,0026$, порог $\alpha$ с поправкой на Бонферрони).

Опубликованное исследование, проведенное CDC США, сравнивало шансы лабораторно подтвержденного COVID-19 между невакцинированными взрослыми пациентами ( $\geq 18$ лет) с предыдущей инфекцией SARS-CoV-2, возникшей за 90-179 дней до госпитализации, и пациентами, которые были полностью вакцинированы мРНК-вакциной COVID-19 за 90-179 дней до госпитализации без ранее зарегистрированной инфекции SARS-CoV-2. Пациенты включались в исследование, если они проходили тестирование хотя бы дважды: один раз в связи с госпитализацией по поводу COVID-19-подобного заболевания в течение периода исследования (1 января-2 сентября 2021 г.) и, по крайней мере, один раз ранее (в период с 1 февраля 2020 г. и $\geq 14$ дней до текущего приема). Среди 201269 госпитализированных с заболеванием, похожим на COVID-19, 7348 соответствовали критериям включения в исследование, из которых 1020 были ранее инфицированы и не вакцинированы, а 6328 - полностью вакцинированы и ранее не инфицированы. При многомерной логистической регрессии скорректированные шансы лабораторно подтвержденной COVID-19 были в 5,49 раза выше (95\% ДИ 2,75-10,99) среди тех, кто не был вакцинирован от предыдущей инфекции, по сравнению с теми, кто был полностью вакцинирован без предыдущей инфекции. Эти данные свидетельствуют о том, что иммунитет, индуцированный вакциной, обеспечивает лучшую защиту, чем иммунитет, индуцированный инфекцией, против лабораторно подтвержденной COVID-19.

Таблица 3: Сводные данные о фенотипических изменениях* у VOC

\begin{tabular}{|c|c|c|c|c|c|}
\hline $\begin{array}{c}\text { Обозначе- } \\
\text { ние ВО3 }\end{array}$ & Альфа & Бета & Гамма & Дельта & Омикрон \\
\hline $\begin{array}{l}\text { Трансмис- } \\
\text { ивность }\end{array}$ & Повышенная & Повышенная & Повышенная & Повышенная & $\begin{array}{l}\text { Нет прямых } \\
\text { данных }\end{array}$ \\
\hline $\begin{array}{l}\text { Тяжесть } \\
\text { заболева- } \\
\text { ния }\end{array}$ & $\begin{array}{l}\text { Возможен по- } \\
\text { вышенный } \\
\text { риск госпита- } \\
\text { лизации, тяже- } \\
\text { лого течения и } \\
\text { летальности }\end{array}$ & $\begin{array}{l}\text { Возможен } \\
\text { повышен- } \\
\text { ный риск } \\
\text { госпитали- } \\
\text { зации и вну- } \\
\text { трибольнич- } \\
\text { ной смерт- } \\
\text { ности }\end{array}$ & $\begin{array}{l}\text { Возможен по- } \\
\text { вышенный } \\
\text { риск госпита- } \\
\text { лизации и тя- } \\
\text { желого тече- } \\
\text { ния }\end{array}$ & $\begin{array}{l}\text { Повышенный } \\
\text { риск госпитали- } \\
\text { зации }\end{array}$ & $\begin{array}{l}\text { Пока неиз- } \\
\text { вестно. } \\
\text { Данные по } \\
\text { клиниче- } \\
\text { ским исхо- } \\
\text { дам изуча- } \\
\text { ются }\end{array}$ \\
\hline $\begin{array}{l}\text { Риск ре- } \\
\text { инфекции }\end{array}$ & $\begin{array}{l}\text { Сохраняется } \\
\text { нейтрализую- } \\
\text { щая актив- } \\
\text { ность, риск } \\
\text { повторного за- } \\
\text { ражения оста- } \\
\text { ется аналогич- }\end{array}$ & $\begin{array}{l}\text { Сообщается } \\
\text { о снижении } \\
\text { нейтрализу- } \\
\text { ющей актив- } \\
\text { ности; Т- } \\
\text { клеточный } \\
\text { ответ на ви- }\end{array}$ & $\begin{array}{l}\text { Сообщается } \\
\text { об умеренном } \\
\text { снижении } \\
\text { нейтрализу- } \\
\text { ющей актив- } \\
\text { ности }\end{array}$ & $\begin{array}{l}\text { Сообщается о } \\
\text { снижении } \\
\text { нейтрализующей } \\
\text { активности }\end{array}$ & $\begin{array}{l}\text { Предвари- } \\
\text { тельные } \\
\text { данные сви- } \\
\text { детельству- } \\
\text { ют в пользу } \\
\text { возможного } \\
\text { повышения }\end{array}$ \\
\hline
\end{tabular}




\begin{tabular}{|c|c|c|c|c|c|}
\hline & ным & $\begin{array}{l}\text { рус D614G, } \\
\text { остается эф- } \\
\text { фективным }\end{array}$ & & & $\begin{array}{l}\text { риска реин- } \\
\text { фекции }\end{array}$ \\
\hline $\begin{array}{l}\text { Влияние } \\
\text { на диагно- } \\
\text { стику }\end{array}$ & $\begin{array}{l}\text { Ограниченное } \\
\text { воздействие - } \\
\text { несостоятель- } \\
\text { ность мишени } \\
\text { гена S (SGTF); } \\
\text { не влияет на } \\
\text { общий резуль- } \\
\text { тат ОТ-ПЦР с } \\
\text { множеством } \\
\text { мишеней. Не } \\
\text { наблюдается } \\
\text { влияния на } \\
\text { RDTs на АГ }\end{array}$ & $\begin{array}{l}\text { Влияния на } \\
\text { OT-ПЦР или } \\
\text { RDTs на АГ } \\
\text { не наблюда- } \\
\text { лось }\end{array}$ & $\begin{array}{l}\text { На сегодняш- } \\
\text { ний день нет } \\
\text { сообщений }\end{array}$ & $\begin{array}{l}\text { Влияния на ОT- } \\
\text { ПЦР или RDTs на } \\
\text { АГ не наблюда- } \\
\text { лось }\end{array}$ & $\begin{array}{l}\text { ПЦР выяв- } \\
\text { ляет вари- } \\
\text { ант Омик- } \\
\text { рон. Влия- } \\
\text { ние на RDTs } \\
\text { на АГ изу- } \\
\text { чается }\end{array}$ \\
\hline
\end{tabular}

* Обобщенные результаты по сравнению с ранее/совместно циркулирующими вариантами. Основано на новых данных, в т. ч. на препринтах и отчетах, не прошедших экспертную оценку. Все они подлежат постоянному исследованию и пересмотру.

В таблице 4 суммировано влияние вариантов на эффективность / действенность вакцины (VE) для конкретного продукта и дана количественная оценка снижения VE в условиях вариантов по сравнению с параметрами не VOC. На момент написания этого обновления исследований по нейтрализации или эффективности вакцины против варианта Омикрон не проводилось. После обновления от 16 ноября шесть заметных новых исследований предоставили доказательства эффективности вакцины от COVID-19 против других вариантов, вызывающих озабоченность.

В рецензируемом исследовании случай-контроль с отрицательными результатами тестов из Индии оценивалась эффективность инактивированной цельновирионной вакцины Бхарат-Коваксин в предотвращении симптоматических заболеваний среди сотрудников больницы в Нью-Дели с 15 апреля 2021 года по 15 мая 2021 г., когда Delta был доминирующим циркулирующим вариантом. VE одной и двух доз вакцины для предотвращения симптоматического заболевания через 14 или более дней после вакцинации составляла 1\% (95\% ДИ: -51-33\%, статистически недостоверно) и 50\% (33-62\%) соответственно. При исключении лиц, которые ранее были инфицированы SARS-CoV-2, VE двух доз вакцины составляла 47\% (29-61\%) против симптоматического заболевания среди этой популяции с высокой экспозицией, со средним сроком наблюдения 50 дней с момента получения второй дозы.

Во втором исследовании случай-контроль (еще не прошедшем экспертную оценку) с отрицательным результатом теста оценивалась эффективность Sinovac-CoronaVac среди 19838 беременных женщин в возрасте 18-49 лет в Бразилии с 15 марта 2021 года по 3 октября 2021 года. Гамма был преобладающим вариантом в течение большей части этого периода, в то время как Delta стал преобладающим циркулирующим вариантом в течение последних 1-2 месяцев исследования. Эффективность одной и двух доз вакцины для предотвращения симптоматического заболевания через 14 или более дней после вакцина- 
ции составила 5\% (-18,2-23,7\%, статистически недостоверно) и 41\% (27,0-52,2\%), соответственно. VE одной и двух доз против развития тяжелого заболевания (определяется как одышка или респираторный дискомфорт, постоянное давление или боль в груди, сатурация кислорода менее 95\% в помещении, цианоз губ или лица) или госпитализация в связи c COVID-19 или смерть среди беременных женщин, инфицированных SARS-CoV-2, coставила $67,7 \%(20,0-87,0)$ и 85,4\% (59,4-94,8\%), соответственно. Максимальное время наблюдения после введения последней дозы составило примерно 28 недель.

В третьем ретроспективном когортном исследовании (еще не прошедшем экспертную оценку) из Объединенных Арабских Эмиратов оценивалась эффективность применения пекинской вакцины CNBG-BBIBP-CorV в отношении госпитализации и смерти жителей Абу-Даби с сентября 2020 года по апрель 2021 года, где изначально была высокая распространенность не-VOC, затем последовал период преобладания альфа, а затем - период преобладания бета в самом конце. Авторы отмечают, что варианты альфа и бета составляли большинство случаев в течение периода исследования, хотя не представлена оценка VE для конкретных вариантов. Однократная доза пекинской вакцины CNBGBBIBP-CorV оказалась неэффективной для предотвращения госпитализации (VE: -35\%, 95\%, ДИ: от -45 до $-26 \%$ ) и показала низкую VE против смерти через 14 или более дней после вакцинации (VE: 12\%, 95\% ДИ: -95\% -61\%, статистически недостоверно). Однако две дозы вакцины имели VE против госпитализации и смерти 74\% (72-76\%) и 96\% (6999\%) через 14 или более дней после иммунизации. Максимальное время наблюдения после введения последней дозы составило примерно 33,5 недели.

Четвертое рецензированное ретроспективное когортное исследование, проведенное в Сингапуре, оценивало VE вакцин Moderna-mRNA-1273 и Pfizer BioNTech-Comirnaty для предотвращения инфекции, симптоматических заболеваний и тяжелых заболеваний среди 1204 семейных контактов 301 подтвержденного случая, вызванного дельта. Две дозы любой вакцины имели VE 61,6\% (95\% ДИ: 37,5-80,4\%), 67,9\% (41,3-87,8\%) и 100\% (ДИ недоступен из-за отсутствия событий среди вакцинированных лиц) для предотвращения инфекции, симптоматического заболевания и тяжелого заболевания, соответственно, через 15 или более дней после приема второй дозы. Более низкие оценки VE для инфекции и симптоматического заболевания, чем в других исследованиях, вероятно, отражают высокий риск заражения среди лиц, контактировавших с больными в семье. Кроме того, после поправки на возраст, пол и вакцинационный статус домашних контактов, показано, что вакцинированные индексные случаи с меньшей вероятностью заражали контактных членов своих семей по сравнению с невакцинированными, хотя этот результат не был статистически значимым (VE против передачи: 27\%, 95\% ДИ: -40-62\%).

Пятое проспективное когортное исследование из Соединенного Королевства (еще не прошедшее экспертную оценку) оценивало VE AstraZeneca-Vaxzevria и Pfizer BioNTechComirnaty в отношении передачи инфекции SARS-CoV-2 лицам, контактирующим в домохозяйствах с больными, зараженными вариантами альфа и дельта, по отдельности. После поправки на возраст и вакцинационный статус контактов VE двух доз вакцин AstraZeneca-Vaxzevria или Pfizer BioNTech-Comirnaty составила 35\% (95\% ДИ: -26-74\%, статистически недостоверно) и 57\% (5-85\%) для предотвращения передачи инфекции в случае варианта Альфа, и 42\% (14-69) и 31\% (-3-61\%, статистически недостоверно) - Delta контактам в домохозяйствах.

Наконец, в исследовании случай-контроль (еще не прошедшем экспертную оценку) с отрицательным результатом теста в Соединенном Королевстве оценивалась VE третьей 
дозы Pfizer BioNTech-Comirnaty в дополнение к первичной вакцинации двумя дозами AstraZeneca-Vaxzevria, либо двумя дозами Pfizer BioNTech-Comirnaty среди лиц 50 лет и старше в период, когда Delta был доминирующим вариантом. По сравнению с лицами, получавшими две дозы AstraZeneca-Vaxzevria за 140 или более дней до тестирования без ревакцинации, относительная VE двух доз AstraZeneca-Vaxzevria плюс дополнительная доза Pfizer BioNTech-Comirnaty составила 87,4\% (84,9-89,4\%) против симптоматического заболевания через 14 или более дней после введения дополнительной дозы. Относительная VE против симптоматического заболевания третьей дозы Pfizer BioNTech-Comirnaty после первичной серии Pfizer BioNTech-Comirnaty по сравнению только с двумя дозами Pfizer BioNTech-Comirnaty составила 84,4\% (82,8\%-85,8\%). При использовании невакцинированной группы для сравнения, абсолютная VE третьей дозы Pfizer BioNTech-Comirnaty после первичной серии AstraZeneca-Vaxzevria составила 93,1\% (91,7-94,3\%); абсолютная VE трех доз Pfizer BioNTech-Comirnaty составила 94,0\% (93,4-94,6\%). 
Таблица 4. Сводные данные об эффективности вакцин против вызывающих озабоченность вариантов

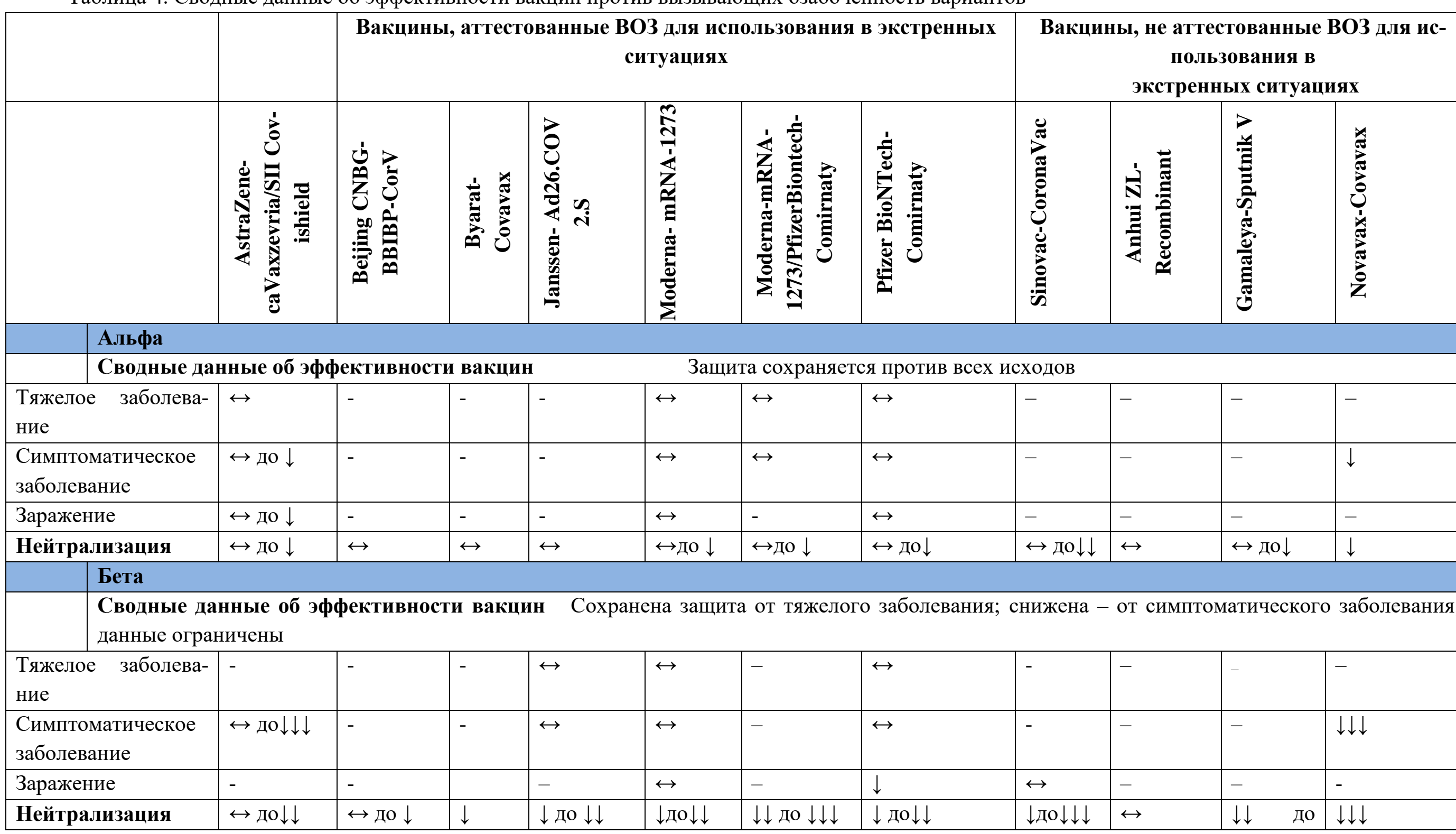




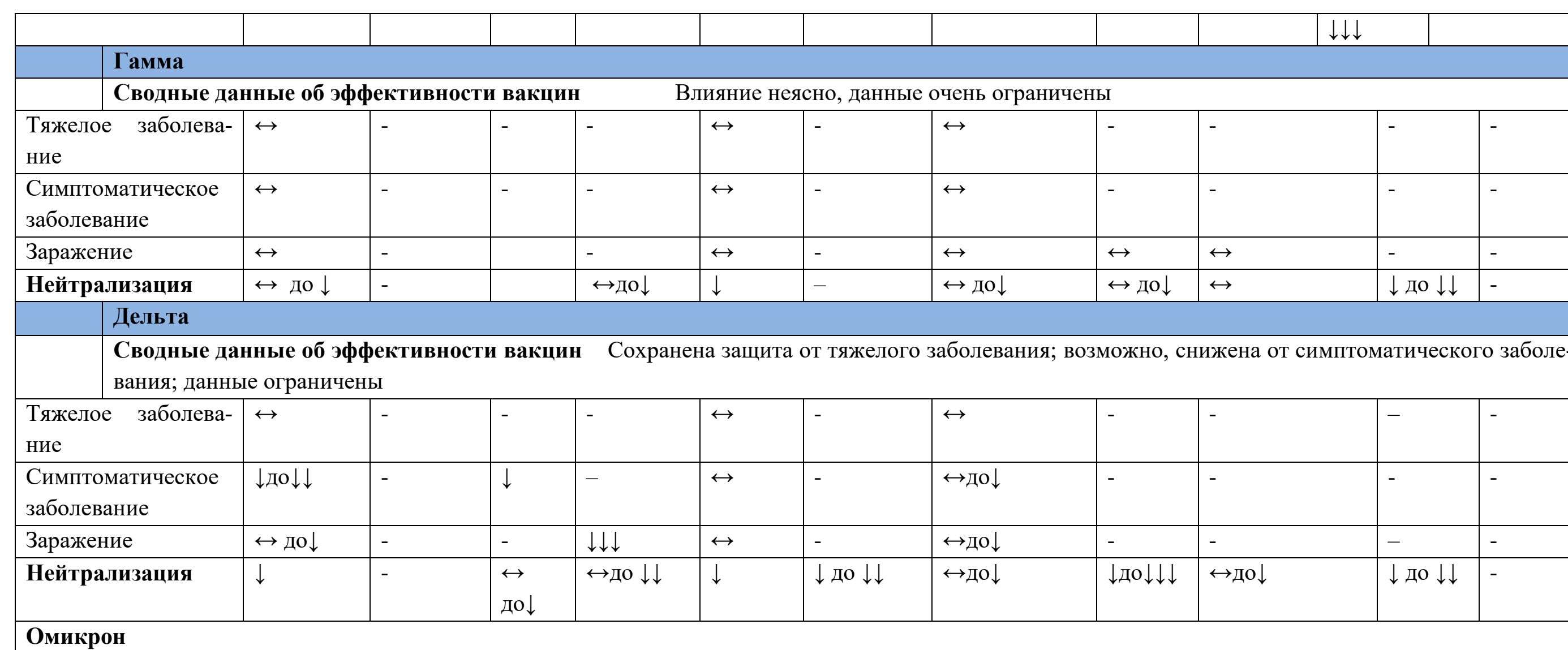

«VE» относится к эффективности вакцины или действенности вакцины. «Краткое изложение VЕ»: указывает общие выводы, но только для вакцин, оцениваемых в отношении конкретных вариантов. Стрелки обобщают величину снижения VE или нейтрализации: «↔» $<10 \%$

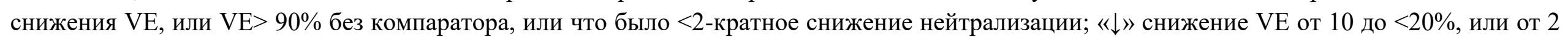

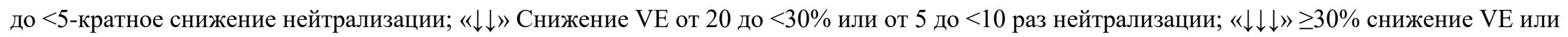
$\geq 10$-кратное снижение нейтрализации. 


\section{Публикации:}

Sci Adv. 2021 Dec 3;7(49):eabk0172.

doi: 10.1126/sciadv.abk0172. Epub 2021 Dec 1. PMID: 34851677

Live attenuated virus vaccine protects against SARS-CoV-2 variants of concern B.1.1.7 (Alpha) and B.1.351 (Beta)

Живая аттенуированная вирусная вакцина защищает от вызывающих озабоченность вариантов SARS-CoV-2 B.1.1.7 (Alpha) и B.1.351 (Beta)

Jakob Trimpert, Julia M Adler, Kathrin Eschke, и др.

Авторы сконструировали живые аттенуированные вакцины-кандидаты путем широкомасштабного перекодирования генома SARS-CoV-2 и показали, что ведущий кандидат, обозначенный SCPD9, защищает сирийских хомяков от заражения предковым вирусом. Они оценили иммуногенность и защитную эффективность SCPD9 у карликового хомячка Роборовски, нетрансгенного вида грызунов, который очень чувствителен к SARS-CoV-2 и подвержен тяжелому заболеванию, подобному COVID-19. Показано, что однократная интраназальная вакцинация SCPD9 индуцировала сильные перекрестно-нейтрализующие реакции антител против четырех вызывающих озабоченность вариантов SARS-CoV-2: B.1.1.7 (Альфа), B.1.351 (Бета), В.1.1.28.1 (Гамма) и В.1.617.2 (Дельта). Вакцина sCPD9 обеспечивала полную защиту от COVID-19-подобного заболевания, вызванного предковым SARS-CoV-2 вариантом B.1 и двумя вызывающими озабоченность вариантами В.1.1.7 и В.1.351.

Anal Chem. 2021 Dec 1.

doi: 10.1021/acs.analchem.1c02368. Online ahead of print.

Rapid Identification of SARS-CoV-2 Variants of Concern Using a Portable peak PCR Platform

Быстрая идентификация вызывающих беспокойство вариантов SARS-CoV-2 c помощью портативной платформы для peak ПЦР

Philippe Bechtold, Philipp Wagner, Salome Hosch, и др.

- PMID: 34852455

Потребность в инструментах, которые облегчают быстрое обнаружение и постоянный мониторинг вызывающих озабоченность вариантов SARS-CoV-2 (VOC), как никогда высока, поскольку эти варианты более передаются и, следовательно, увеличивают давление COVID-19 на системы здравоохранения. Чтобы удовлетворить этот спрос, авторы стремились разработать и оценить надежный и быстрый диагностический подход для выявления генных мутаций в спайке у VOC SARS-CoV-2. Эти диагностические тесты обнаруживают однонуклеотидные полиморфизмы (SNP) E484K и N501Y, а также делецию гена-шипа (HV69/70) и могут выполняться на стандартном лабораторном оборудовании или на портативной платформе технологии быстрой диагностики - peakPCR. Продемонстрирована отличная диагностическая эффективность при тестировании РНК, выделенной из культуральных линий VOC SARS-CoV-2, и клинических образцов, собранных в Экваториальной Гвинее, Центральной и Западной Африке. Простота использования и относи- 
тельно низкая стоимость - преимущества, которые делают этот подход подходящим для децентрализованного и быстрого тестирования, особенно в условиях ограниченных ресурсов.

Biochem Biophys Res Commun. 2021 Nov 22;586:87-92.

doi: 10.1016/j.bbrc.2021.11.059. Online ahead of print.

Emerging mutation patterns in SARS-CoV-2 variants

Новые паттерны мутаций в вариантах SARS-CoV-2

David A Ostrov , Glenn W Knox

- PMID: 34837837

Существует острая необходимость в понимании функциональных эффектов мутаций в появляющихся вариантах SARS-CoV-2. Вызывающие озабоченность варианты (альфа, бета, гамма и дельта) имеют четыре типа спайковых мутаций гликопротеина, которые усиливают трансмиссивность и уклонение от иммунитета: 1) мутации в N-концевом домене (NTD), 2) мутации в рецепторсвязывающем домене (RBD) 3) мутации в межцепочечных контактах тримера шипа и 4) мутации сайта расщепления фурином. Наиболее отличительные мутации среди вызывающих озабоченность вариантов проявляются в NTD и локализованы в сайтах с высокой структурной гибкостью. Новые представляющие интеpec варианты, такие как Mu, Lambda и C.1.2, демонстрируют те же паттерны мутаций, что и вызывающие озабоченность варианты. Существует большая вероятность того, что варианты SARS-CoV-2 будут продолжать появляться с мутациями в этих определенных паттернах, что обеспечит основу для разработки противовирусных препаратов следующей линии и вакцин-кандидатов.

Commun Biol. 2021 Nov 30;4(1):1343.

doi: 10.1038/s42003-021-02858-9. PMID: 34848826

Template switching and duplications in SARS-CoV-2 genomes give rise to insertion variants that merit monitoring

Переключение матрицы и дупликации в геномах SARS-CoV-2 приводят к появлению инсерционных вариантов, которые должны отслеживаться

Sofya K Garushyants, Igor B Rogozin, Eugene V Koonin

Появление множества новых вариантов SARS-CoV-2 во время пандемии COVID-19 вызывает серьезную озабоченность. Некоторые из этих вариантов, такие как В.1.617.2, В.1.1.7 и В.1.351, проявляют более высокую инфекционность и вирулентность, чем более ранние варианты SARS-CoV-2, с потенциально драматическим влиянием на течение пандемии. До сих пор анализ новых вариантов SARS-CoV-2 был сосредоточен в первую очередь на заменах нуклеотидов и коротких делециях, которые легко идентифицировать при сравнении с согласованными последовательностями генома. Напротив, вставки в значительной степени ускользнули от внимания исследователей, хотя вставка сайта фурина в белке Spike (S) считается определяющим фактором вирулентности SARS-CoV-2. Авторы идентифицируют 346 уникальных вставок разной длины в геномах SARS-CoV-2 и представляют доказательства того, что эти вставки отражают фактическую дисперсию вируса, а не артефакты секвенирования. Два основных механизма, по-видимому, объясняют 
вставки в геномах SARS-CoV-2: проскальзывание полимеразы и переключение матрицы, которые могут быть связаны с синтезом субгеномных РНК. Предполагается, что по крайней мере три вставки в $\mathrm{N}$-концевом домене $\mathrm{S}$-белка приведут к ускользанию от нейтрализующих антител, тогда как другие вставки могут привести к ускользанию от Т-клеточного иммунитета. Таким образом, вставки в S-белок могут влиять на его антигенные свойства и должны отслеживаться.

Curr Opin Environ Sci Health. 2021 Dec;24:100308.

doi: 10.1016/j.coesh.2021.100308. Epub 2021 Nov 6. PMID: 34849439

Looking for a needle in a haystack. SARS-CoV-2 variant characterization in sewage Поиск иголки в стоге сена. Выявление вариантов SARS-CoV-2 в сточных водах Marta Itarte, Sílvia Bofill-Mas, Sandra Martínez-Puchol , и др.

Обзор. Варианты SARS-CoV-2 появляются во всем мире, и их мониторинг играет ключевую роль в обеспечении раннего предупреждения. Авторы суммируют различные аналитические подходы, используемые в настоящее время для изучения распространения вариантов SARS-CoV-2 в сточных водах, и обсуждают их преимущества и недостатки. Они также предоставляют предварительные результаты двух чувствительных и экономически эффективных подходов: вариантно-специфичных ПЦР с обратной транскрипцией и невариантно-специфической стратегии глубокого секвенирования ампликона, нацеленной на три ключевые области вирусного шипового белка. Подходы к секвенированию нового поколения позволяют одновременно обнаруживать сигнатурные мутации различных вариантов, вызывающих озабоченность, в одном анализе и могут быть лучшим вариантом для изучения реальной картины в определенное время. Целевые подходы ПЦР, ориентированные на конкретные сигнатурные мутации, потребуют постоянного обновления, но они чувствительны и рентабельны.

Nat Commun . 2021 Nov 30;12(1):6977.

doi: 10.1038/s41467-021-27325-1. PMID: 34848718

Molecular insights into receptor binding energetics and neutralization of SARS-CoV2 variants

Молекулярные представления об энергетике связывания рецепторов и нейтрализации вариантов SARS-CoV-2

Melanie Koehler, Ankita Ray, Rodrigo A Moreira , Blinera Juniku, Adolfo B Poma, David Alsteens

Несмотря на беспрецедентное глобальное накопление данных с момента появления SARS-CoV-2, почти все механистические знания, касающиеся молекулярных и клеточных деталей вирусной репликации, патологии и вирулентности, были получены с использованием ранних прототипных изолятов SARS-CoV-2. Авторы, используя атомно-силовую микроскопию и молекулярную динамику, исследовали, как эти мутации количественно влияют на кинетические, термодинамические и структурные свойства образования комплекса RBD-ACE2. Они наблюдали для нескольких вызывающих озабоченность вариантов значительное повышение стабильности комплекса RBD-ACE2. В то время как мута- 
ции N501Y и E484Q особенно важны для большей стабильности, мутация N501Y вряд ли существенно повлияет на нейтрализацию антител. Эта работа предоставляет беспрецедентно подробные сведения о связывании вариантов SARS-CoV-2 и дает представление о влиянии вирусных мутаций на индуцированный инфекцией иммунитет.

PLoS Pathog. 2021 Dec 2;17(12):e1010022.

doi: 10.1371/journal.ppat.1010022. eCollection 2021 Dec. PMID: 34855916

Reduced neutralisation of the Delta (B.1.617.2) SARS-CoV-2 variant of concern following vaccination

Сниженная нейтрализация вызывающего беспокойство варианта SARS-CoV-2 дельта (В.1.617.2) после вакцинации

Chris Davis, Nicola Logan, Grace Tyson, Richard Orton, и др.

Оценка способности сывороток реципиентов вакцины нейтрализовать варианты SARS-CoV-2 будет способствовать успеху стратегий по минимизации случаев COVID19 и разработке эффективных антигенных составов. Авторы исследуют чувствительность вызывающих озабоченность вариантов (VOCs) SARS-CoV-2, представляющих линии В.1.617.1 и В.1.617.2 (впервые связанные с инфекциями в Индии) и В.1.351 (впервые связанные с инфекцией в Южной Африке) к нейтрализации сывороткой от лиц, вакцинированных вакцинами BNT162b2 (Pfizer / BioNTech) и ChAdOx1 (Oxford / AstraZeneca). У всех вакцинированных лиц спайковые гликопротеины В.1.617.1 и В.1.617.2 снижали нейтрализацию в 4,31 и 5,11 раза соответственно. Снижение, наблюдаемое для линии В.1.617.2, приближается к тому, которое обеспечивается гликопротеином из варианта В.1.351 (Южная Африка) (6,29-кратное снижение), что, как известно, связано со снижением эффективности вакцины. Титры нейтрализующих антител после вакцинации двумя дозами BNT162b2, были значительно выше, чем титры, после двух доз ChAdOx1. Кратное уменьшение величины титра нейтрализации после двух доз BNT162b2 составило 7,77, 11,30 и 9,56 раза соответственно для псевдовирусов В.1.617.1, В.1.617.2 и В.1.351, снижение нейтрализации дельта-варианта В.1.617.2 превосходило таковое для варианта В.1.351. Кратность изменений у вакцинированных двумя дозами ChAdOx1 составила 0,69, 4,01 и 1,48 соответственно. Накопление мутаций в этих и других VOCs демонстрирует поддающийся количественной оценке риск антигенного дрейфа и последующего снижения эффективности вакцины. Соответственно, со временем, вероятно, потребуются бустерные вакцины на основе обновленных вариантов, чтобы предотвратить продуктивную инфекцию. Это исследование также предполагает, что для максимального индуцированного BNT162b2 и ChAdOx1 иммунитета необходимы две схемы дозирования вакцины. 